\title{
مفهوم الحرية في الفقه الحنفي: الحرية في أفق المصالح والحقوق عبد الله عتر
}

باحث في الدراسات الإسلامية، كلية الإلميات، جامعة غازي عنتاب، غازي عنتاب، تركيا abdullaiter@gmail.com

\section{الخلاصة}

ييرهن البحث أن فكرة الحرية كانت حاضرة ومؤثرة في التشريع الإسلامي، وأنها انتقلت مع الحنفية

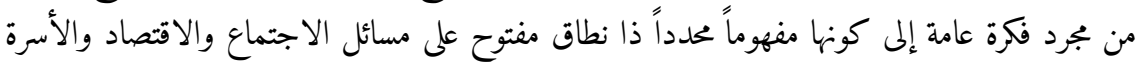

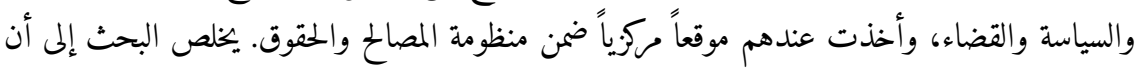

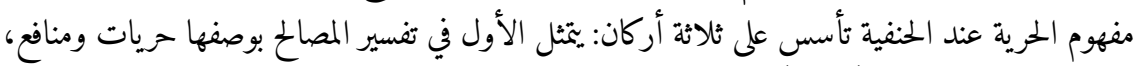

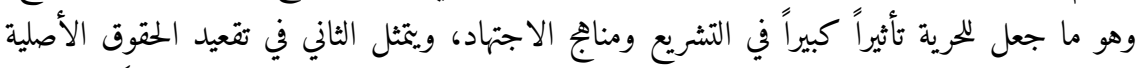

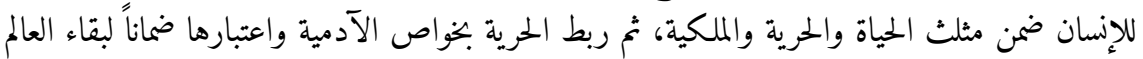

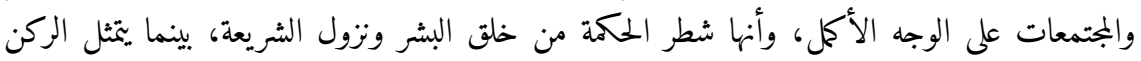

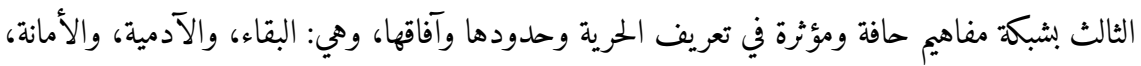
والمنغعة، والعبادة، والعقل والقوة.

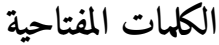

الفقه الحنفي - المقاصد - الحرية - المنفعة - الآدمية - الحقوق الأصلية 


\title{
The Concept of Freedom in the Ḥanafî School: Freedom in Relation to Interests and Rights
}

\author{
Abdulla Iter \\ Department of Islamic Studies, University of Gaziantep, Gaziantep, Turkey \\ abdullaiter@gmail.com
}

\begin{abstract}
The paper demonstrates that the notion of freedom played an important role in Islamic legislation. "Freedom" transformed from being a general concept in the Hanafi School to a well-defined concept with a scope that covers social, economic, family, political and judicial aspects. The concept also played a central role in dealing with issues of public interests/welfare (mașālih) and rights (huqūq). This article argues that the Hanafĩ notion of freedom is based on three pillars. The first pillar consists of interpreting public interests/welfare in terms of freedoms and benefits, which granted the notion of freedom a pivotal role in legislation and the methododology of legal/ independent reasoning (ijtiha $\bar{d}$ ). The second pillar entails its use to provide the logical foundations for "fundamental human rights," through the triangle of life, freedom and property. The notion was subsequently used to link freedom to the merits of humanity, and was considered to be a warranty for the wellness and the wellbeing of societies as well as the wisdom behind the creation of humankind and the revelation of Divine law ( $\operatorname{shari}^{-i} a$ ). The third pillar is based on a network of key concepts that define the notion of freedom and its scope: durability, humanity, trusteeship, [public] interest, worship, reason and power.
\end{abstract}

\section{Keywords}

Ḥanafĩ jurisprudence - objectives - freedom - interest - humanity - fundamental rights

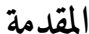

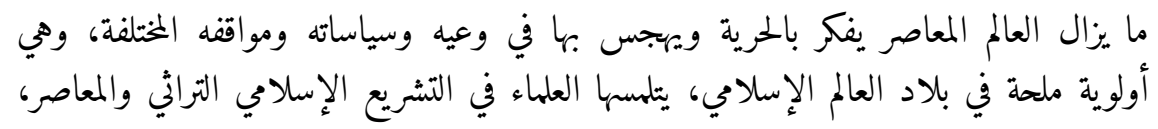


فن الضروري والمفيد إعادة فتح أنماط تفكير واجتهاد تنتقل بالحرية من كونها فكرة وقيمة

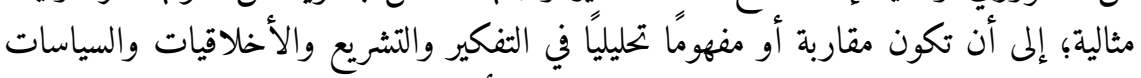

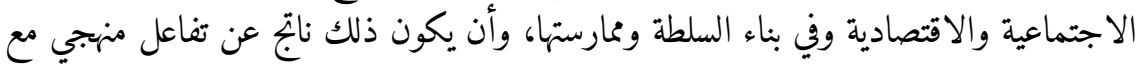
اجتهادات المسلمين في فهمه.

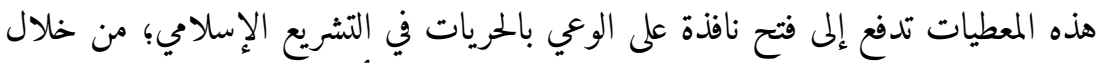

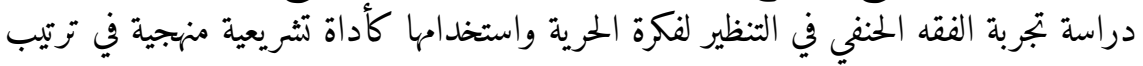

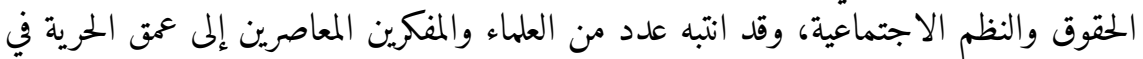

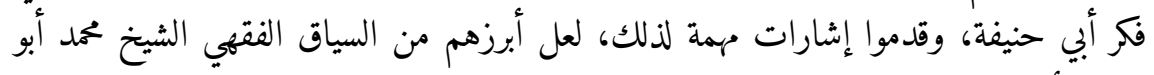

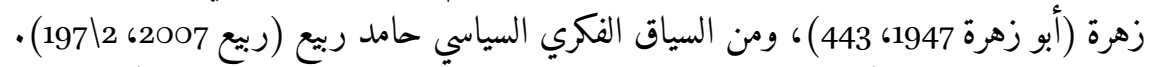

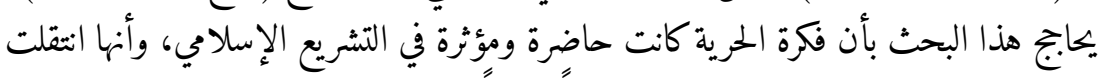

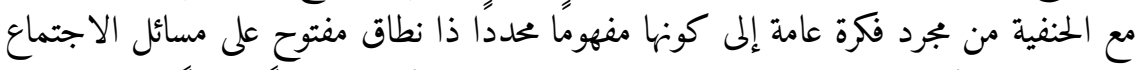

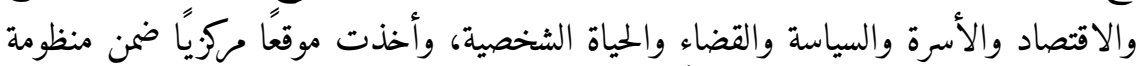

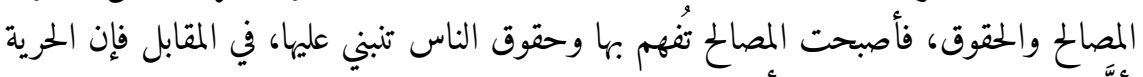

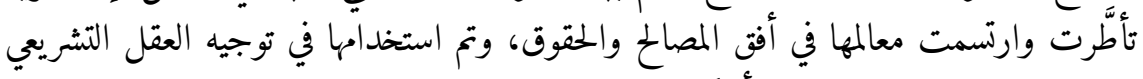

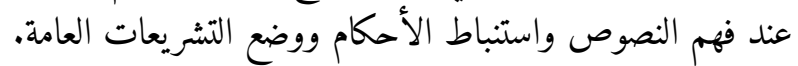

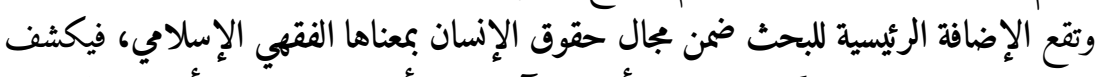

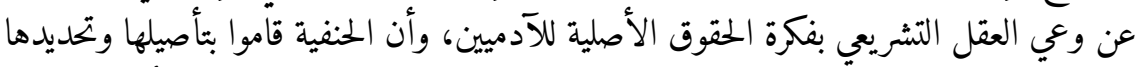

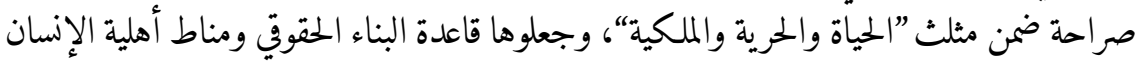

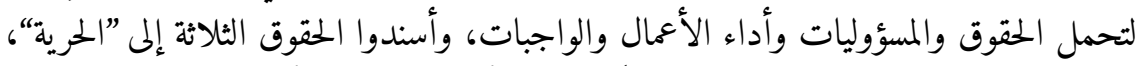

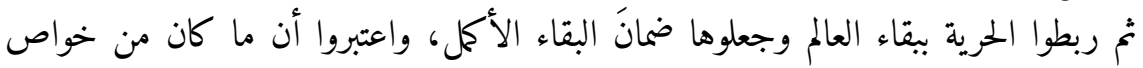

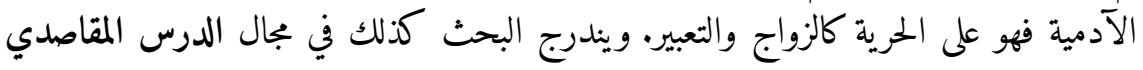

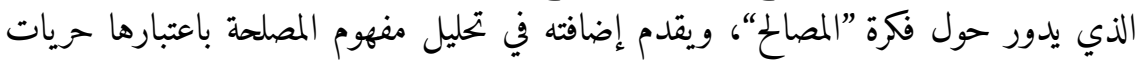

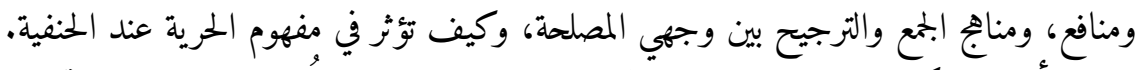

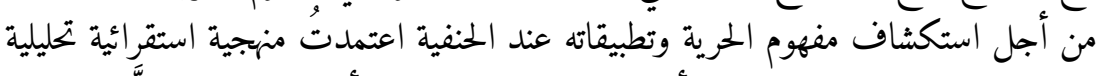

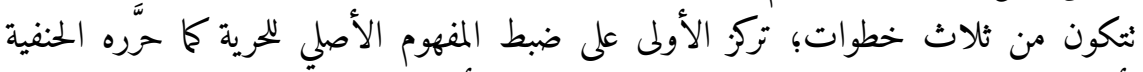

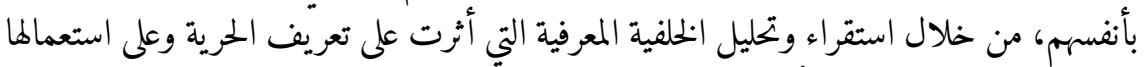

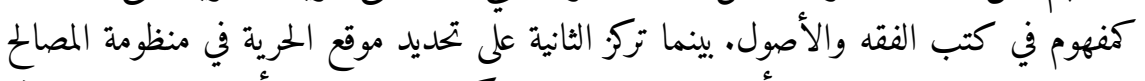

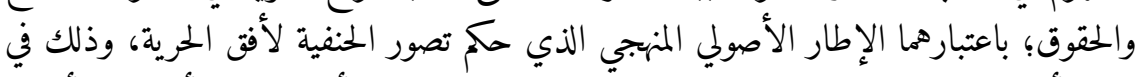

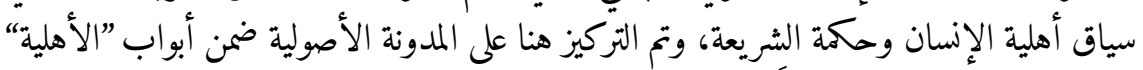

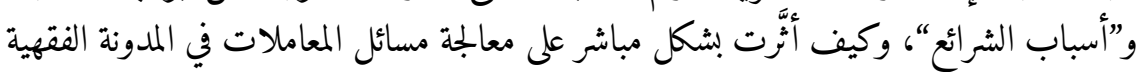

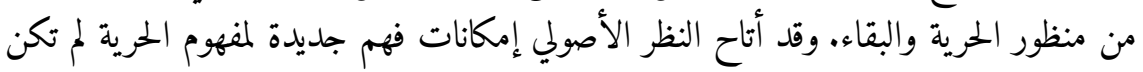

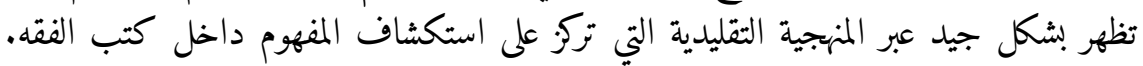




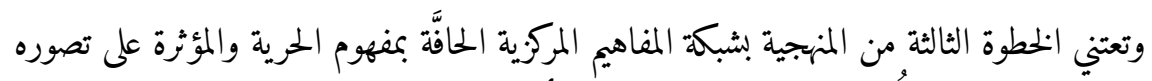

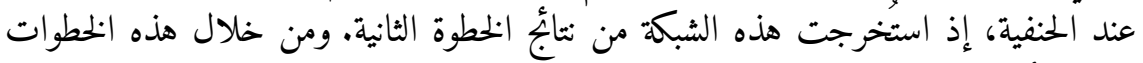

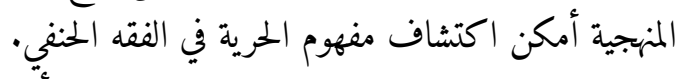

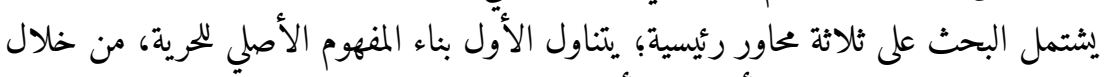

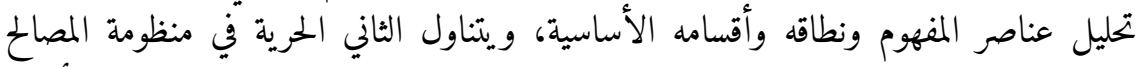

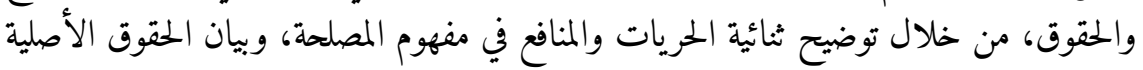

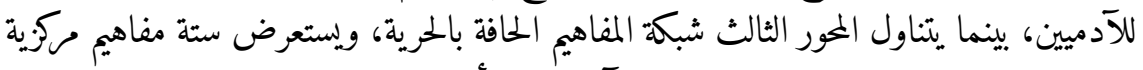

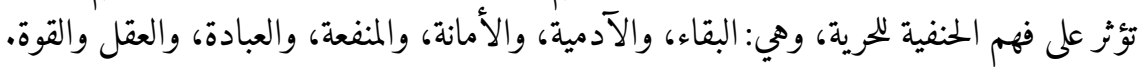

\section{بناء المفهوم الأصلي للمرية}

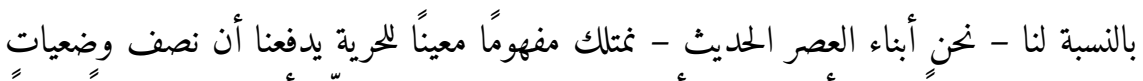

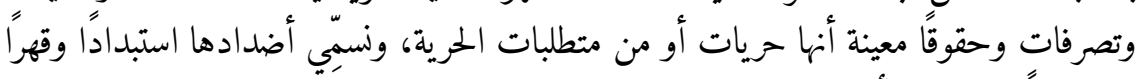

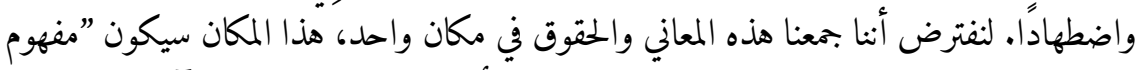

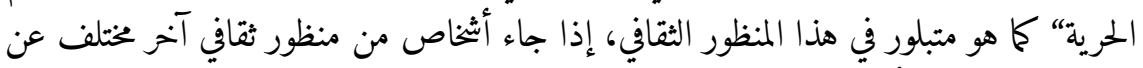

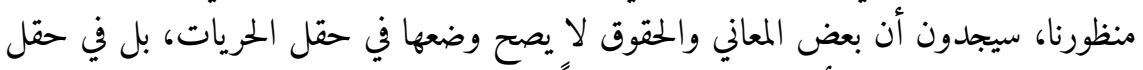

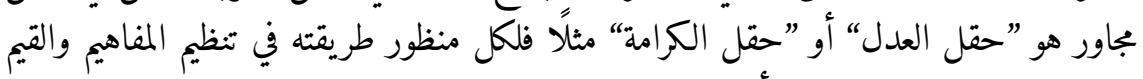

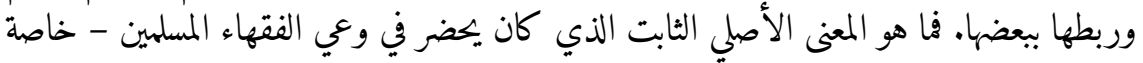

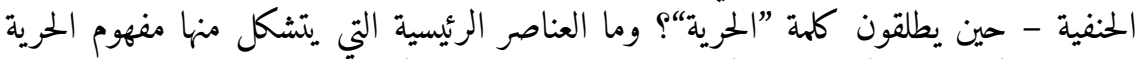

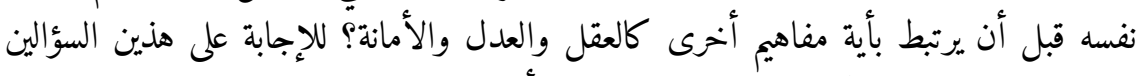

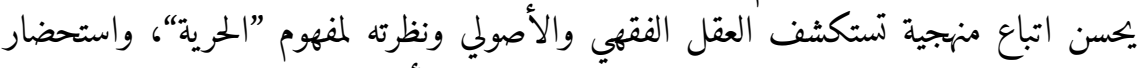

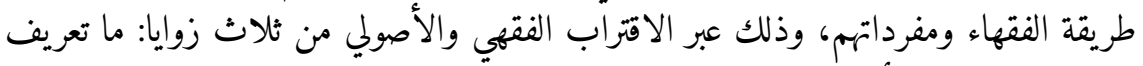

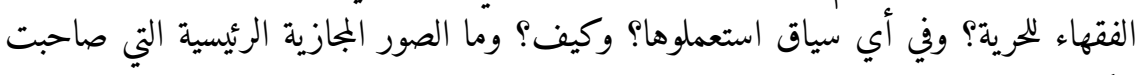
تفكيرهم بالحرية؟

\section{عناصر المفهوم: البنية الداخلية الصلبة}

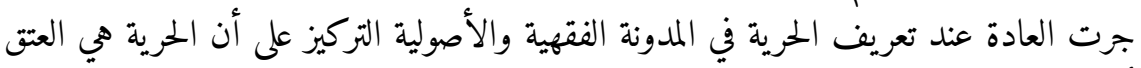

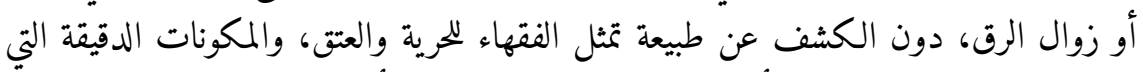

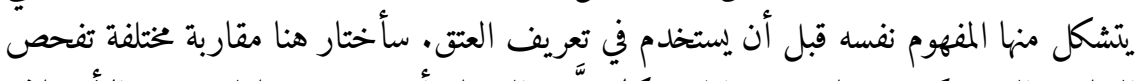

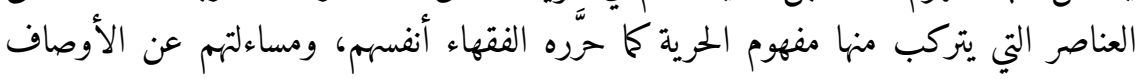

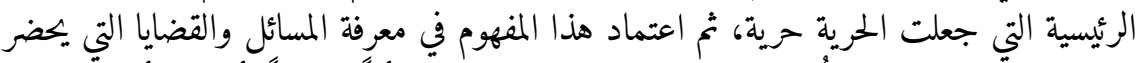

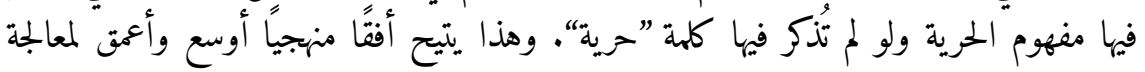




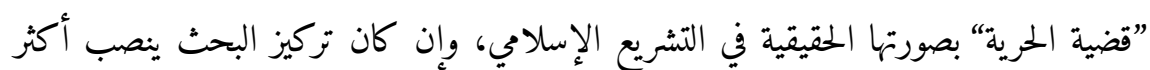

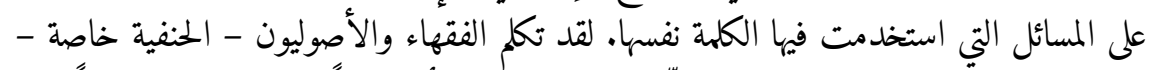

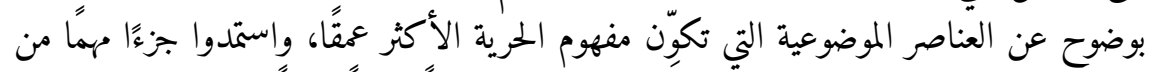

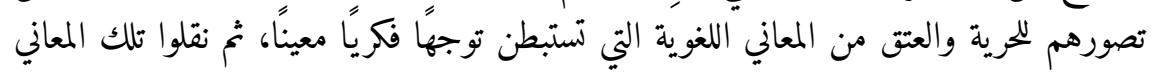

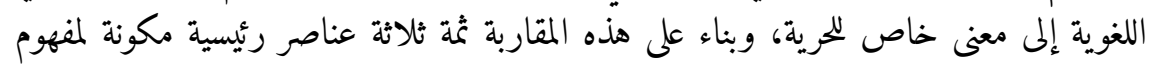
الحرية.

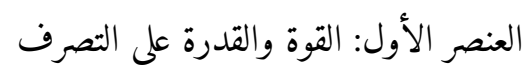

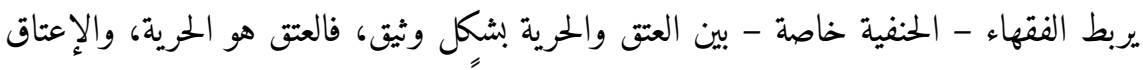

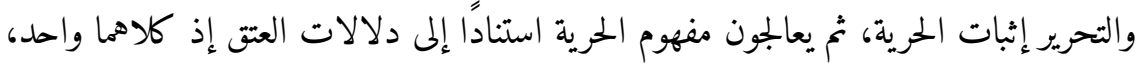

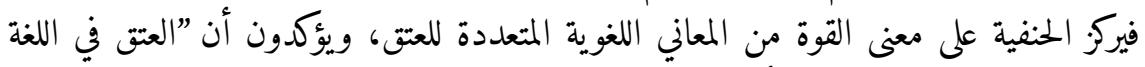

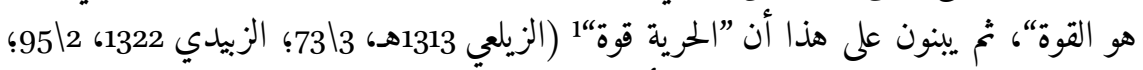
ابن عابدين 1992،

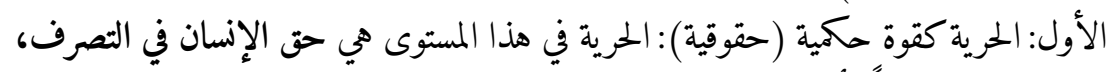

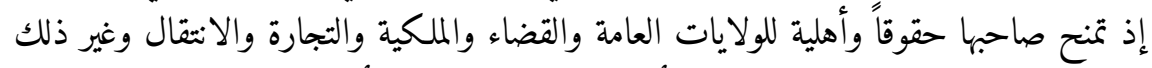

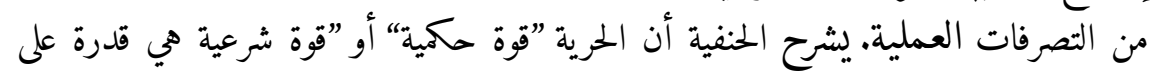

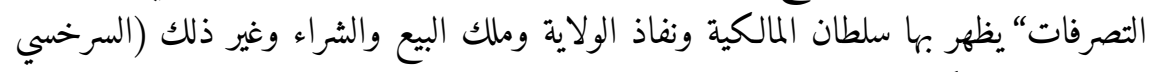

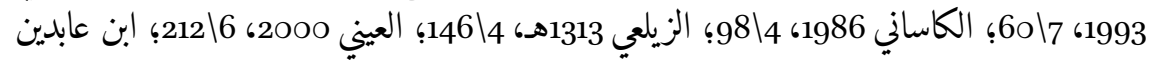
$\cdot(658 \backslash 361992$ الثاني: الحرية كقوة حقيقية: الحرية في هذا المستوى هي القدرة الفعلية على التصرف، وهذا

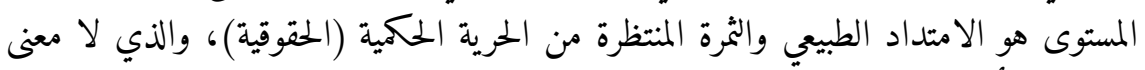

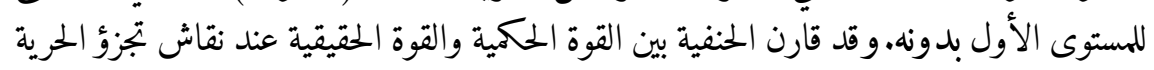

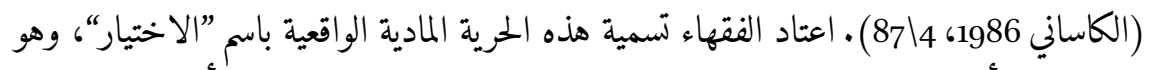

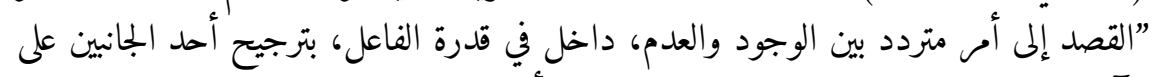

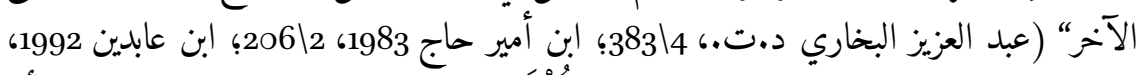

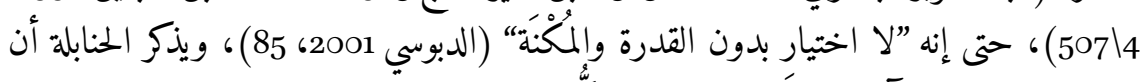

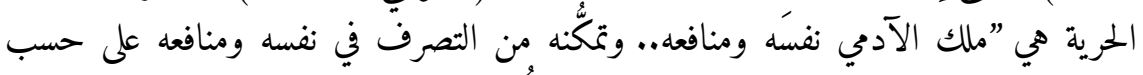

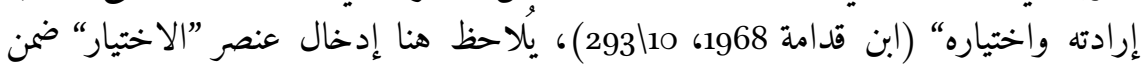
مفهوم الحرية بشكل صريح.

1 يؤك ابن عابدين أن ”العتق والحرية قوة، (ابن عابدين 1992، 3658). 


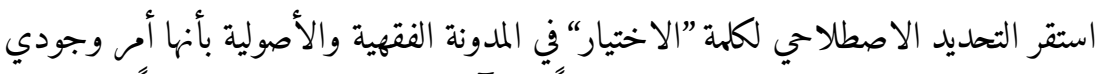

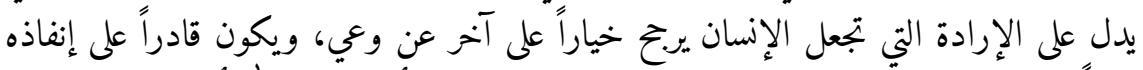

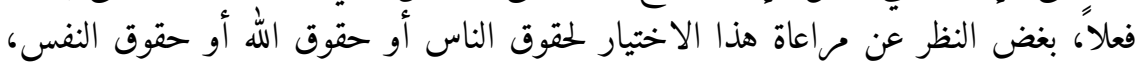

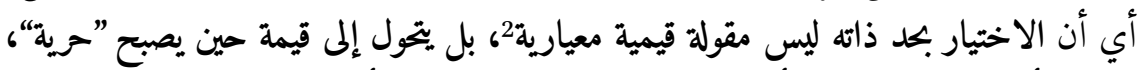

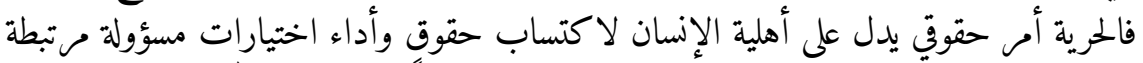

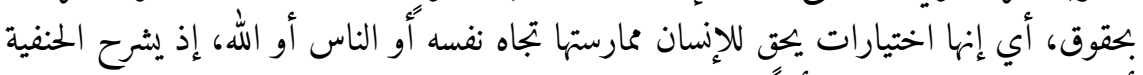

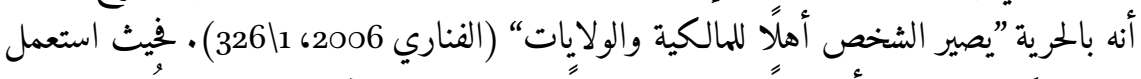

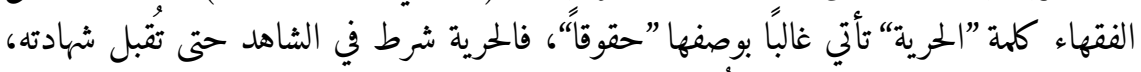

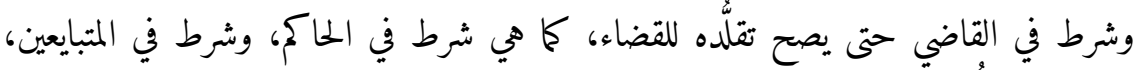

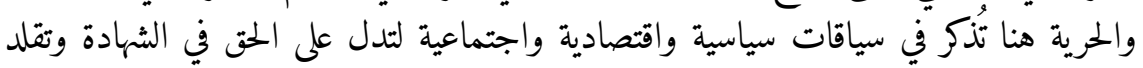

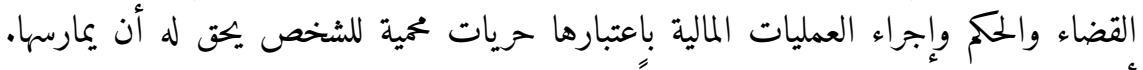

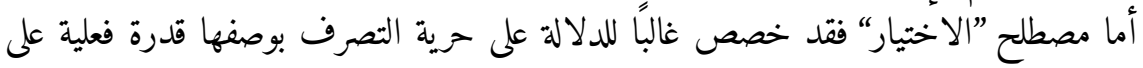

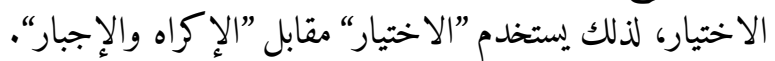

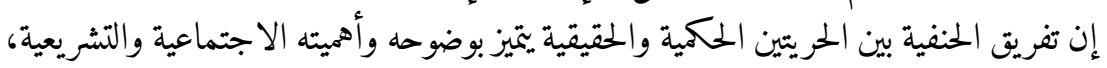

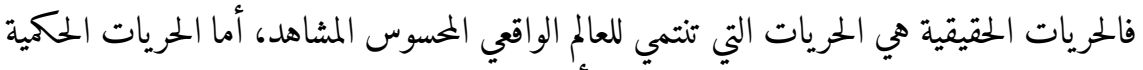

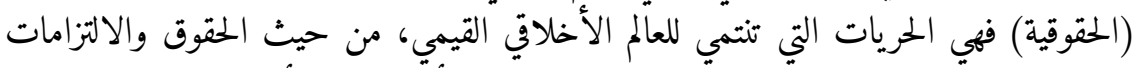

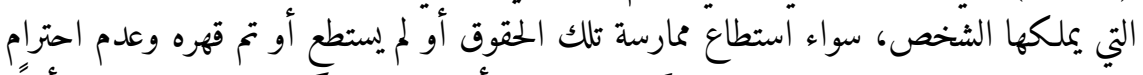

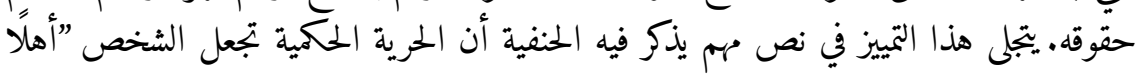

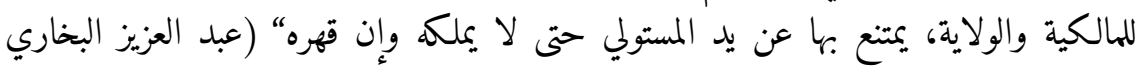
. $(282 \backslash 4$.

$$
\text { العنصر الثاني: التخلص من القيود وسلطة الغير }
$$

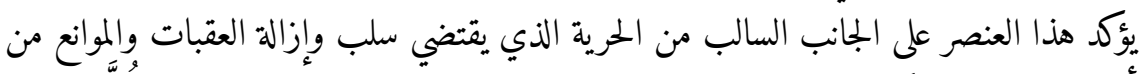

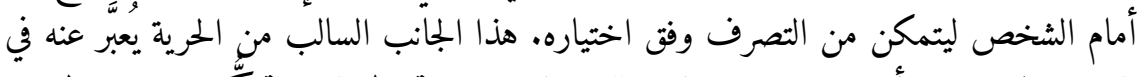

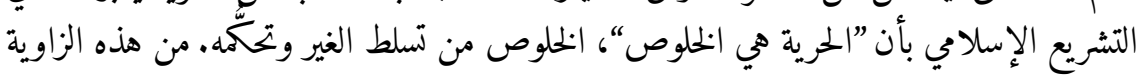

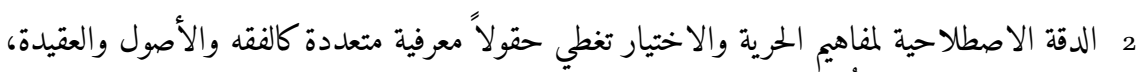

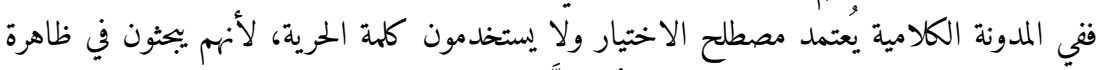

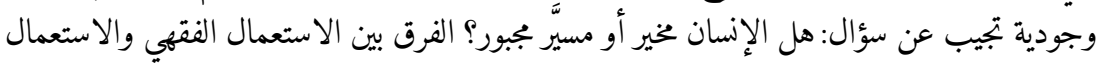

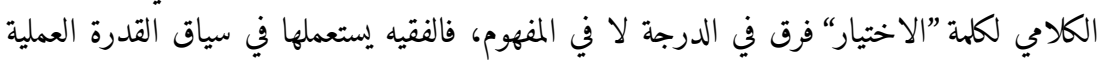

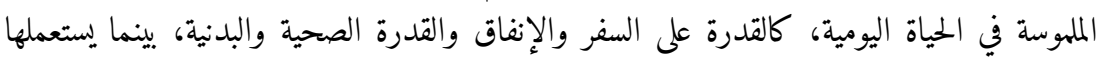

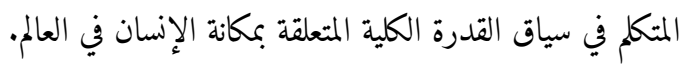




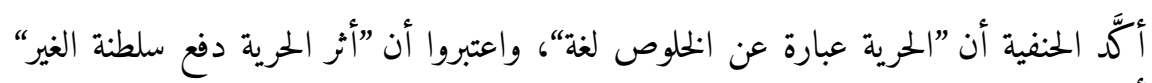

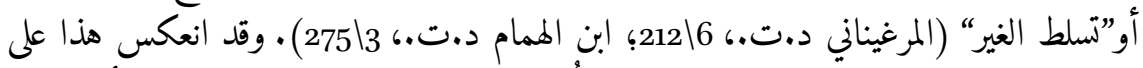

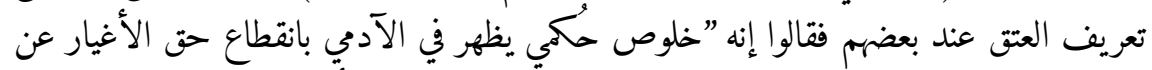

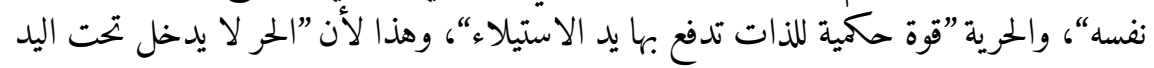

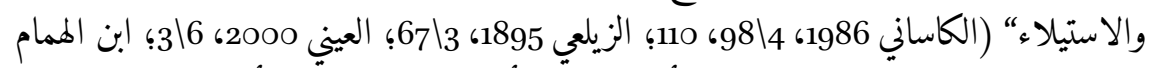

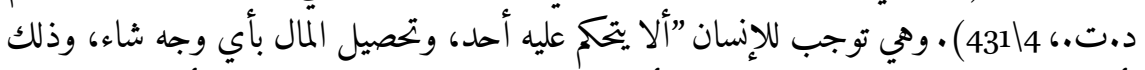

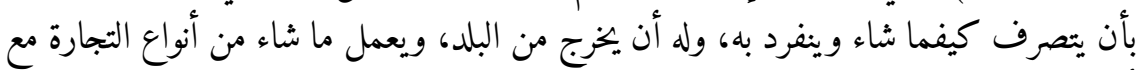

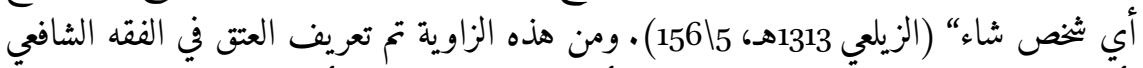

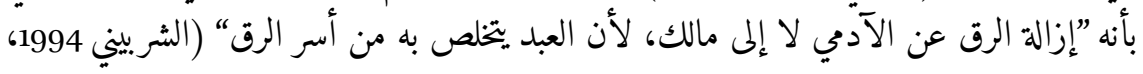
46 445؛ الجمل د.ت.

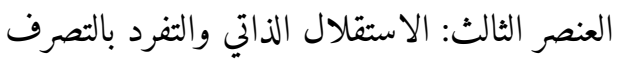

3.1.1

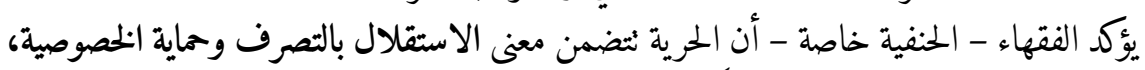

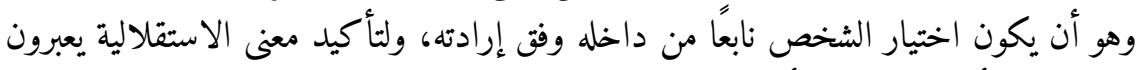

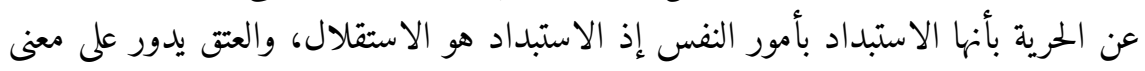

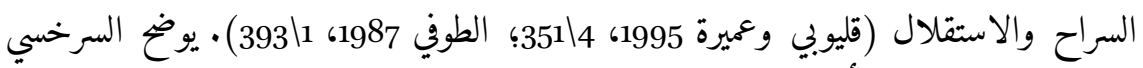

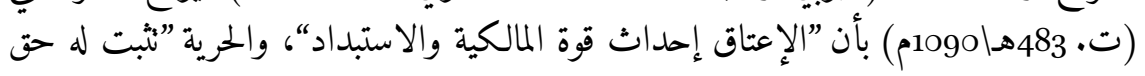

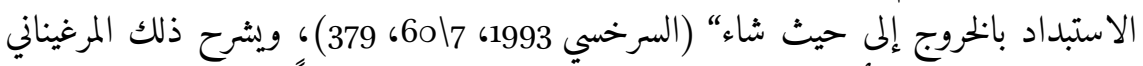

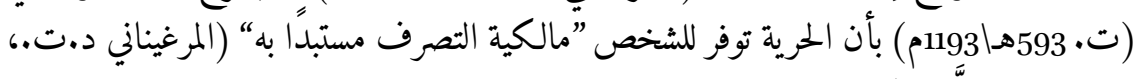

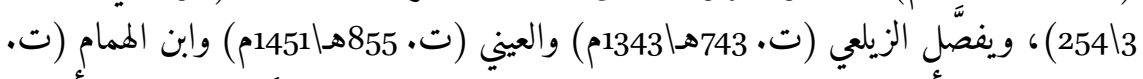

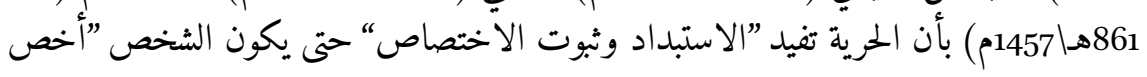

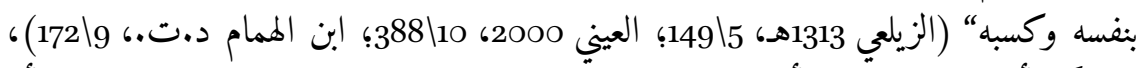

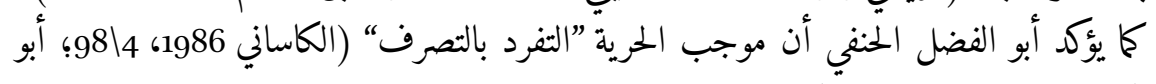

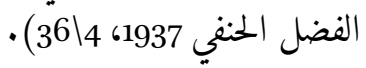

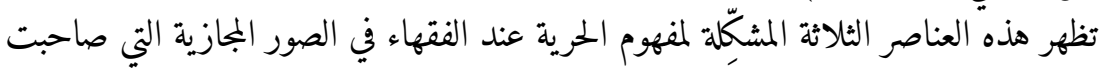

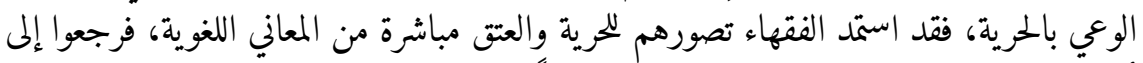

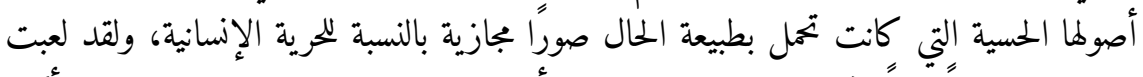

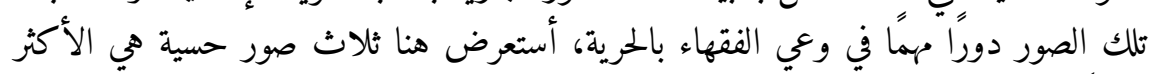

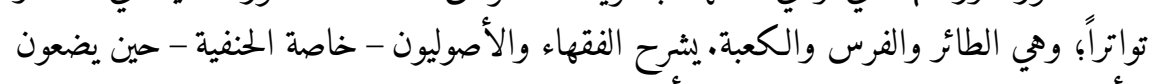

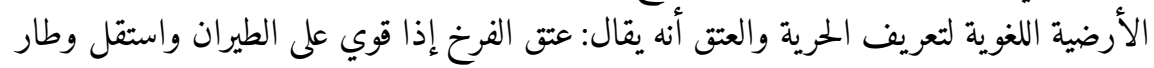

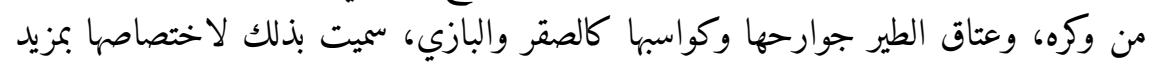

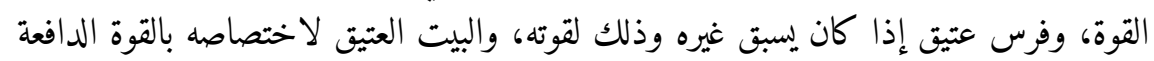




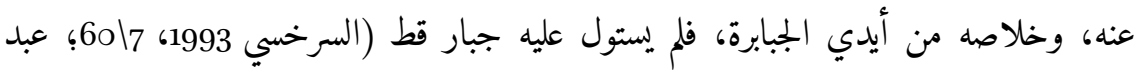

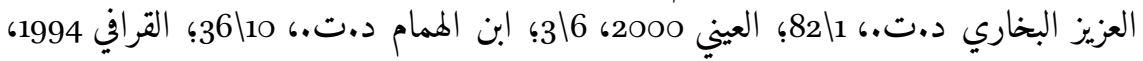

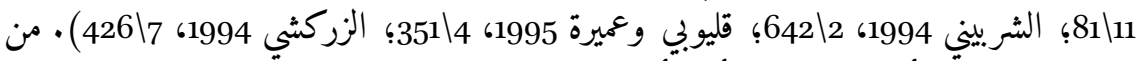

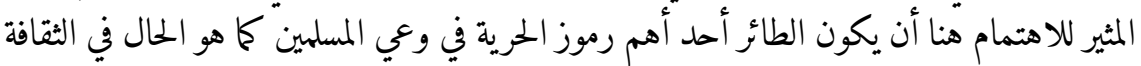

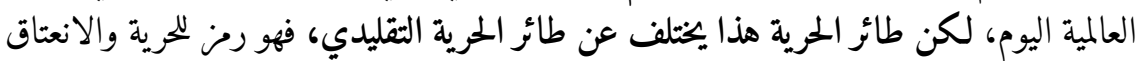

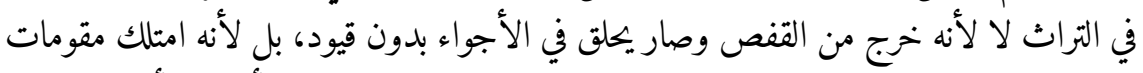

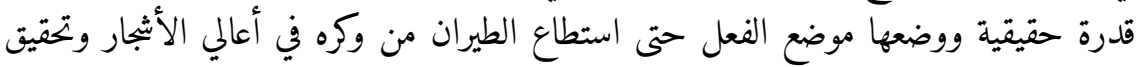

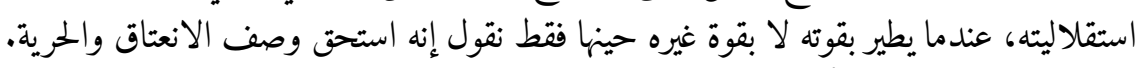

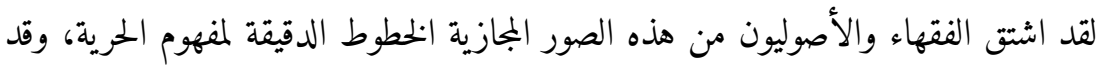

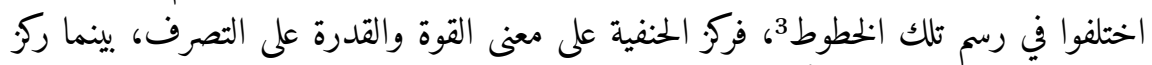

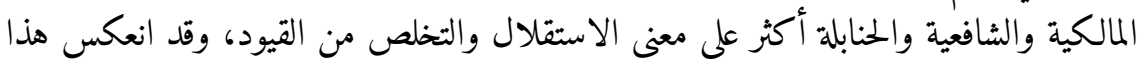

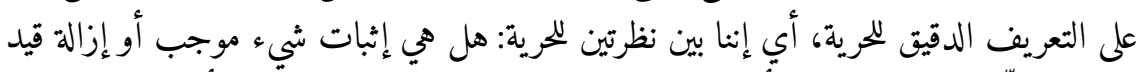

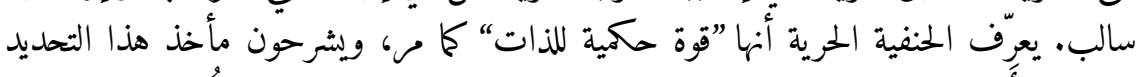

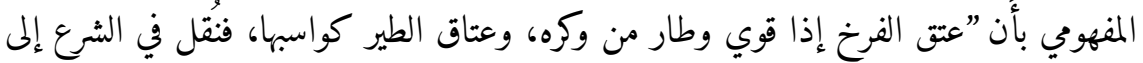

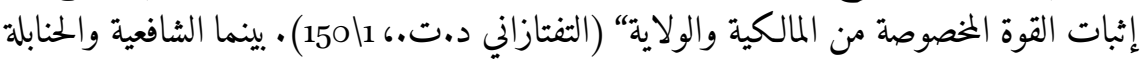

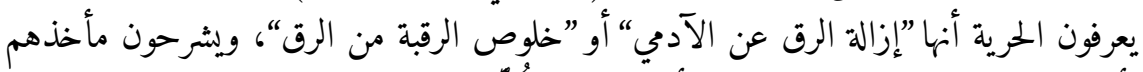

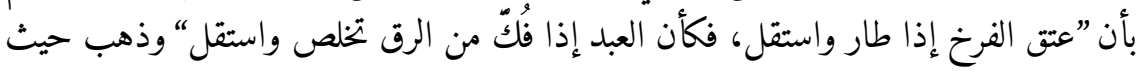

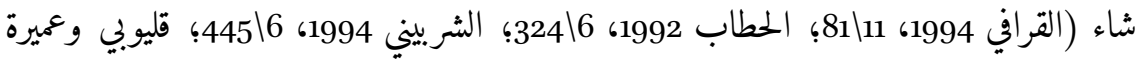

$$
\begin{aligned}
& \text { 1995، 3514؛ الزركشي 1994، } 194 \\
& \text { نطاق المفهوم: الحرية والحريات }
\end{aligned}
$$

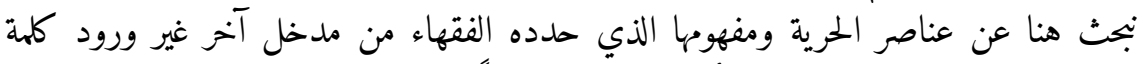

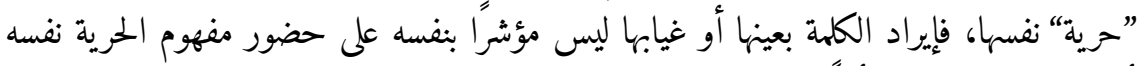

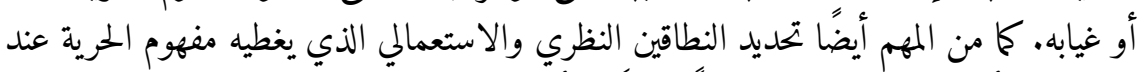

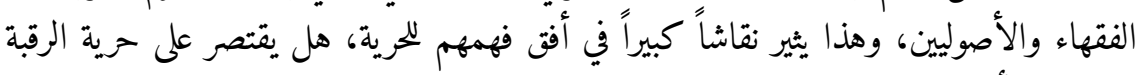

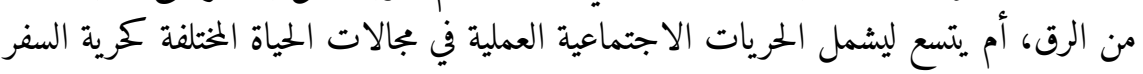

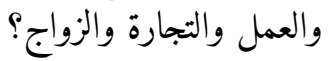

3 لم يهِِّل الفقهاء والأصوليون المعاني اللغوية للحرية إلى معان فقهية بآلية بسيطة، بل انتقوا من المعاني

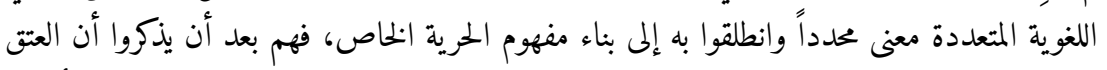

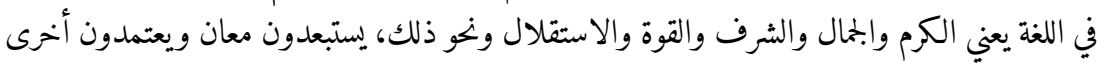
ضمن اجتهاد خاص في تصور الحرية. 


$$
\text { حرية رقبة موصولة ومتجسدة بحريات تصرف }
$$

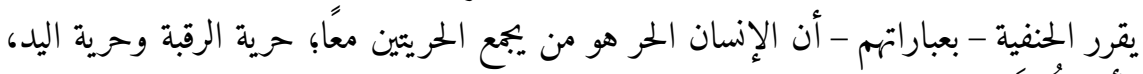

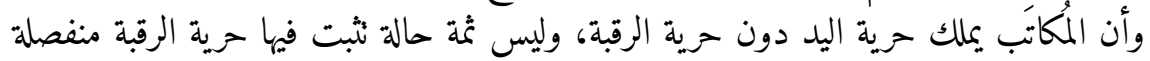

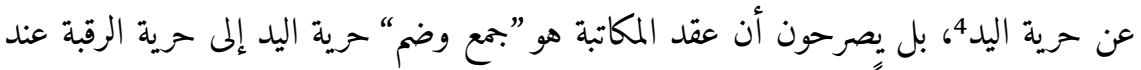

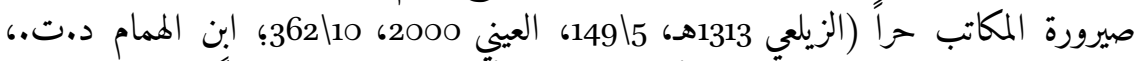

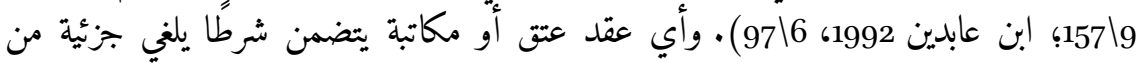

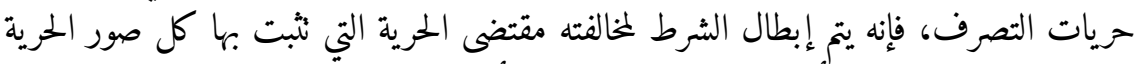

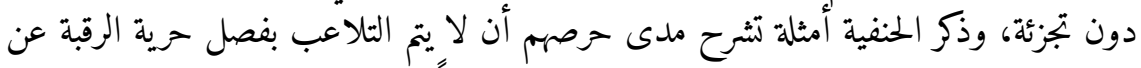

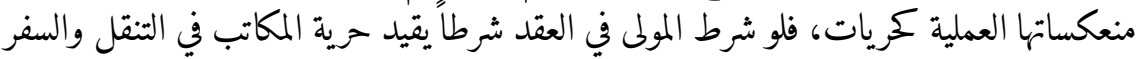

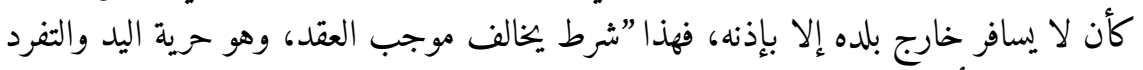

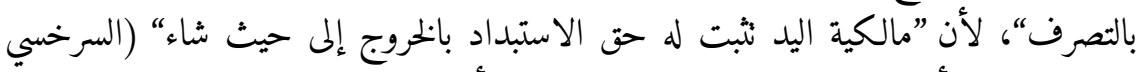

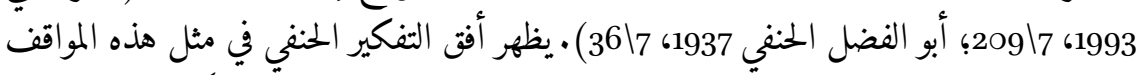

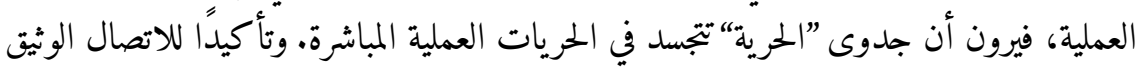

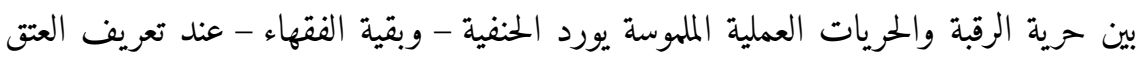

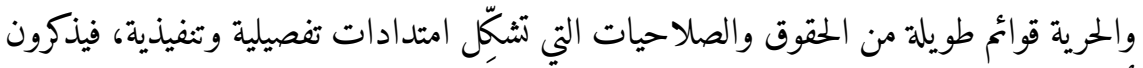

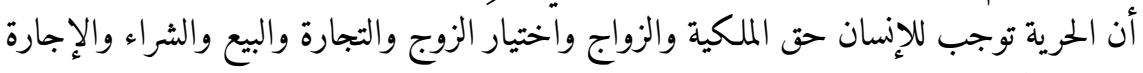

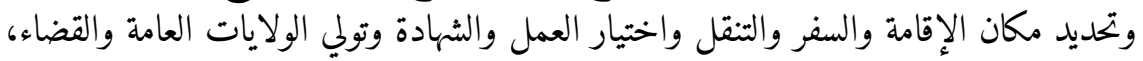

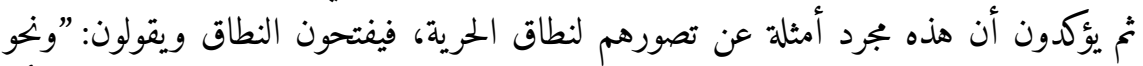

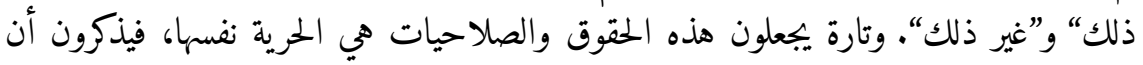

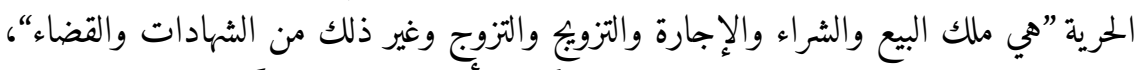

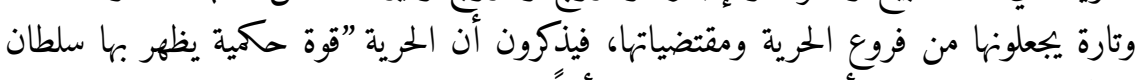

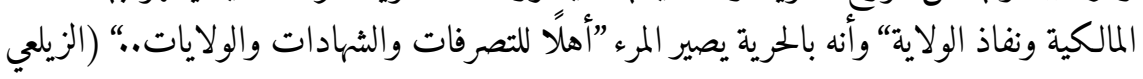

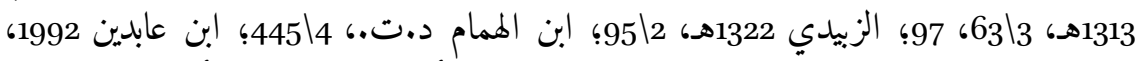

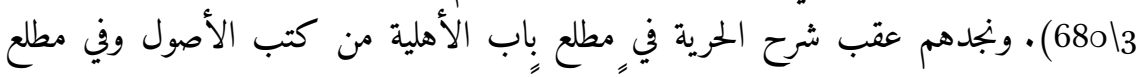

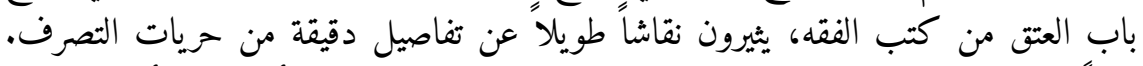

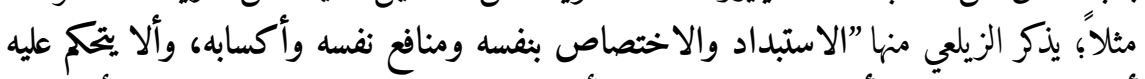

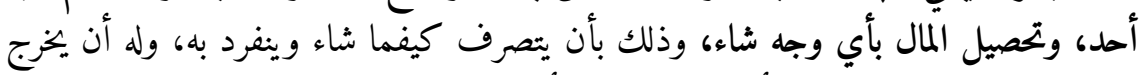

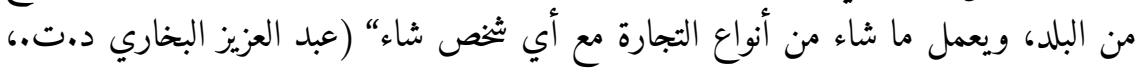

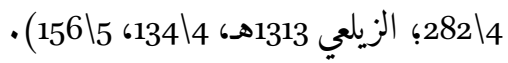

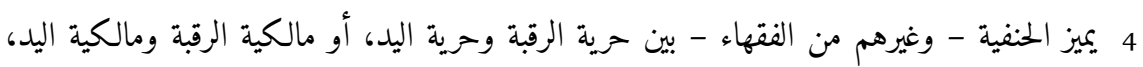

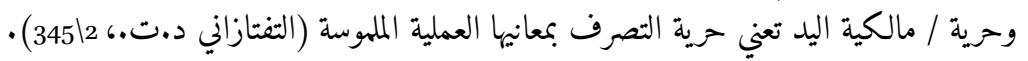




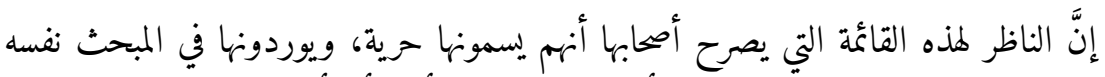

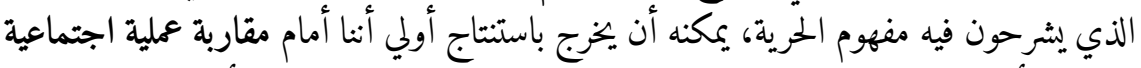

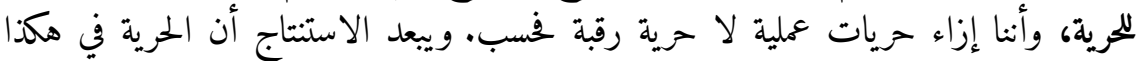

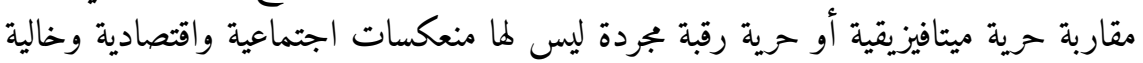

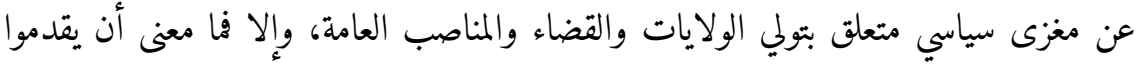

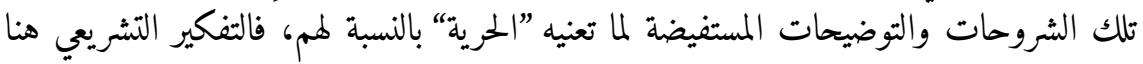

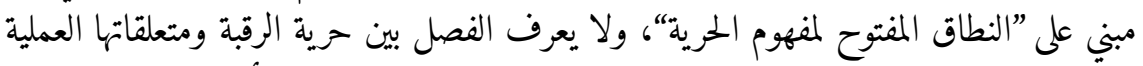

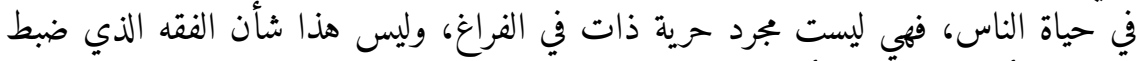

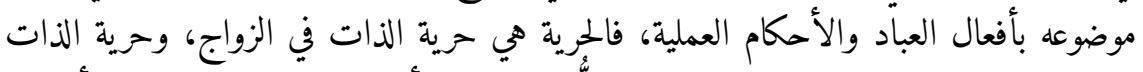

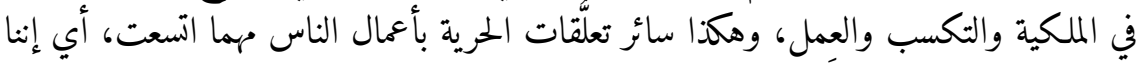
نتحدث عن ”حريات" منبثَّة في سياقات وميادين الحياة.

$$
\text { حريات في أبواب فقهية متنوعة }
$$

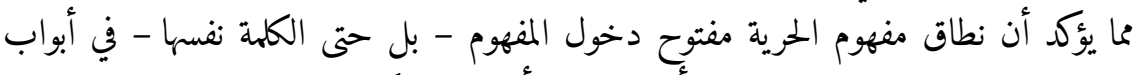

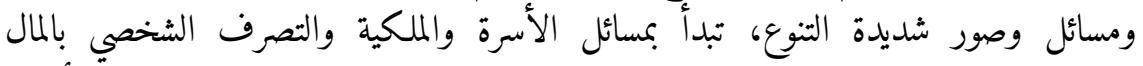

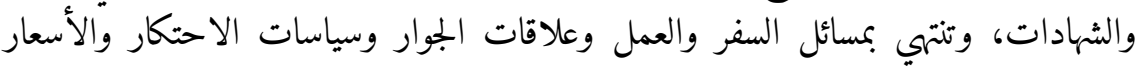

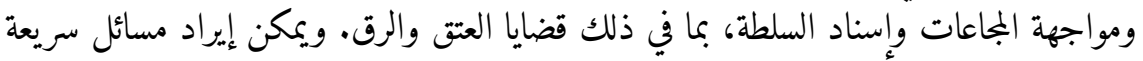

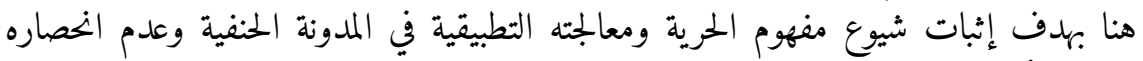
بكوضوع أو نمط معين من المسائل.

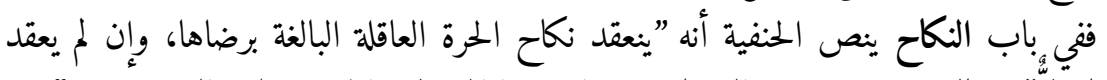

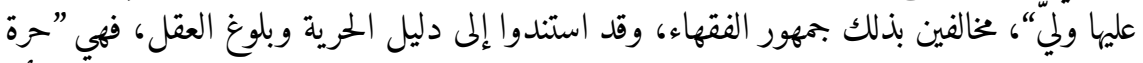

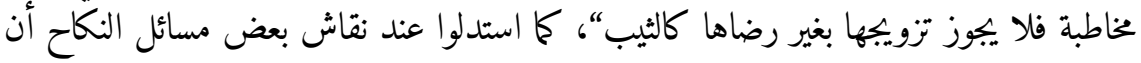

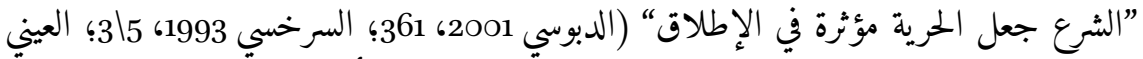

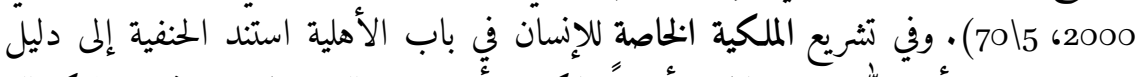

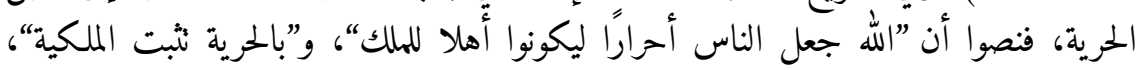

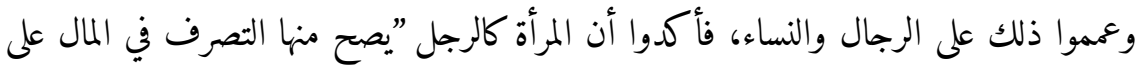

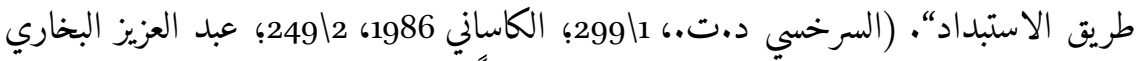

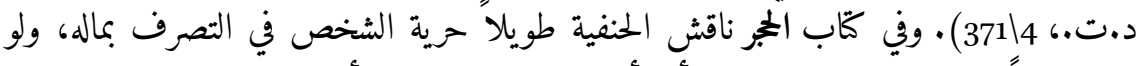

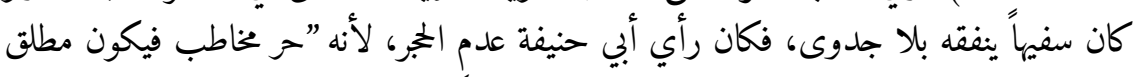

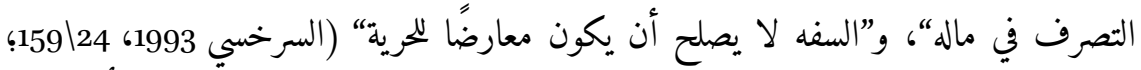

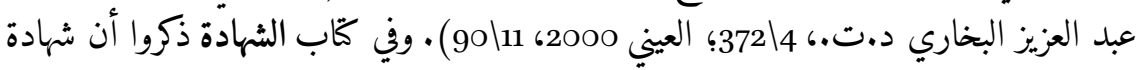


النساء ججة أصلية كشهادة الرجال؛ لأن ”الإنسان إنما يصير شاهداً بالولاية، وهي مبنية على الحرية

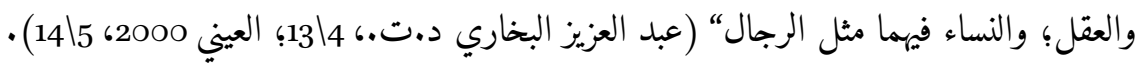

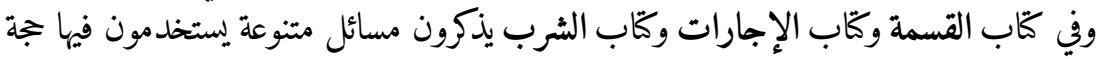

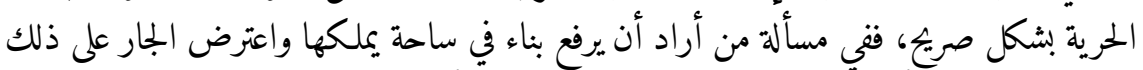

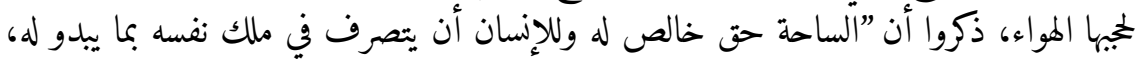

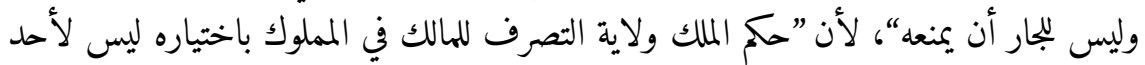

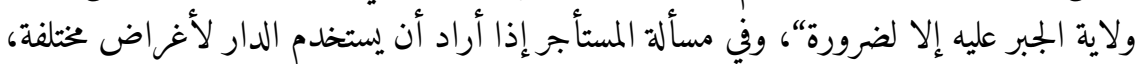

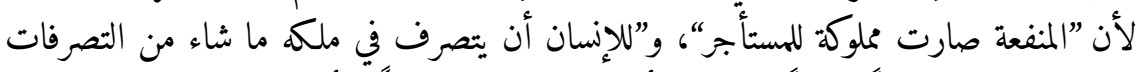

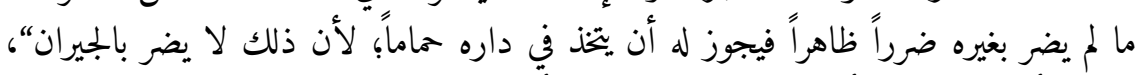

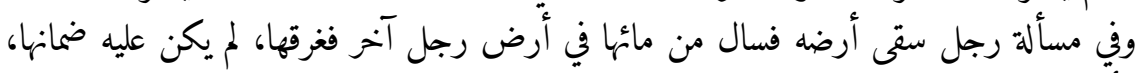

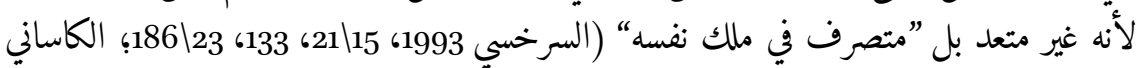

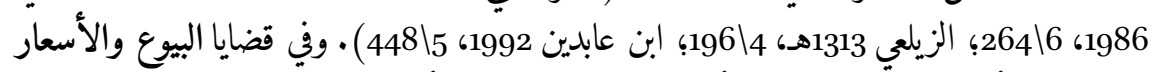

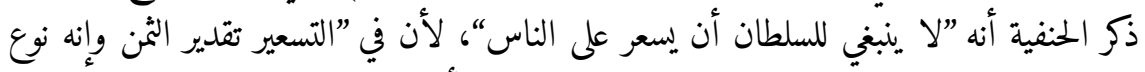

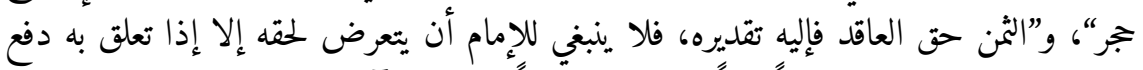

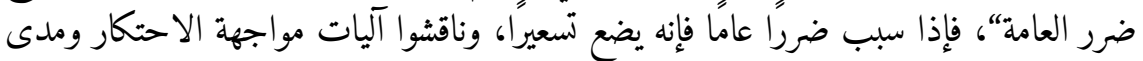

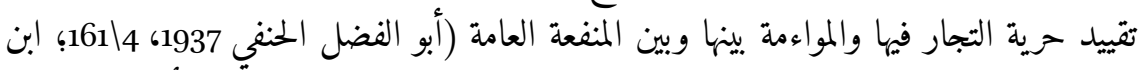

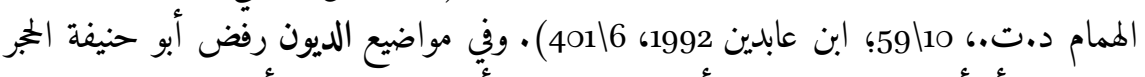

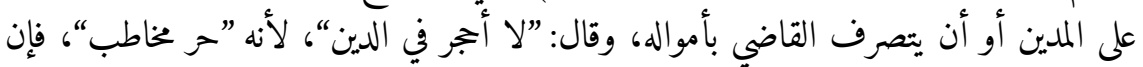

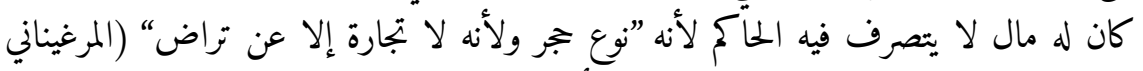

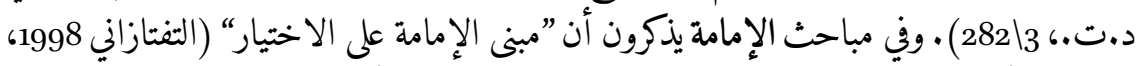

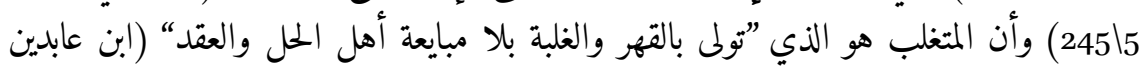
- (549\1 61992 يلاحظ من المسائل السابقة أن مفهوم الحرية - الذي حرَّره الحنفية - كان حاضراً في معالجة

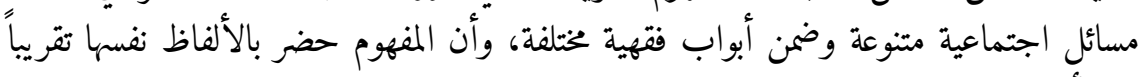

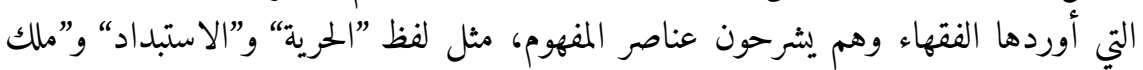

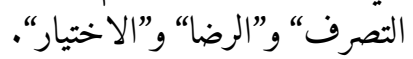

أبعاد المفهوم: زوايا متعددة 3.1

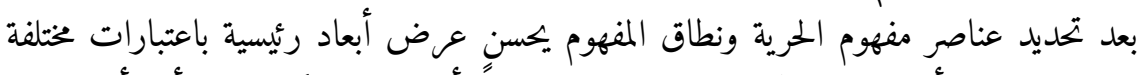

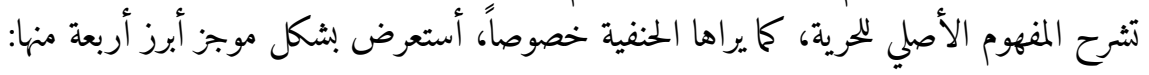


الحرية ملكية واختيار

سلك الفقهاء طريقة خاصة في استخدام المصطلحات التي تنتمي لمفهوم المار الحرية، سأعالج هنا

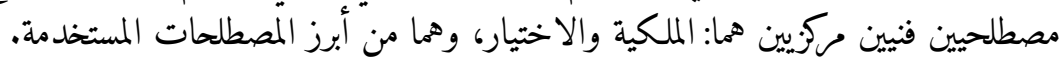

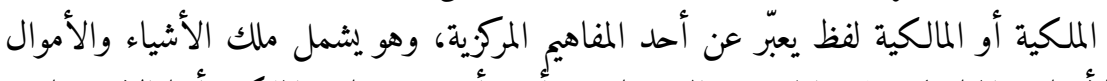

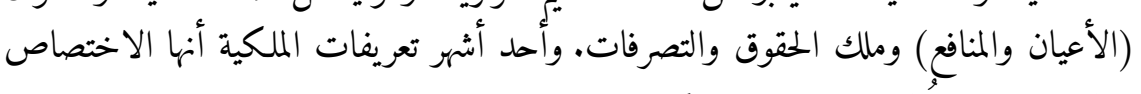

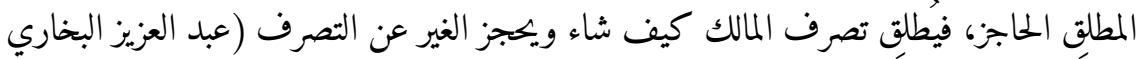

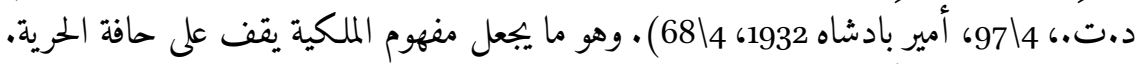

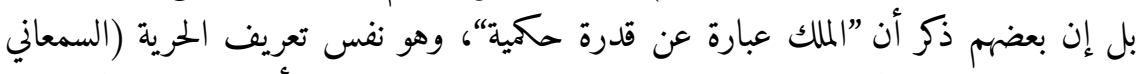

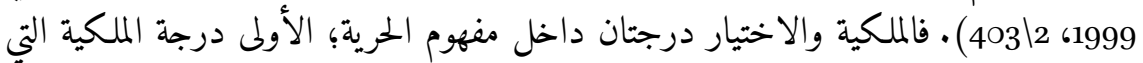

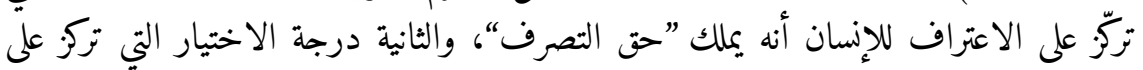

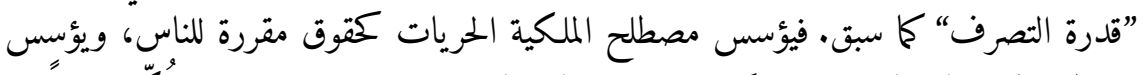

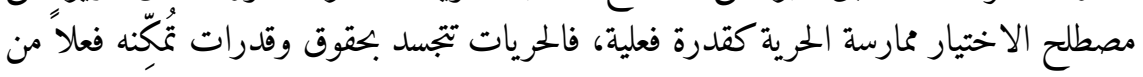
ممارسة حريته.

$$
\text { الحرية الممكنة والحرية الميسرة }
$$

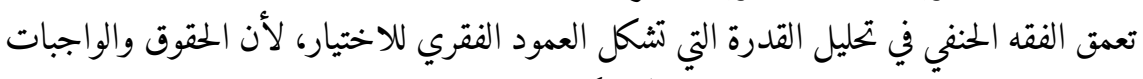

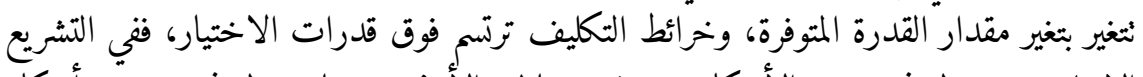

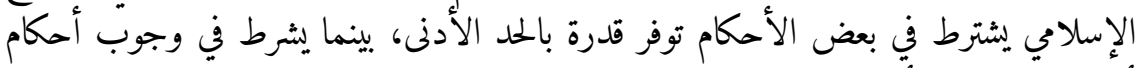

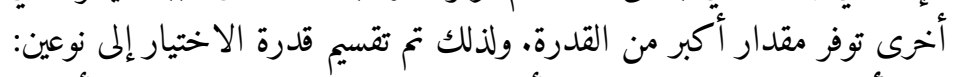

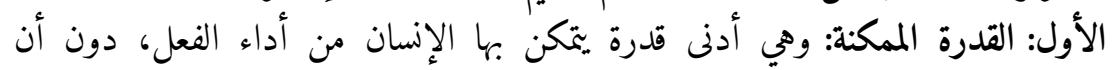

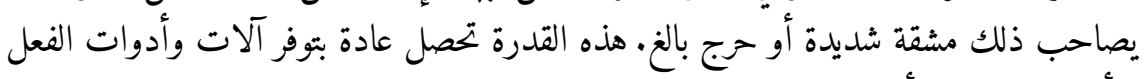

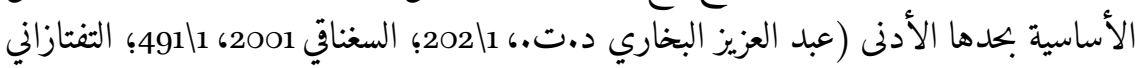

$$
\text { د. }
$$

الثاني: القدرة الميسّرّة: وهي قدرة أقوى من القدرة الممكنة يتيسر معها أداء الفعل المطلوب

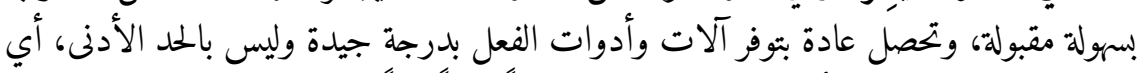

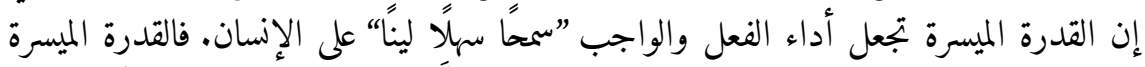

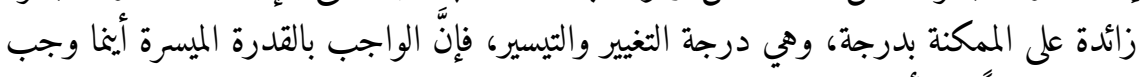

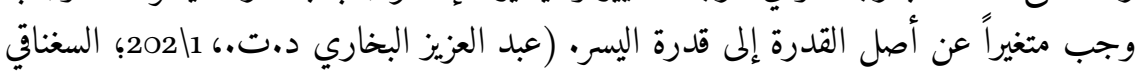

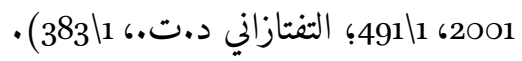

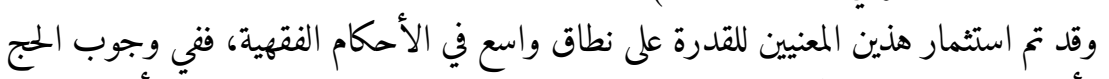

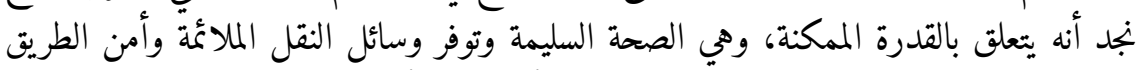

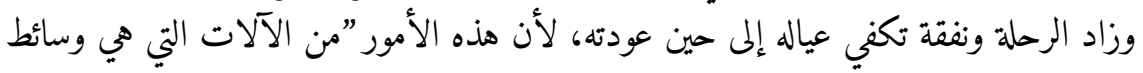




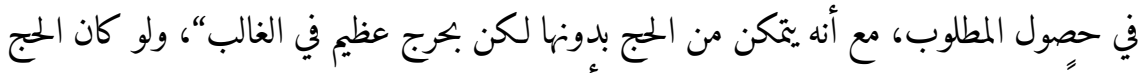

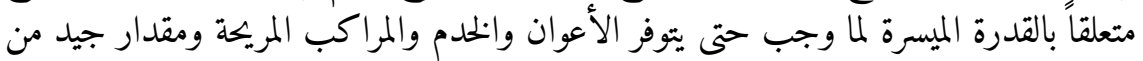

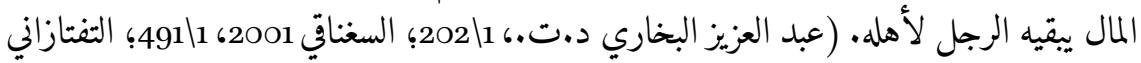

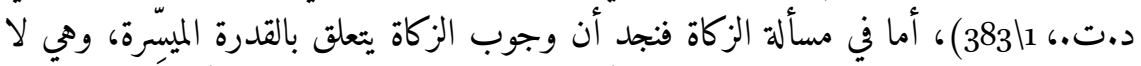

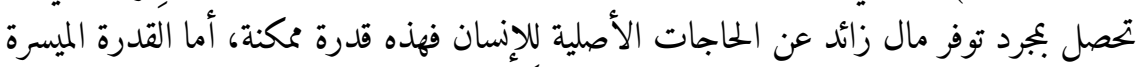

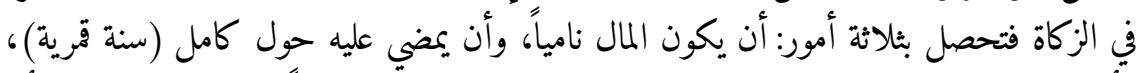

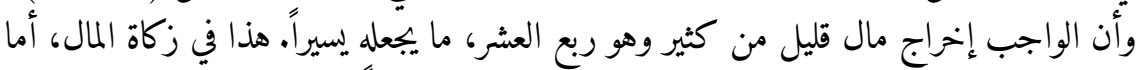

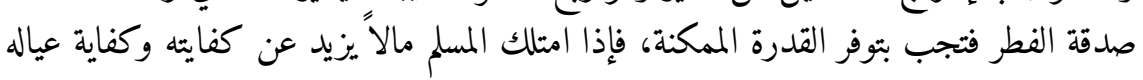

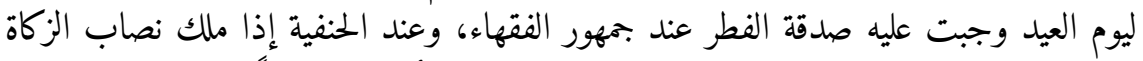

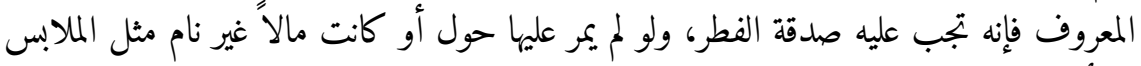

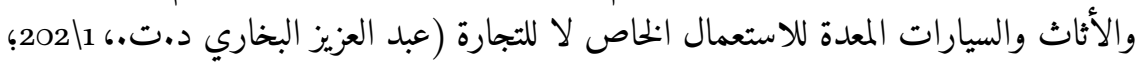

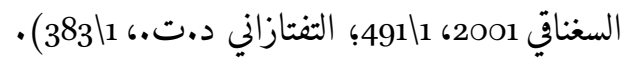

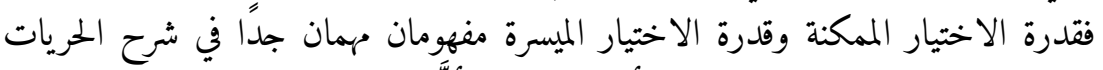

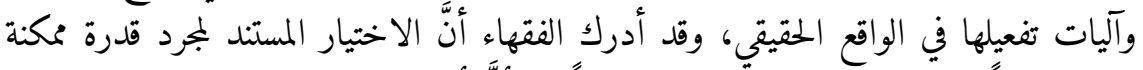

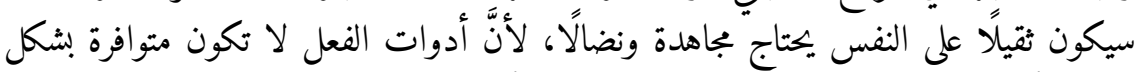

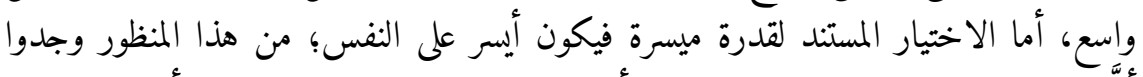

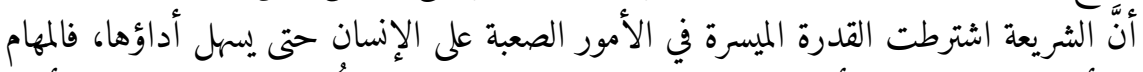

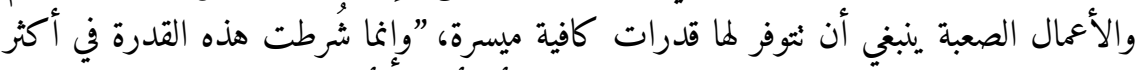

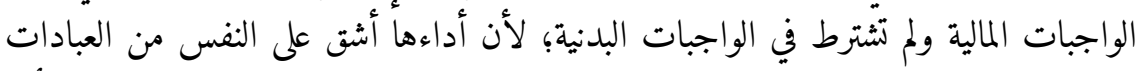

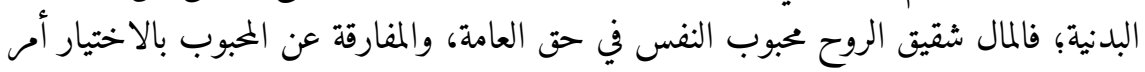

$$
\text { شاق" (عبد العزيز البخاري د.ت. }
$$

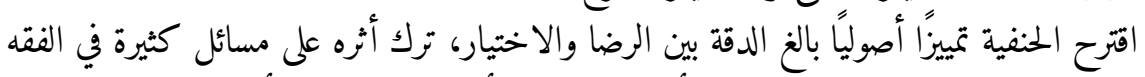

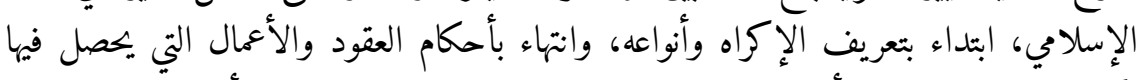

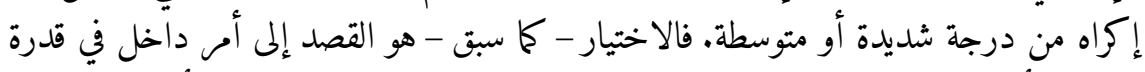

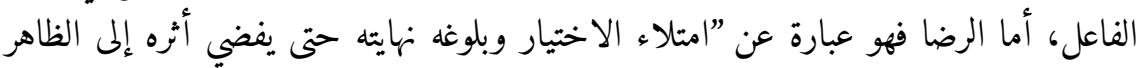

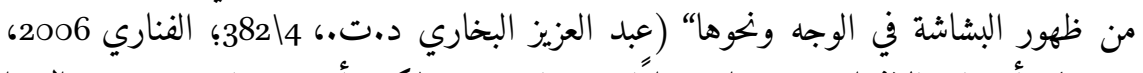

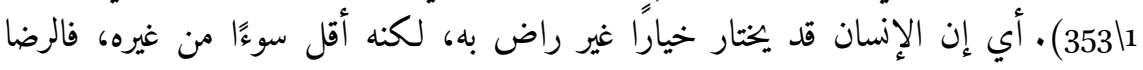

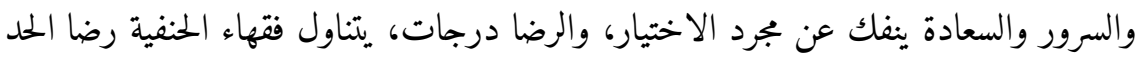
الأدنى المقبول وليس الرضا الكامل لأنه نسبي يتفاوت، وبناء عليه يقسمون الإكراه إلى إكراه 
ملجئ وهو الذي يُعدم الرضا ويفسد الاختيار، فيصير الإنسان كالآلة بيد المكرِه، مثل التهديد بما

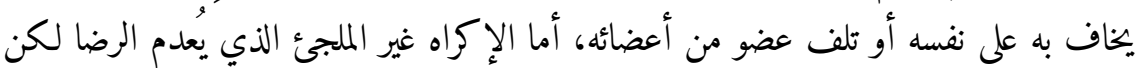

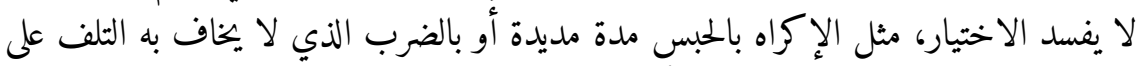

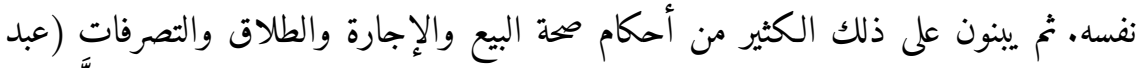

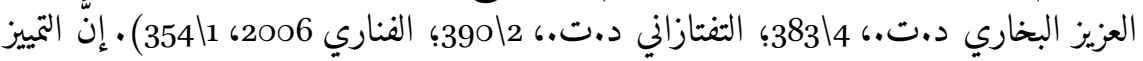

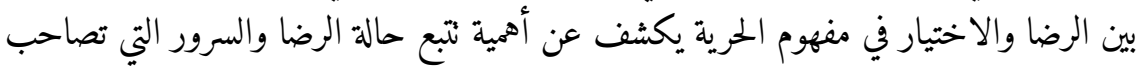

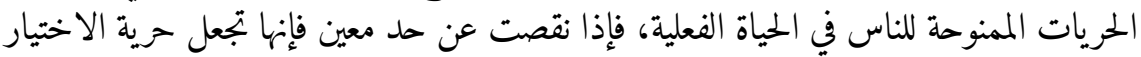

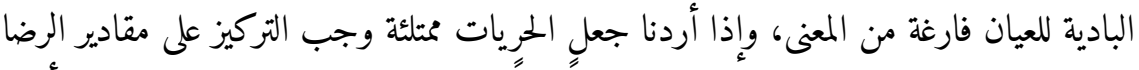

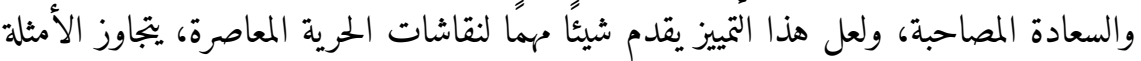
والمسائل الفقهية التشريعية.

$$
\text { توفرِ آلات الفعل وغِيابِ الموانع }
$$

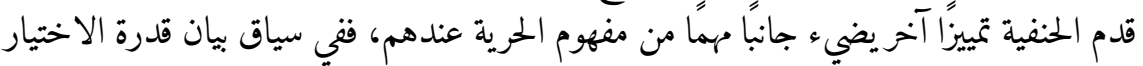

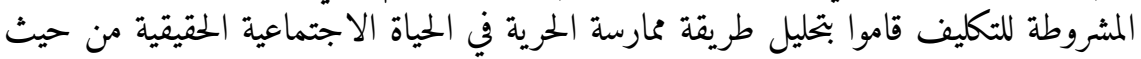

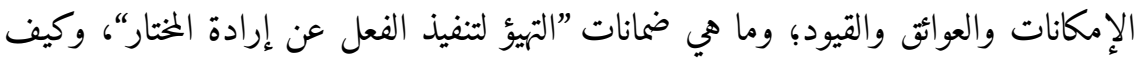

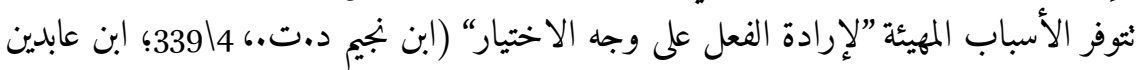

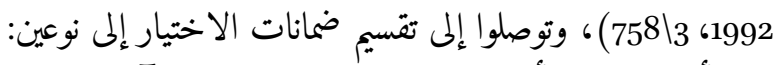

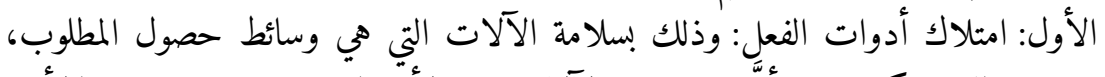

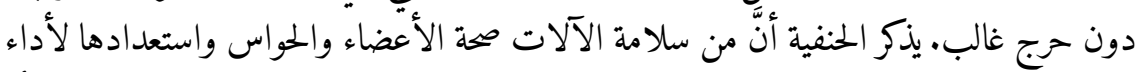

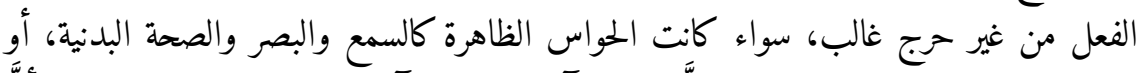

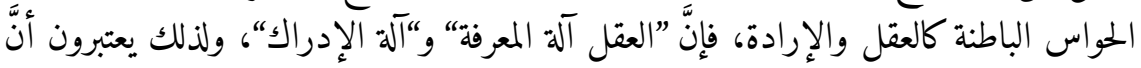

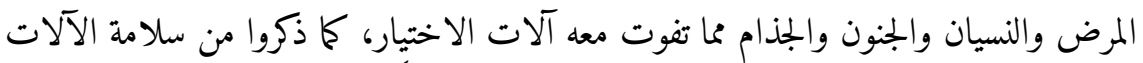

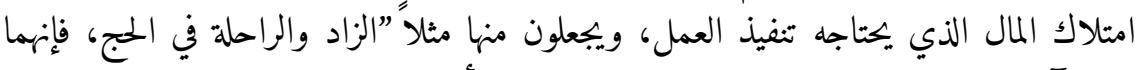

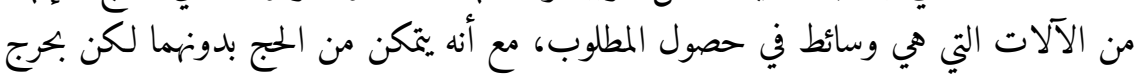

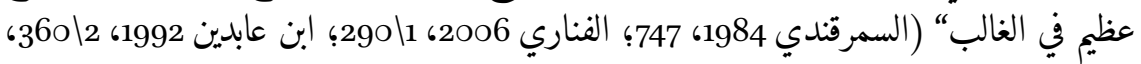
. $(28)_{4}$

الثاني: عدم الموانع: أن لا يكون هناك موانع حسية خارجية مصدرها الغير، ويضرب الماب الحنفية

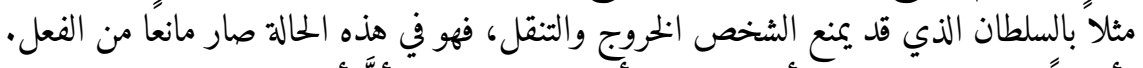

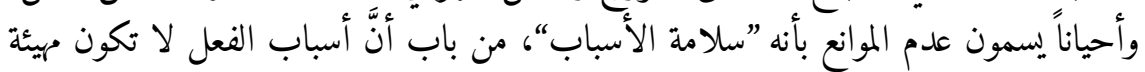

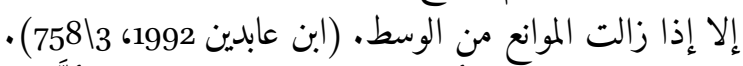

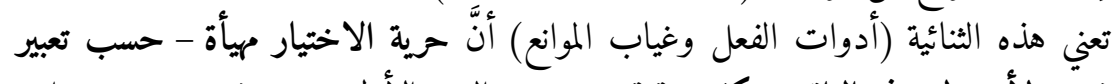

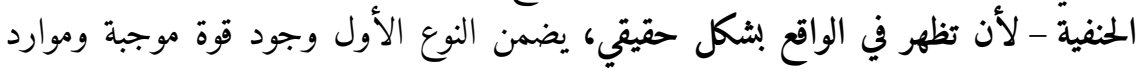


كافية للشخص لتنفيذ اختياره، تبدأ بصحته وتنتهي بتوفر المال اللازم بين يديه، وإلا فهو عاجز، المأي

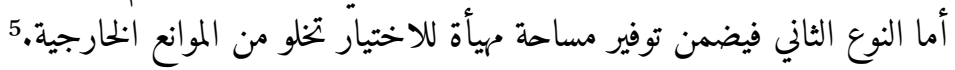

$$
\text { الحرية: بناء المفهوم }
$$

التدقيق في العناصر الثلاثة للحرية وكيفية التفاعل مع الصوم التهور المجازية الرئيسية يتيح بناء المفهوم

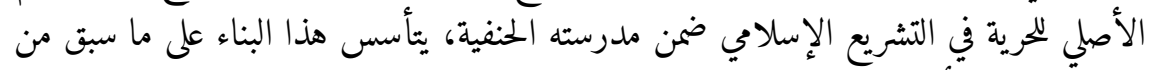

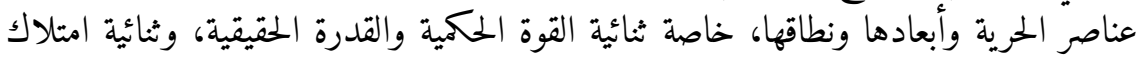

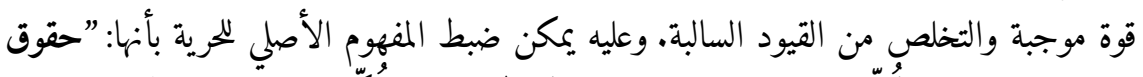

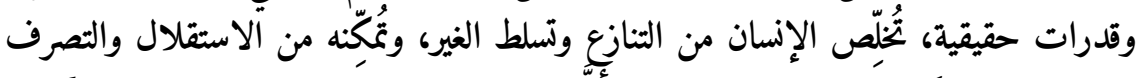

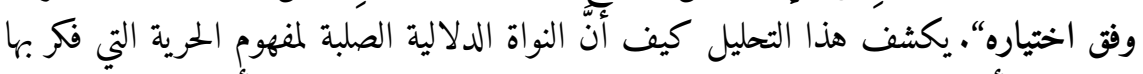

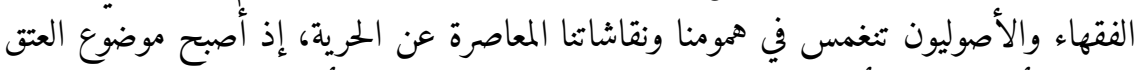

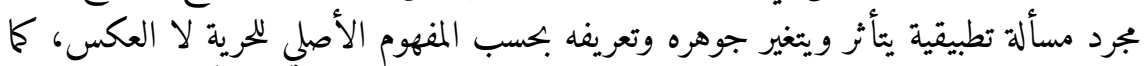

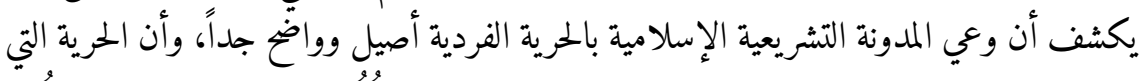

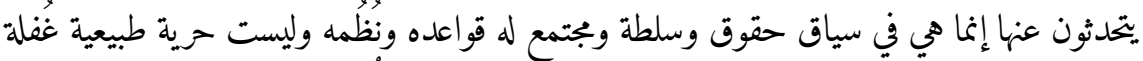

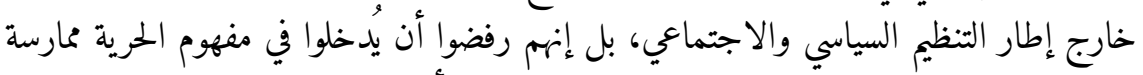

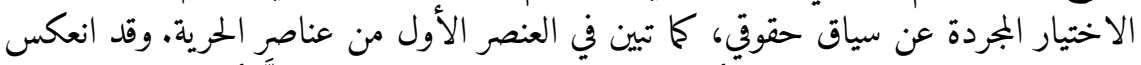

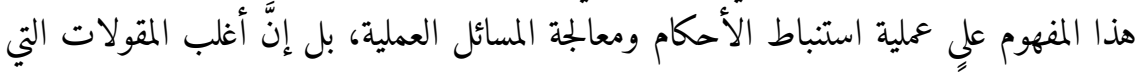

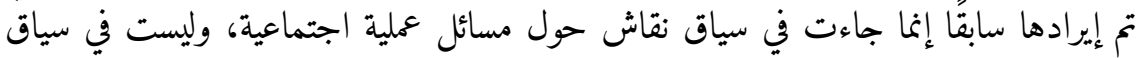

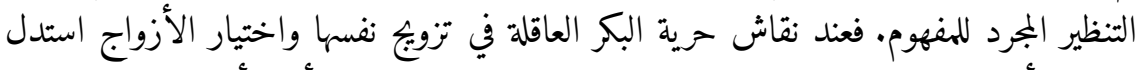

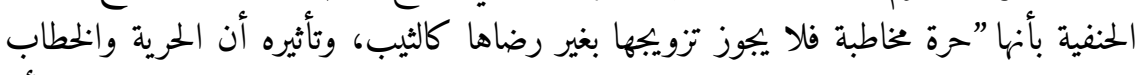

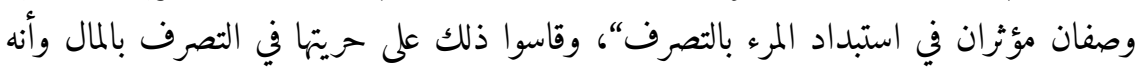

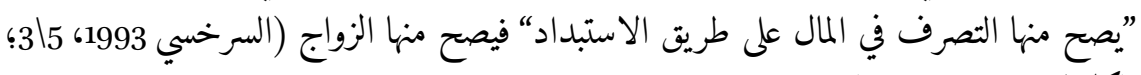

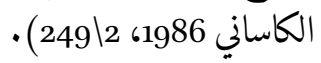

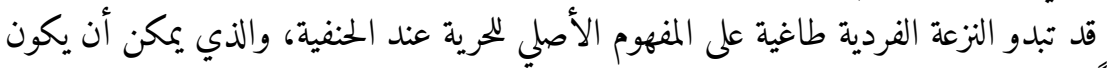

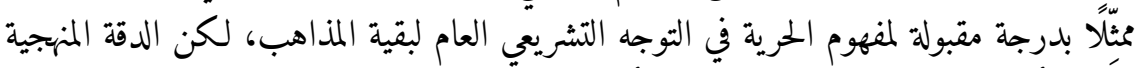

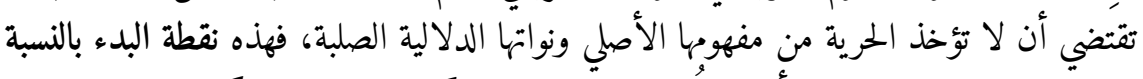

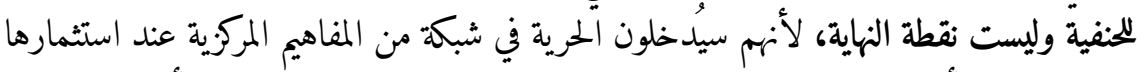

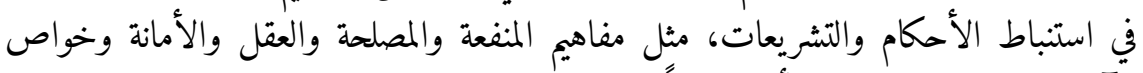

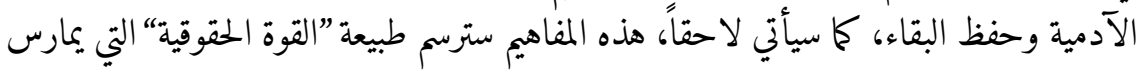

5 يتصل هذا بالنقاشات المعاصرة التي تدور في مباحث الحريات حول ”الحرية الموجبة والحرية السالبة، بركية مع أشعيا بيرلين وغيره (بيرلين 2015، 230) 


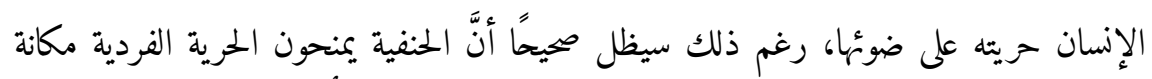

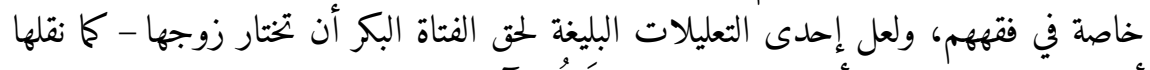

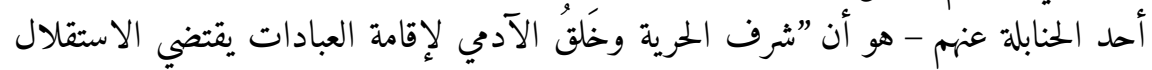
وعدم الاعتراض" (الطوفي 2005، 146).

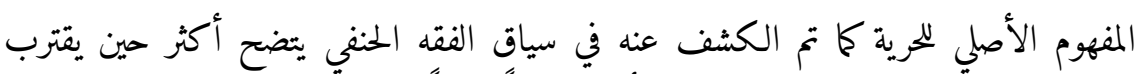

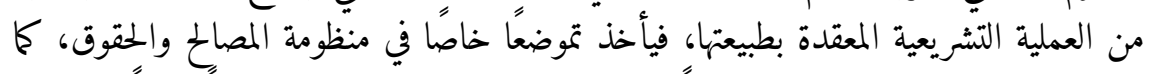

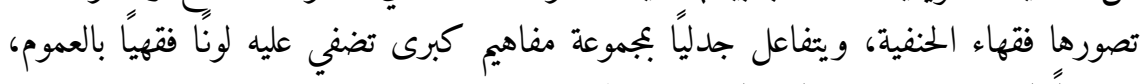

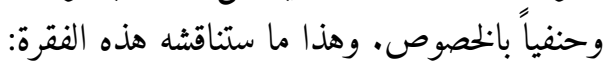

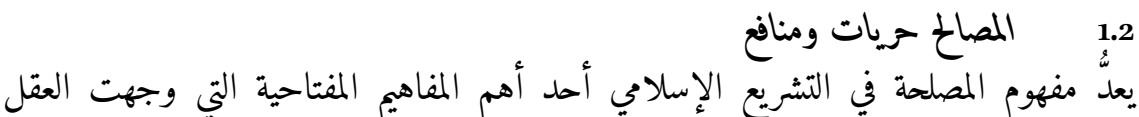

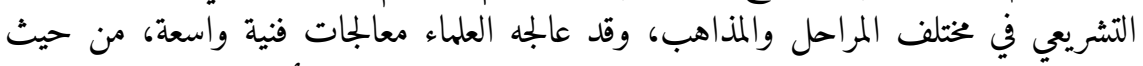

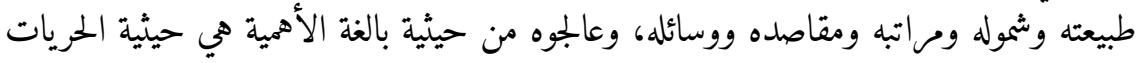

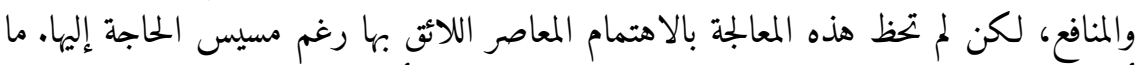

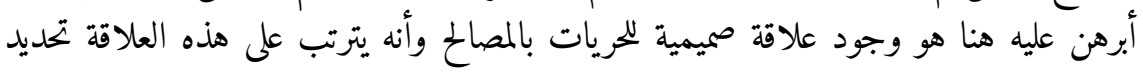

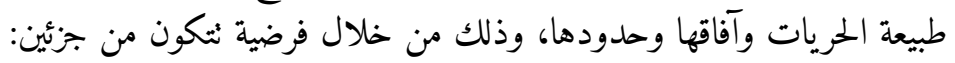

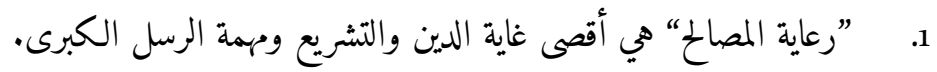

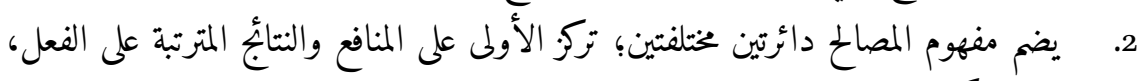

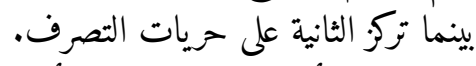

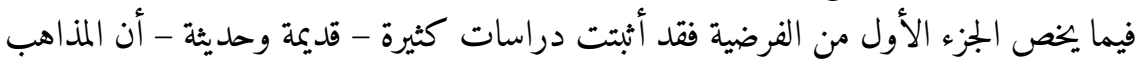

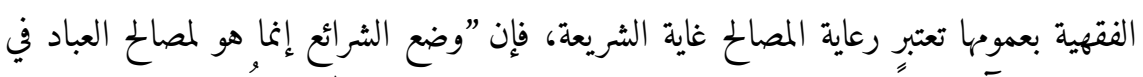

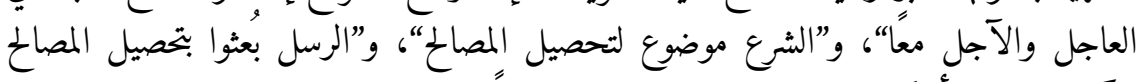

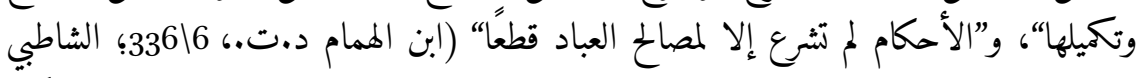

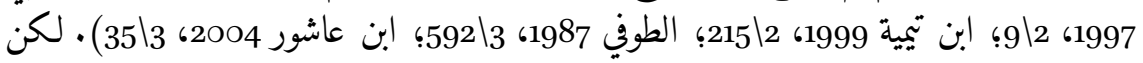

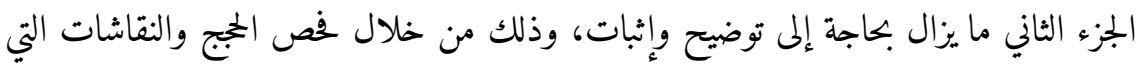

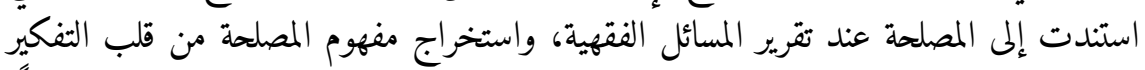

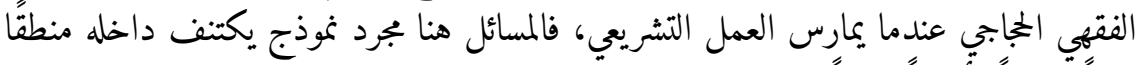

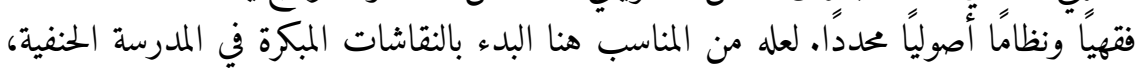


فقد تبلورت المصلحة"6 بوصفها حريات ومنافع في ذلك الجدل المشهور بين أبي حنيفة وصاحبيه

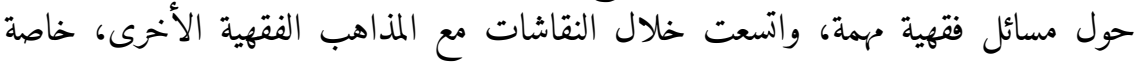
المذهب المالكي.

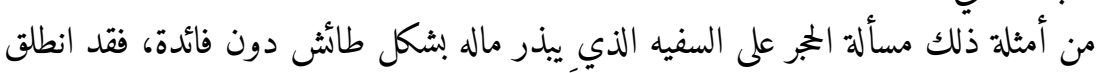

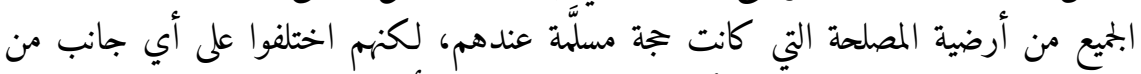

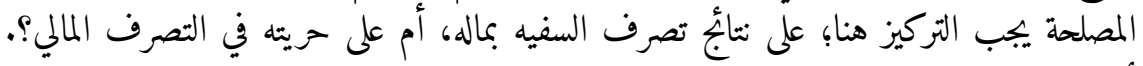

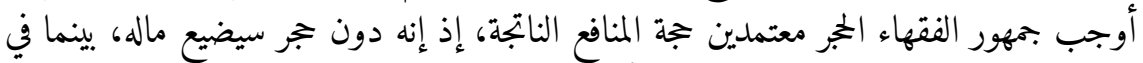

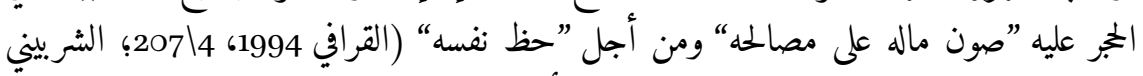

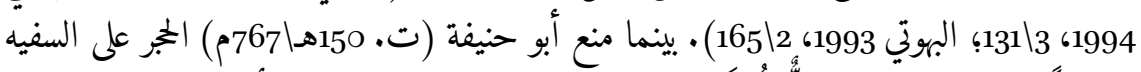

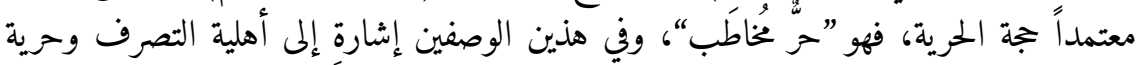

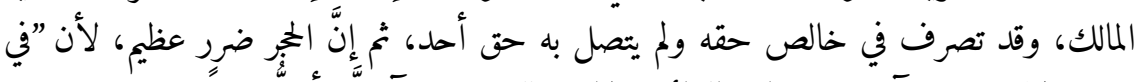

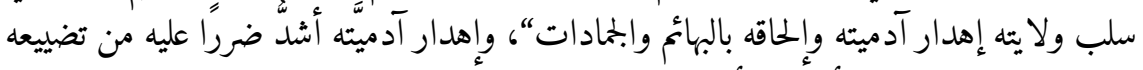

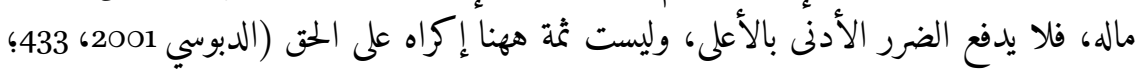

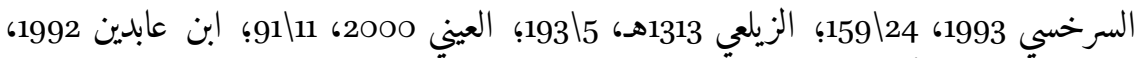

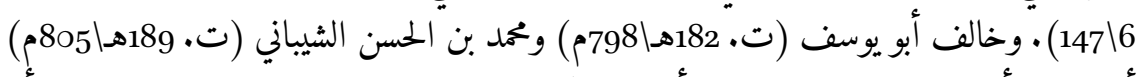

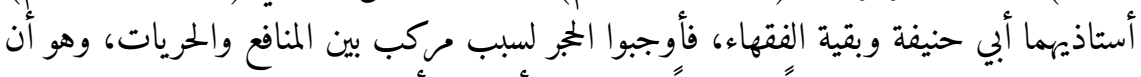

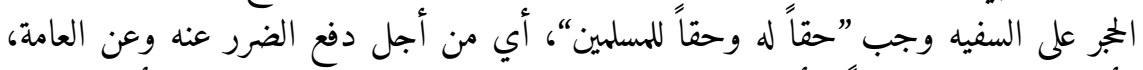

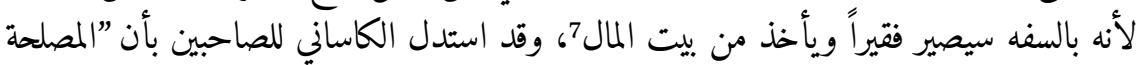

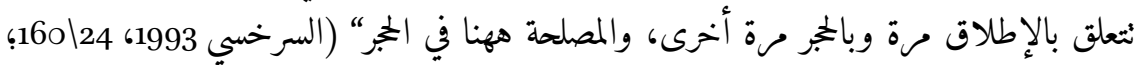

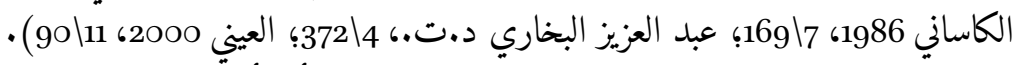

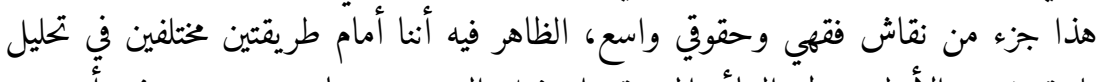

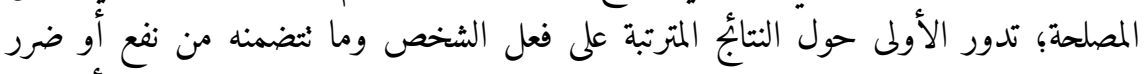

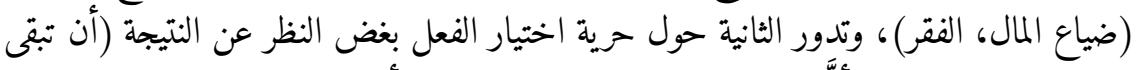

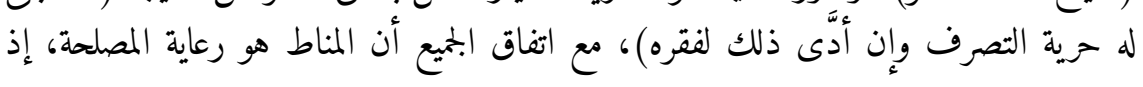

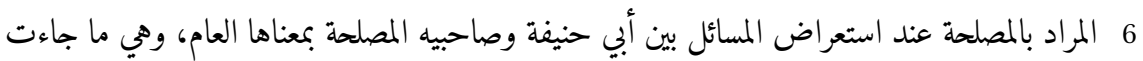

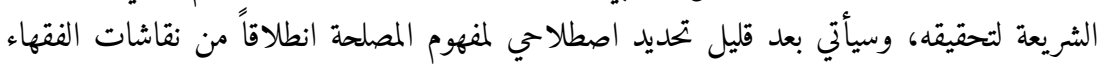
المتقدمين - كأبي حنيفة وصاحبيه ومالك - ومن تأصيل الفقهاء المباء المتأخرين.

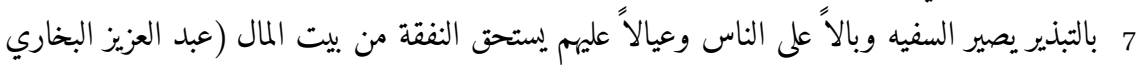

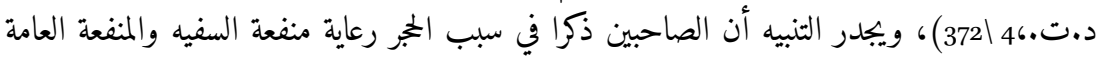

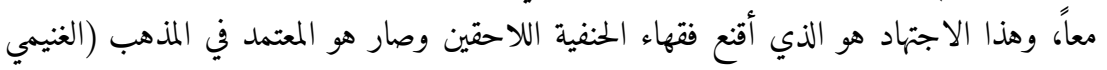


صرح كل الأطراف أن طريقتهم هي التي تحقق أكبر مصلحة في هذا الموقف وتدفع أكبر ضرر.

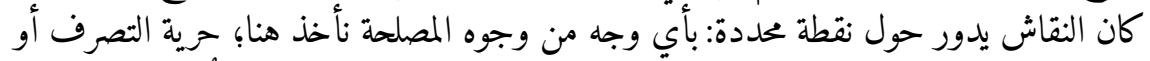

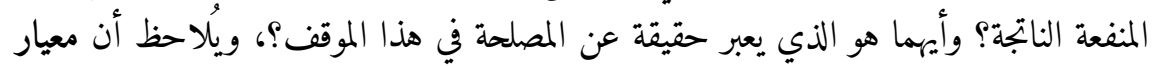

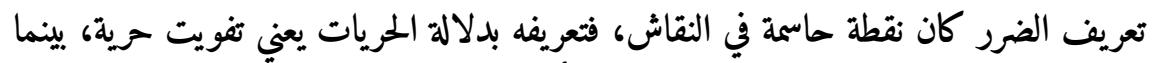

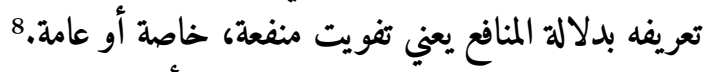

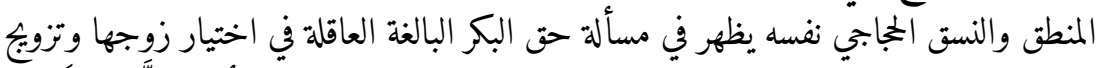

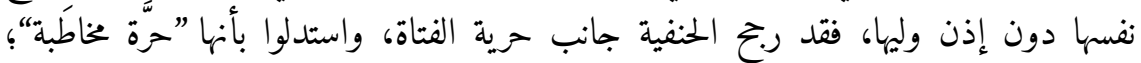

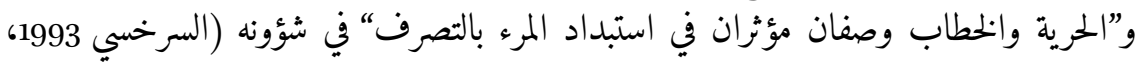

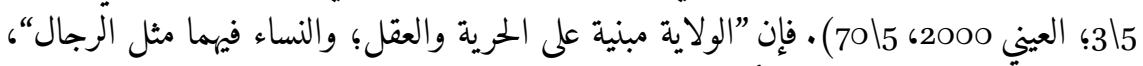

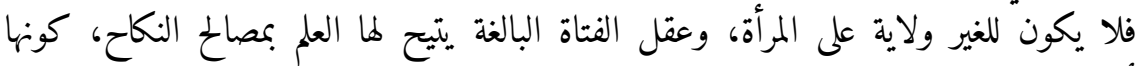

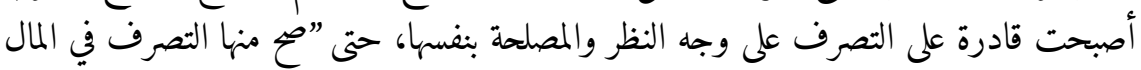

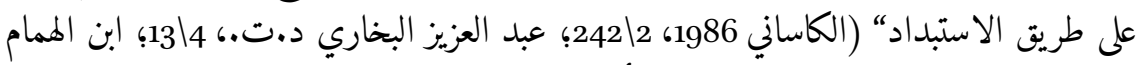

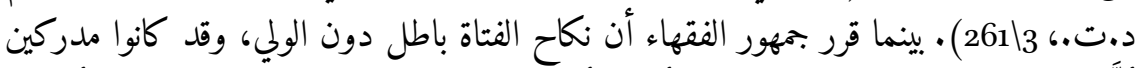

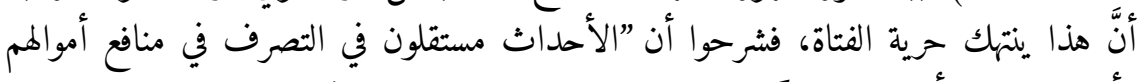

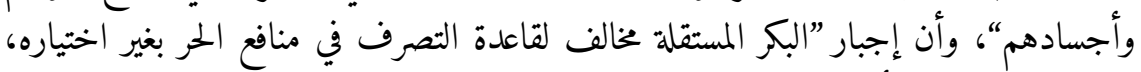

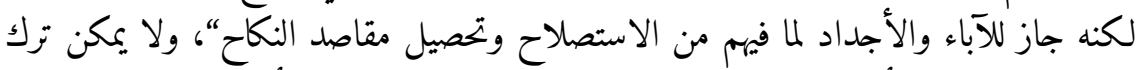

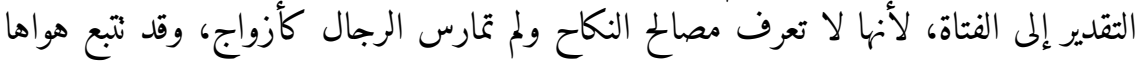

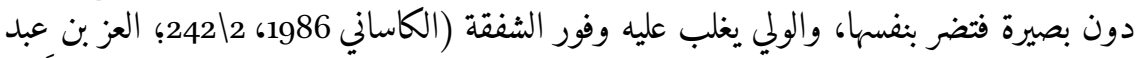

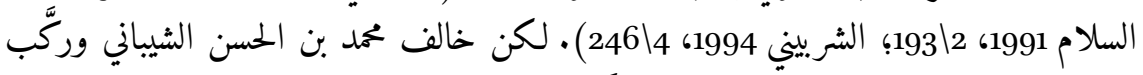

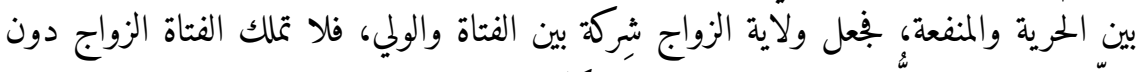

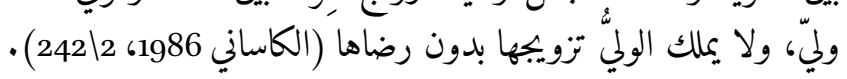

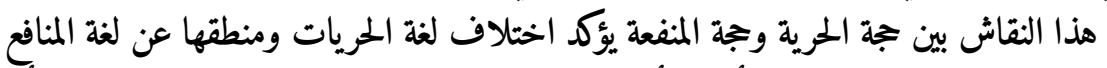

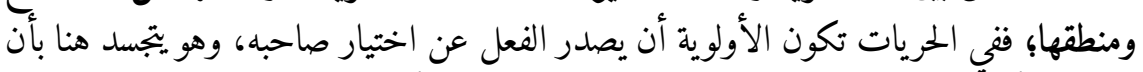

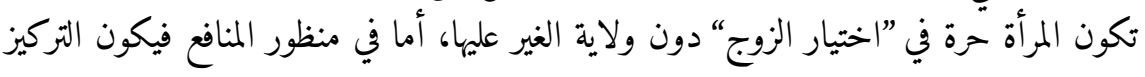

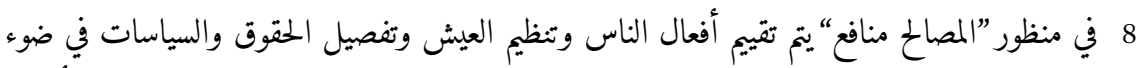

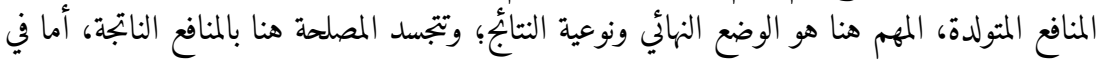

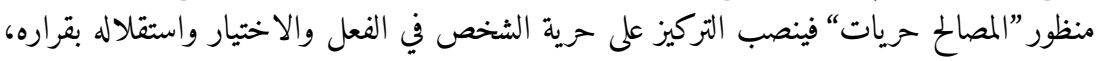

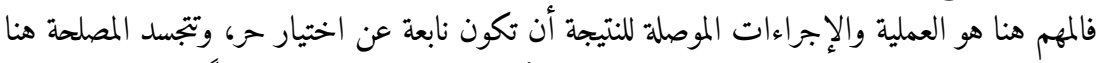

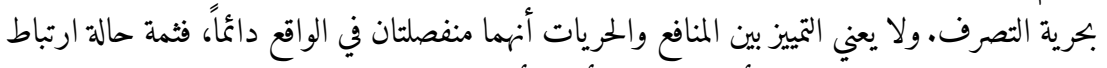
واعتماد متبادل في كثير من الأحيان، كما ستأتي الأمثلة خلال البها البحث. 
على نوعية النتأجُ والعواقب المترتبة، وهو يتجسد هنا بالألفة والاستمتاع بين الزوجين واختيار الزوج يتكرر الأمر في مسألة ثالثة وهي رجل مديون موسر وهو يماطل في الوفاء، فطلب الغرماء

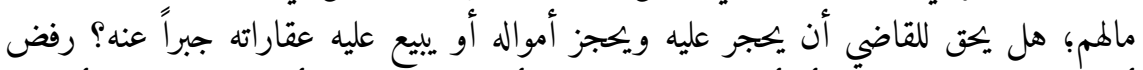

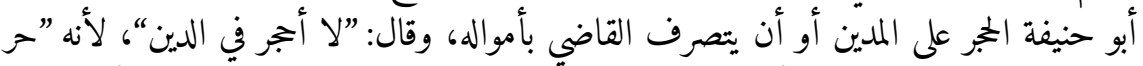

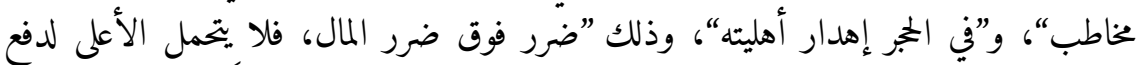

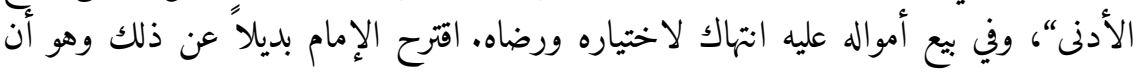

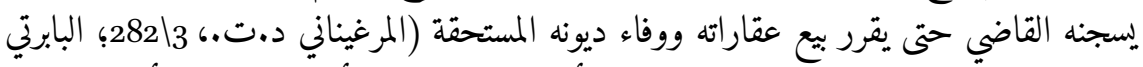

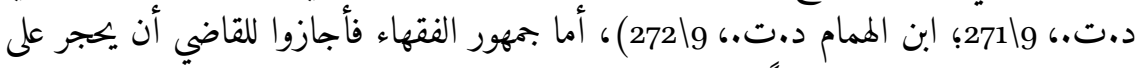

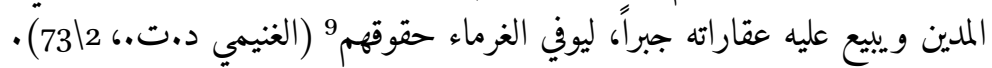

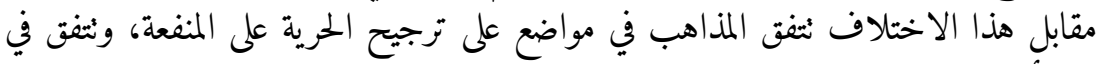

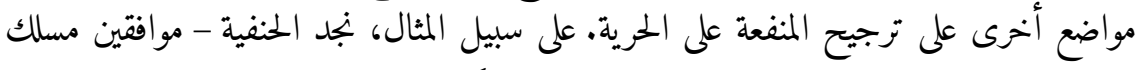

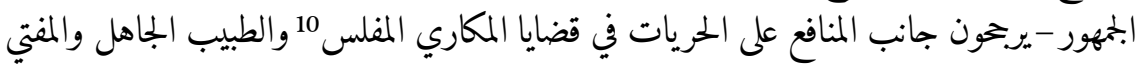

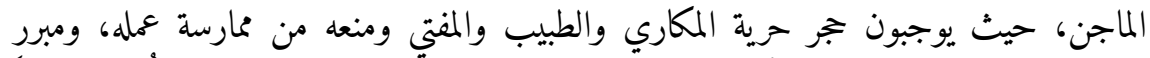

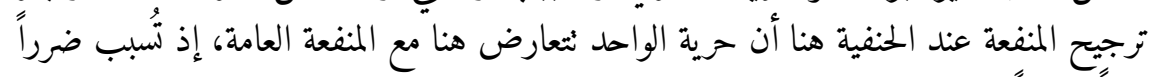

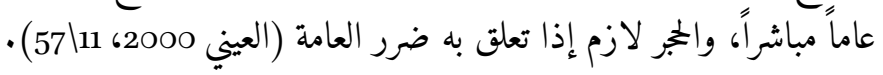

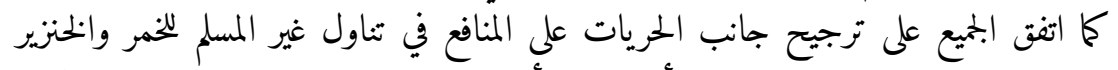

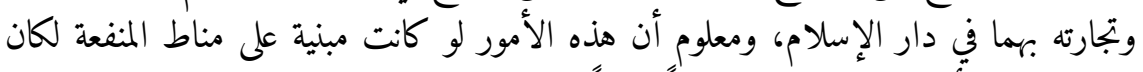

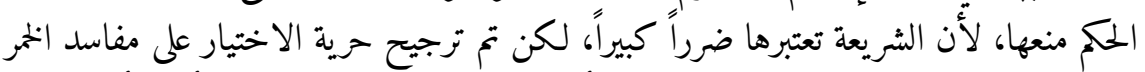

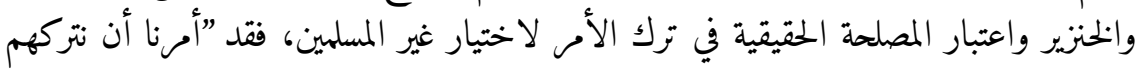

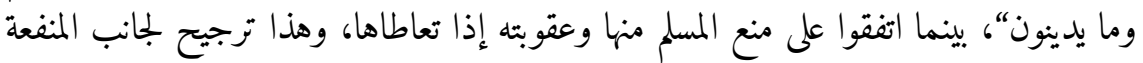

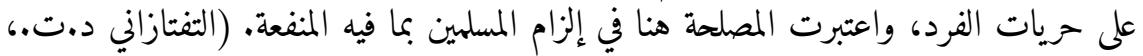

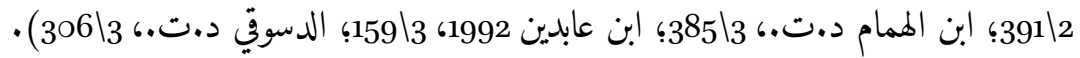

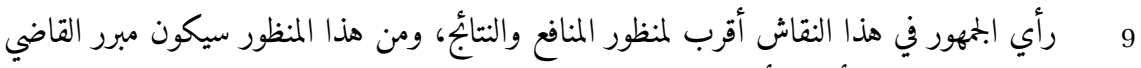

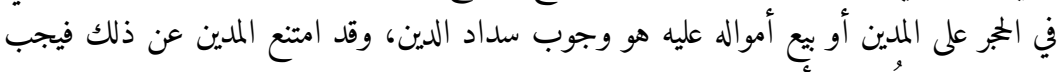

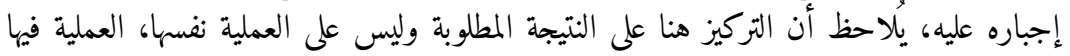
إكراه لكن النتيجة محقة. 10

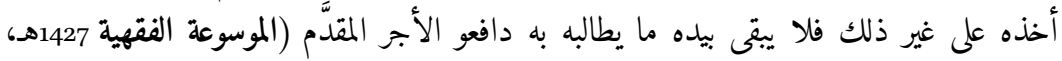


يتبين من دراسة هذه النماذج الدالة من بنية الحجاج الفتهي وتطبيقاته العملية أنَّ المصالح نتقدَّر

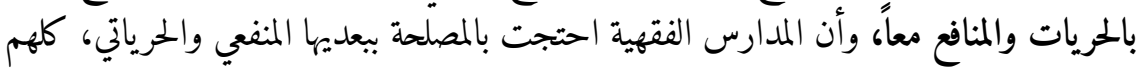

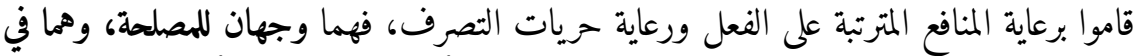

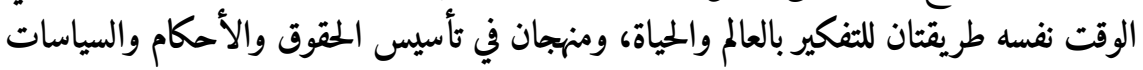

وتعريفها وتفصيلها. ويتأكد تموضع الحرية داخل مفهوم المصلحة وتأطيره بها من خلال نمال نصوص تأصيلية صريحة

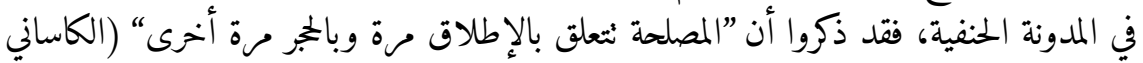

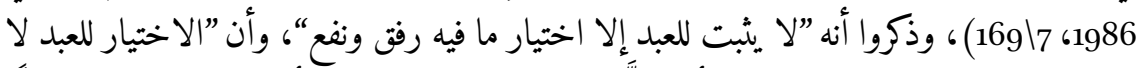

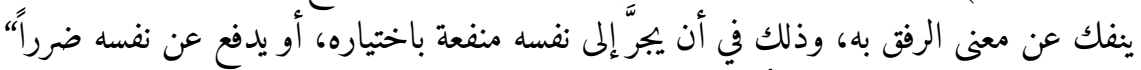

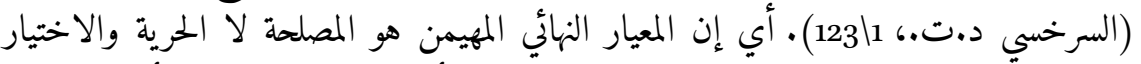

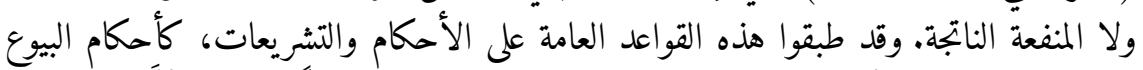

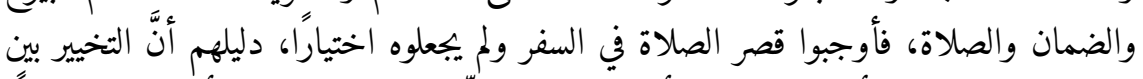

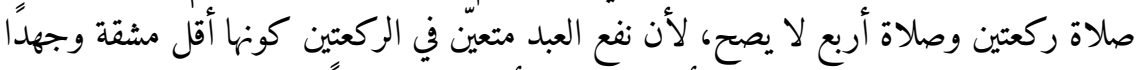

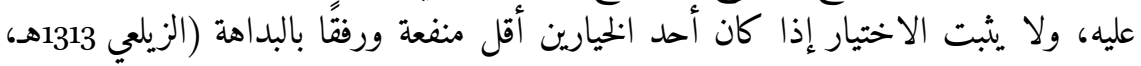

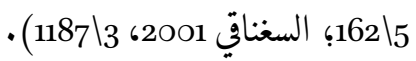
ومن المهم هنا بعد توضيح علاقة الحرية بالمصالح تقديم مقترح اصطلاحي لاستخدام الكلمات المات

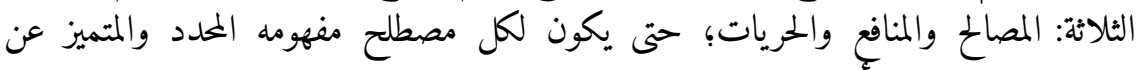

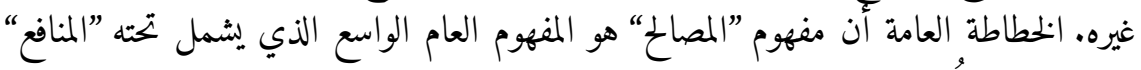

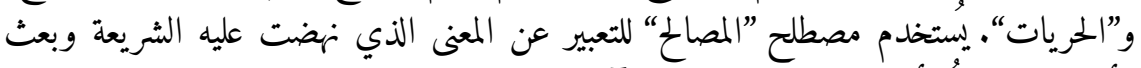

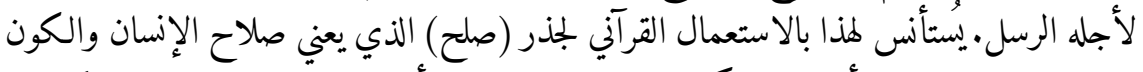

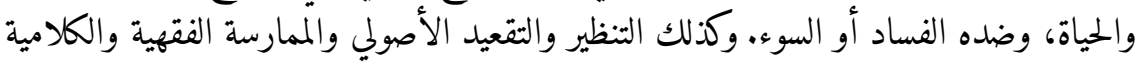

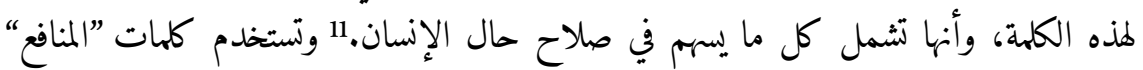

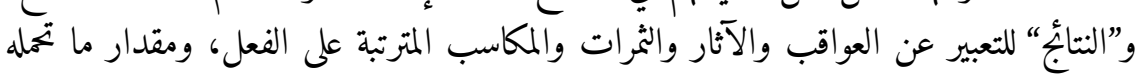

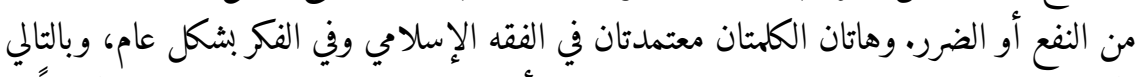

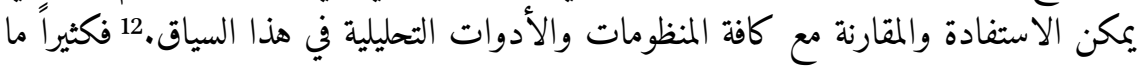

11

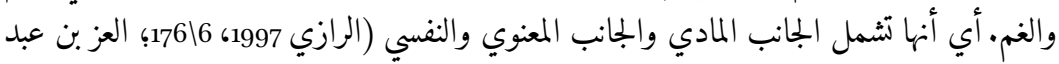
السلام 1991، 1| 11).

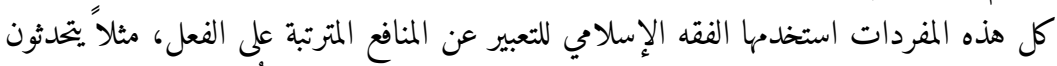
12

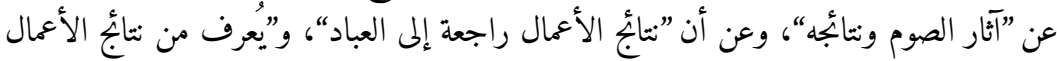

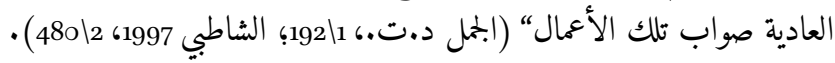




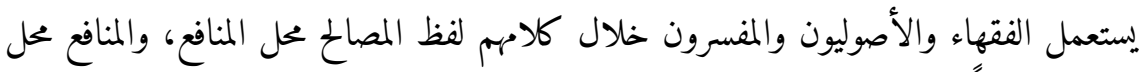

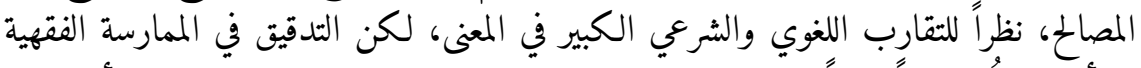

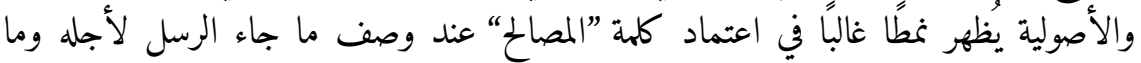

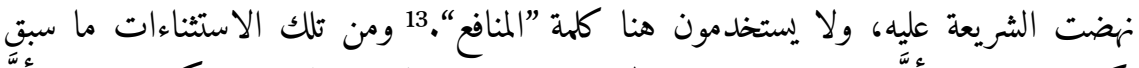

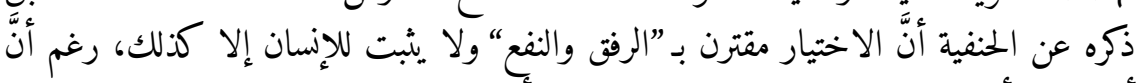

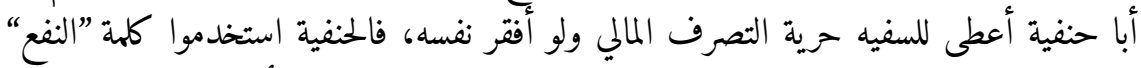

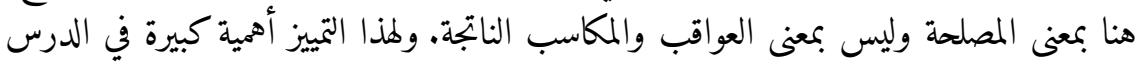

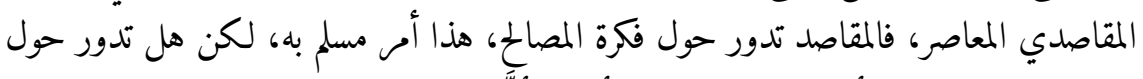

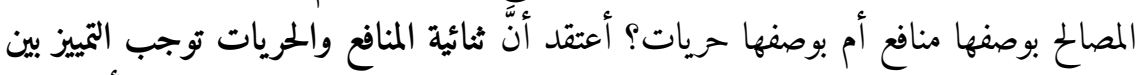

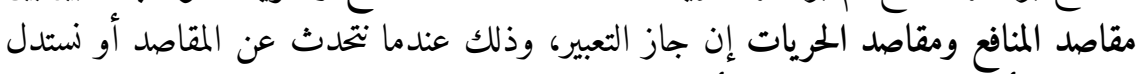

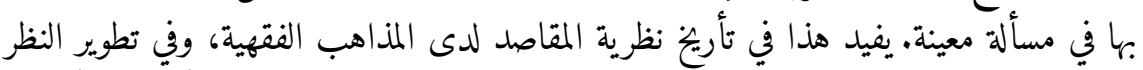

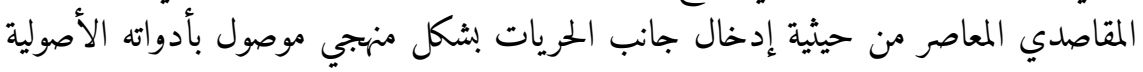
والفقهية.

$$
\text { الحرية والحقوق }
$$

يطرح التفكير الحنفي تصورًا لعلاقة الحرية وحقوق الإنسان يبدو أنه فريد من نوعه داخل

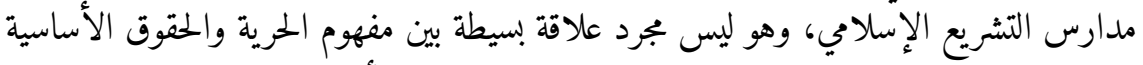

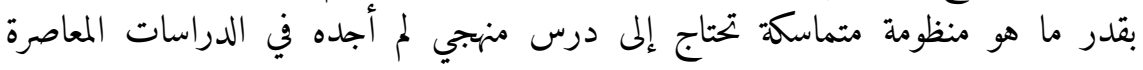

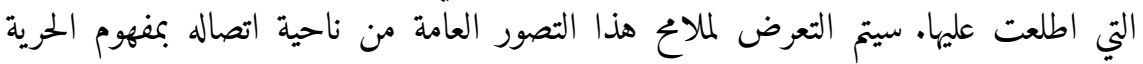
موضوع بحثنا. في نص مؤسس يفتتحون به باب الأهلية في كتب الأصول، يضع الحنفية الإطار الفلسفي

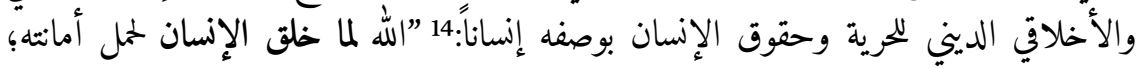

13

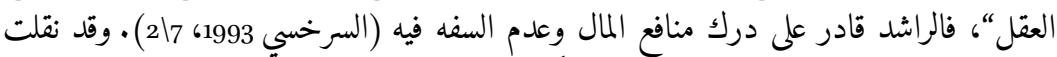

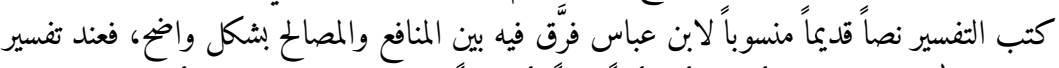

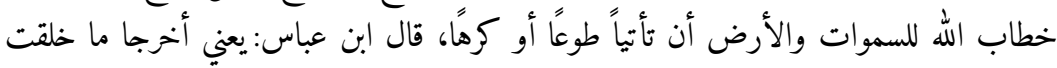

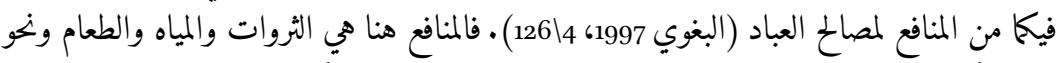

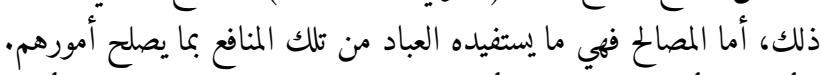

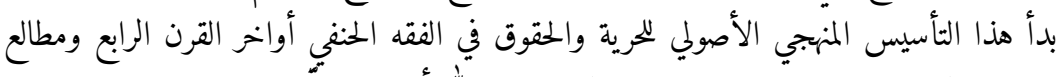
14

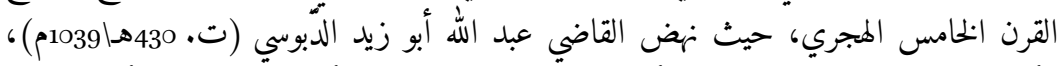

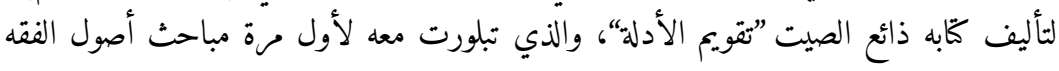




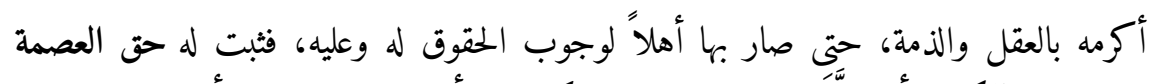

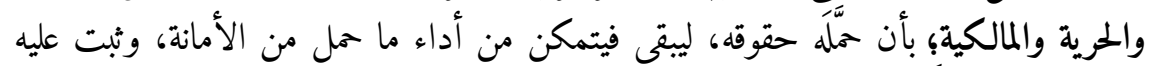

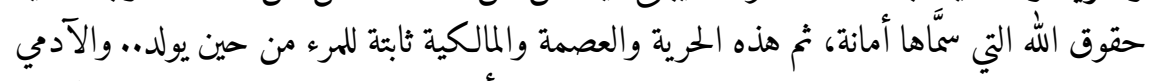

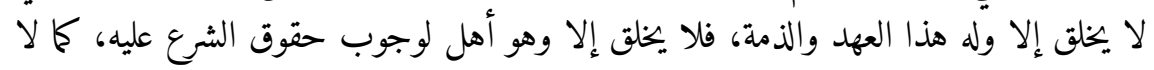

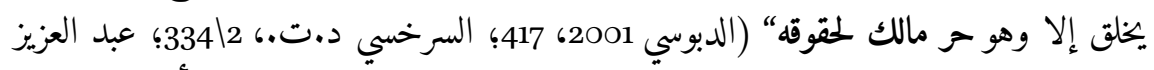

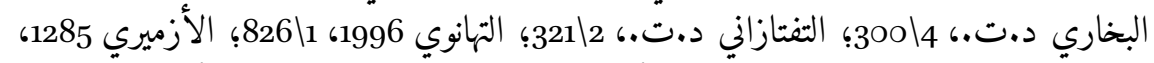
434>2 • يحتوي هذا النص المؤسس على أربعة مبادئ متماسكة نتكون منها الأطروحة:

$$
\text { المبدأ الأول: الحقوق الأصلية }
$$

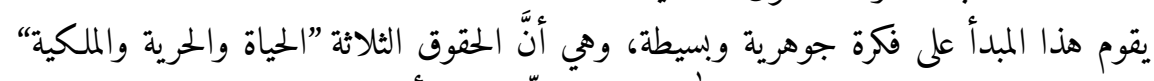

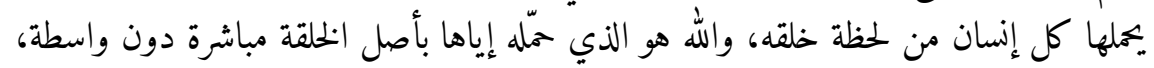

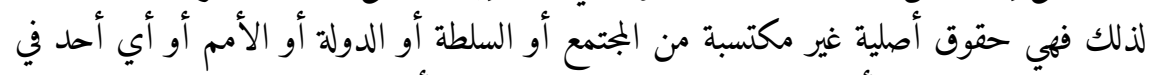

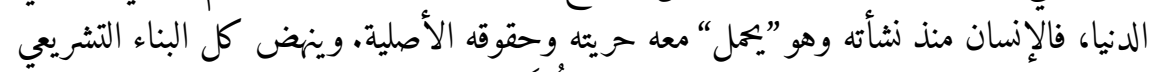

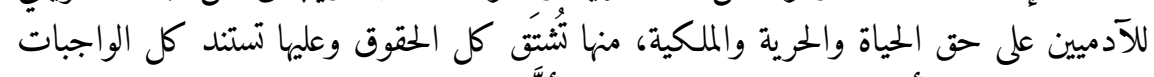

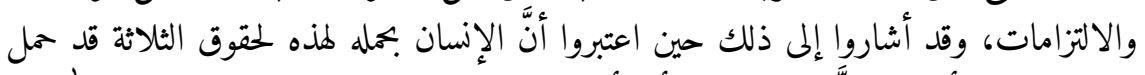

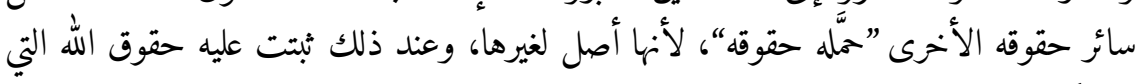

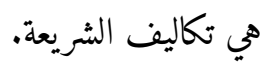

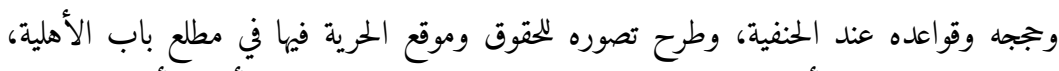

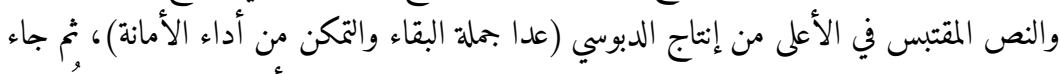

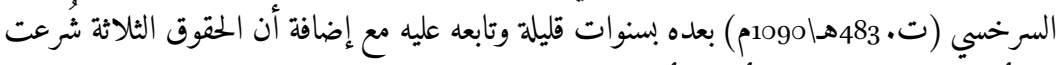

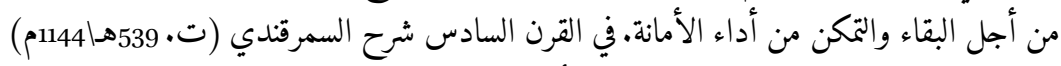

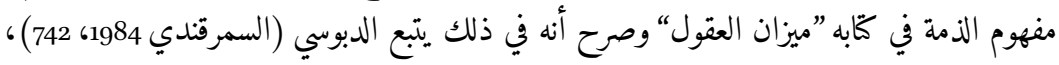

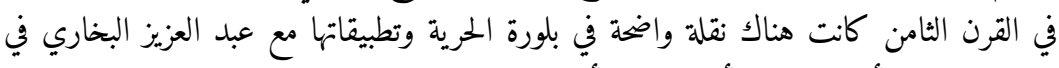

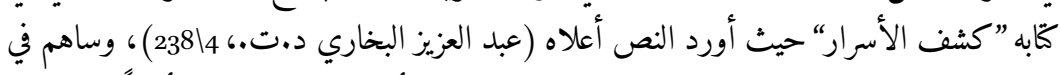

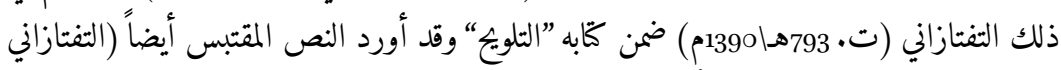

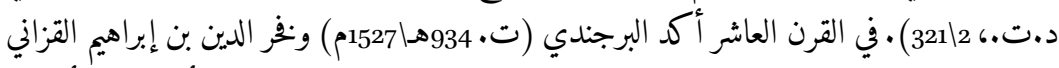

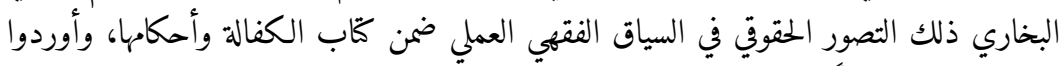

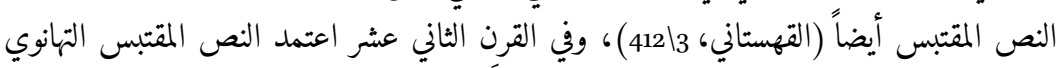

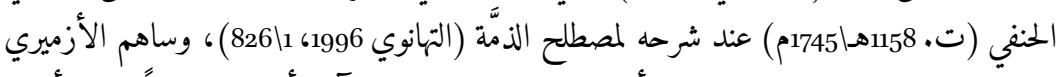

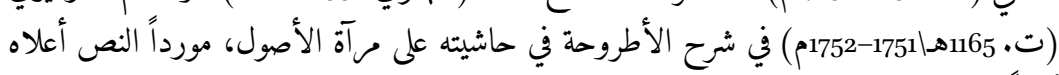

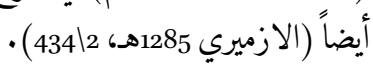




$$
\text { المبدأ الثاني: أصالة الحرية }
$$

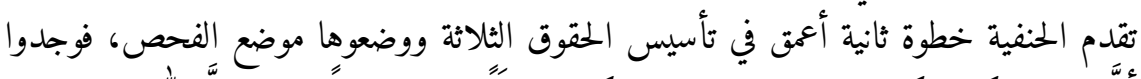

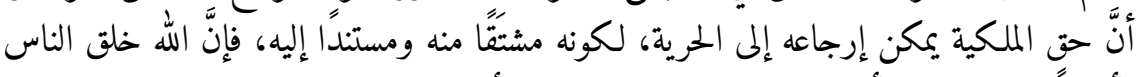

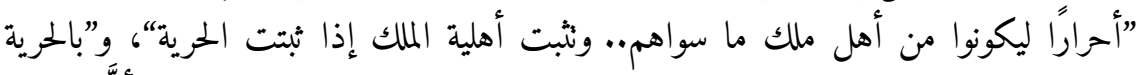

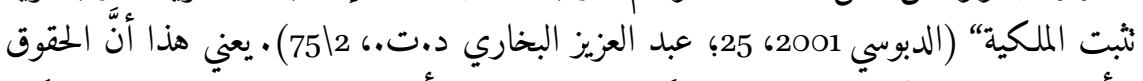

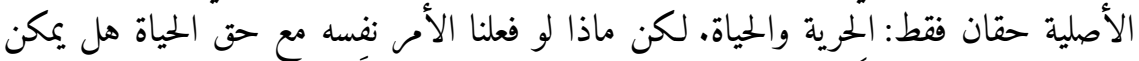

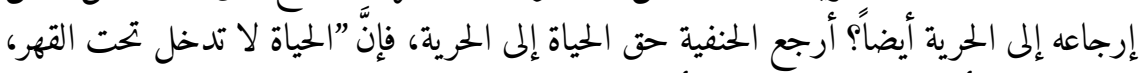

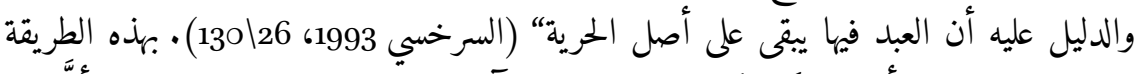

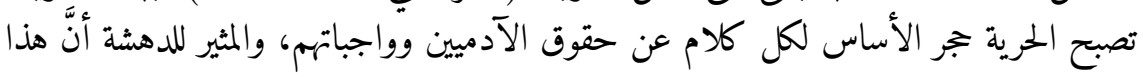

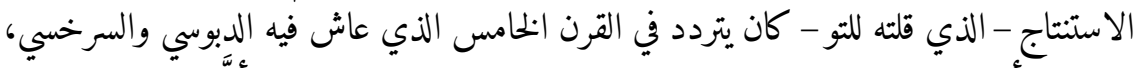

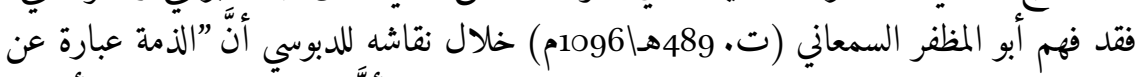

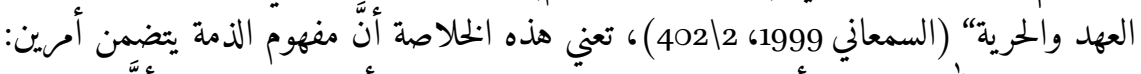

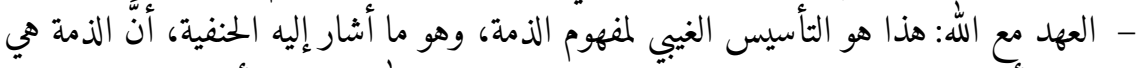

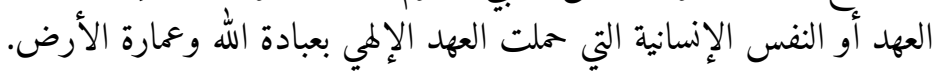

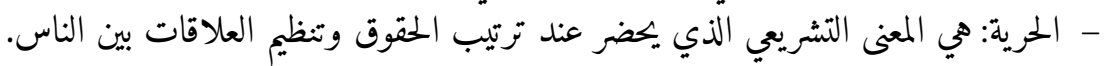

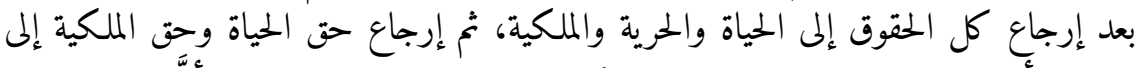

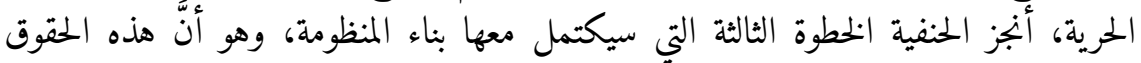

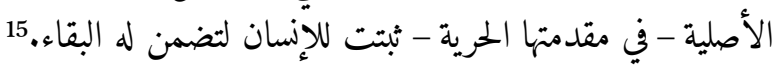

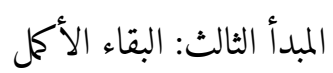

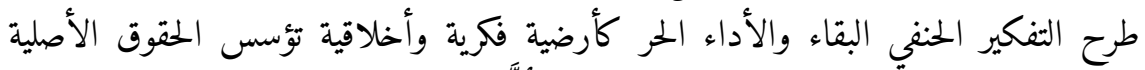

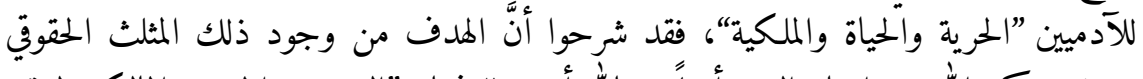

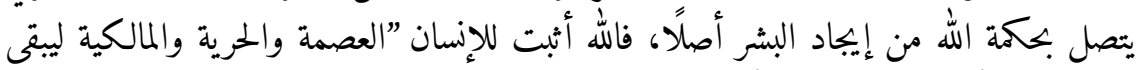

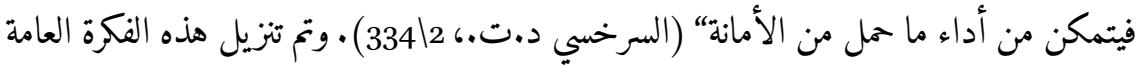

15

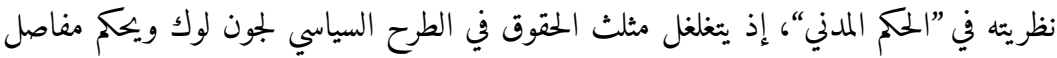

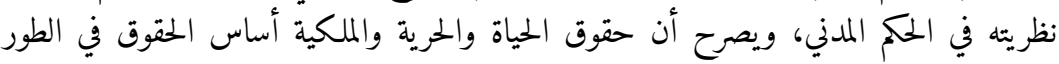

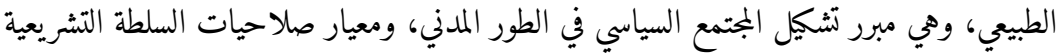

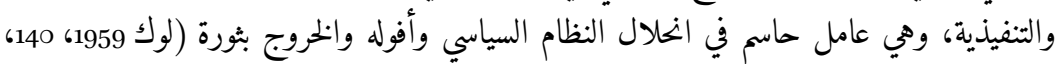

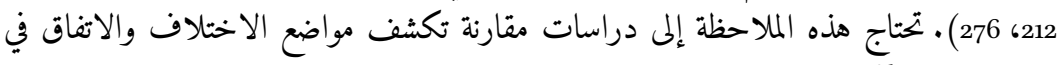
مفهوم الحرية وآفاقه. 
ضمن الحياة الاجتماعية والحقوقية من خلال تسلسل ثلاث خطوات استدلالية: "حكمة التكليف

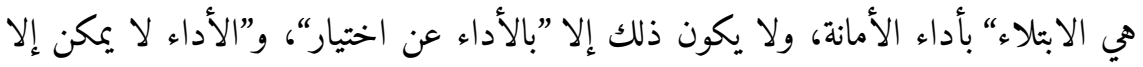

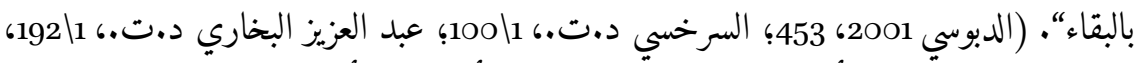

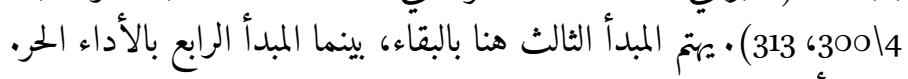

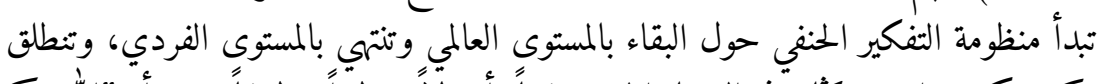

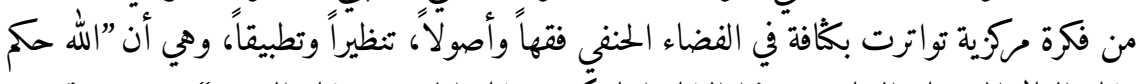

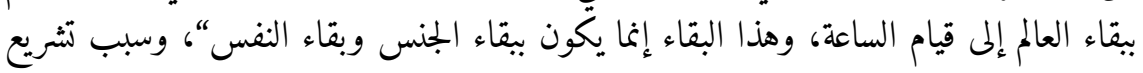

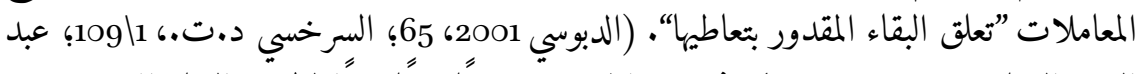
العزيز البخاري د.ت.،

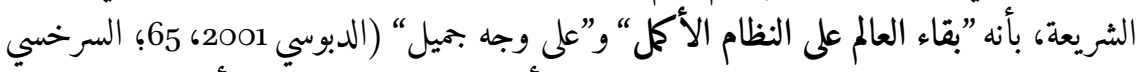

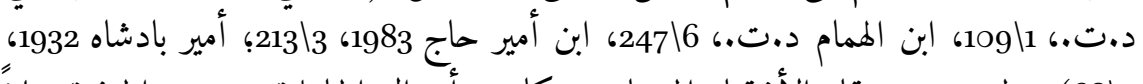

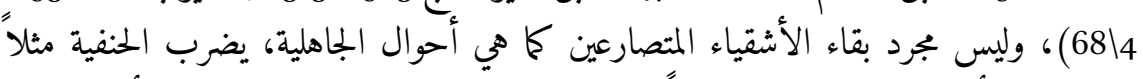

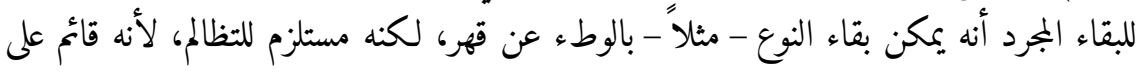

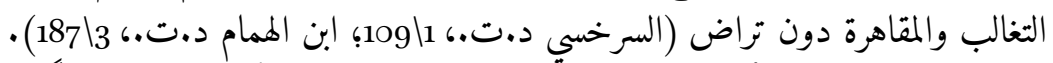

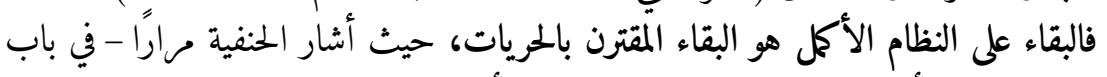

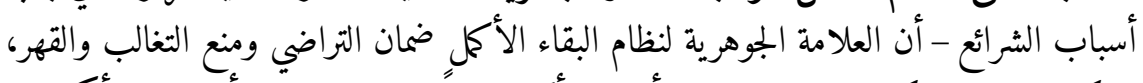

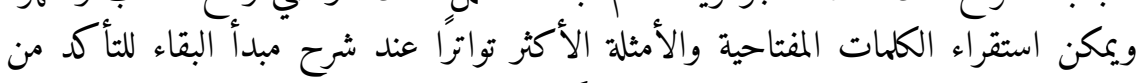

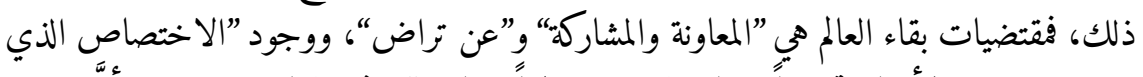

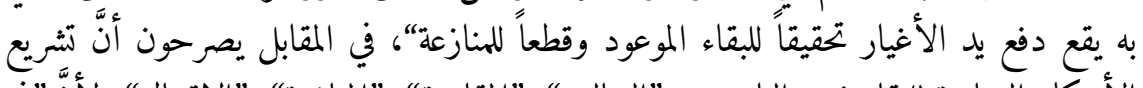

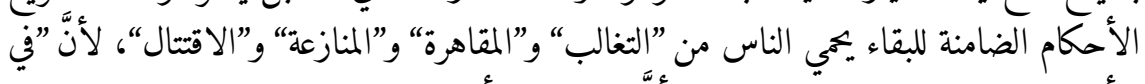

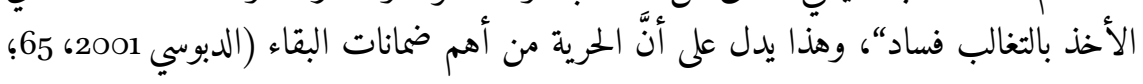

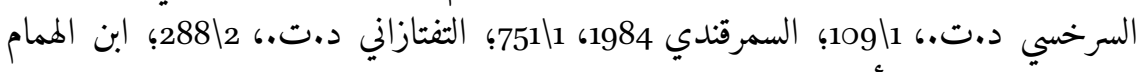

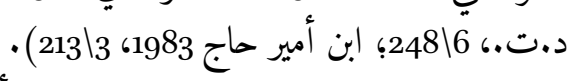

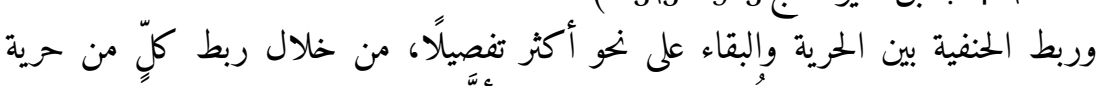

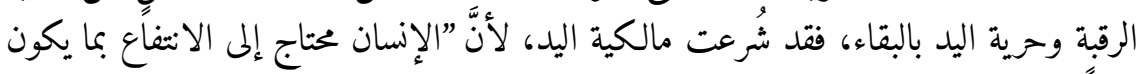

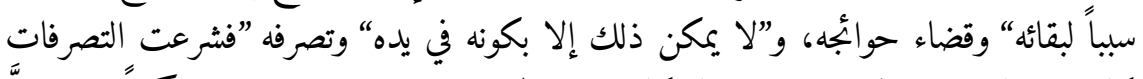

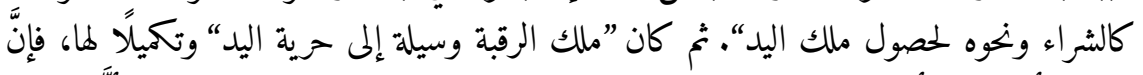

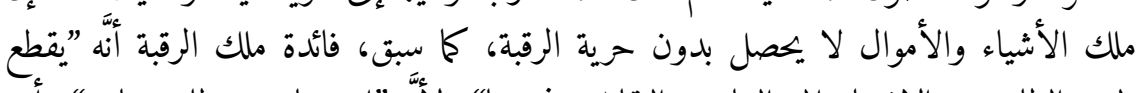

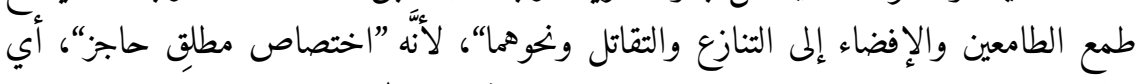

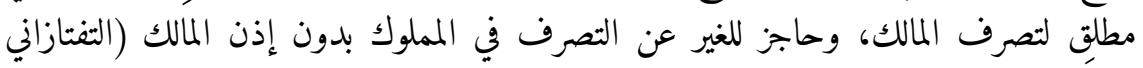

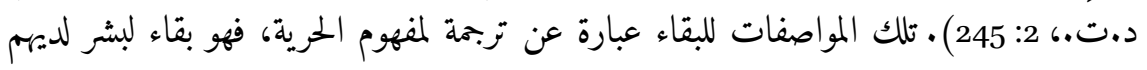


”حقوق“ قررتها الشريعة لتعيد تنظيم وتوزيع "قدرات حقيقية“ يتصرفون فيما بينهم، لتحمي كل

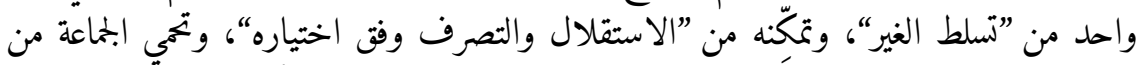

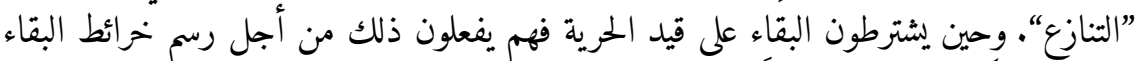

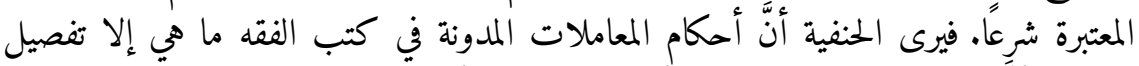

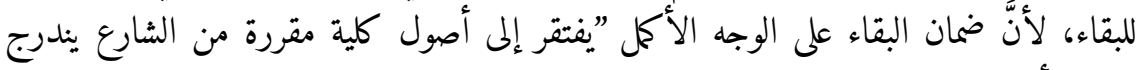

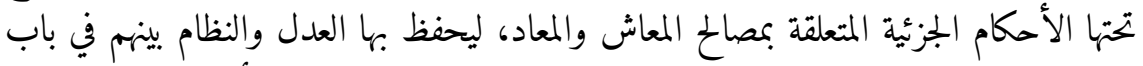

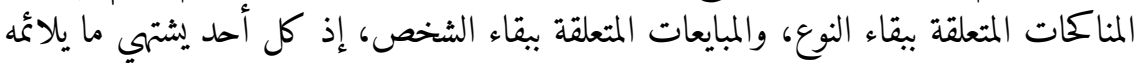

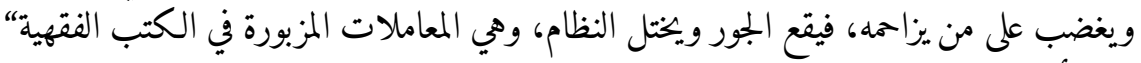

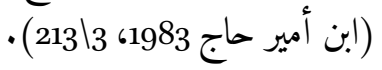

$$
\text { المبدأ الرابع: ابتلاء الأداء الحر }
$$

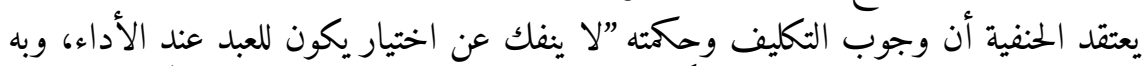

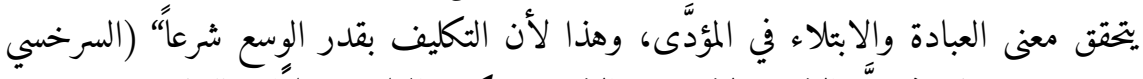

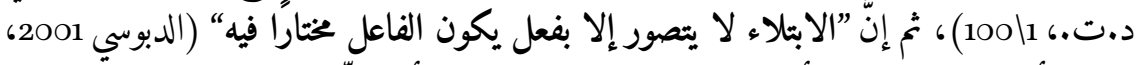

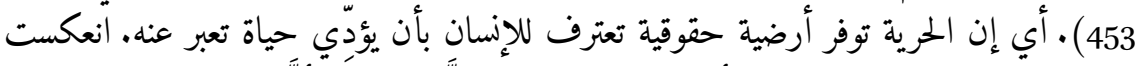

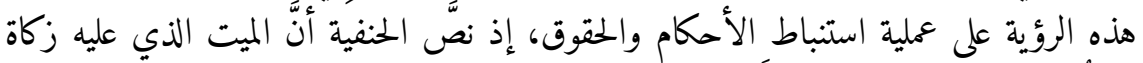

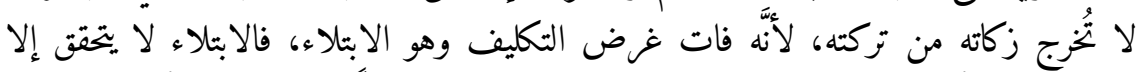

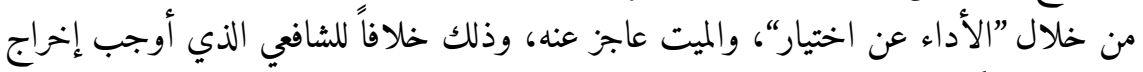

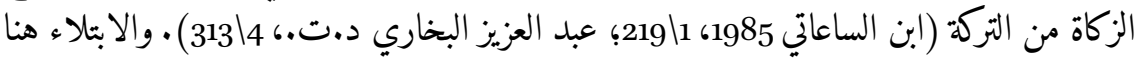

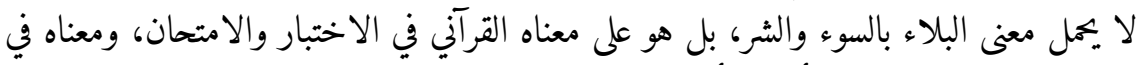

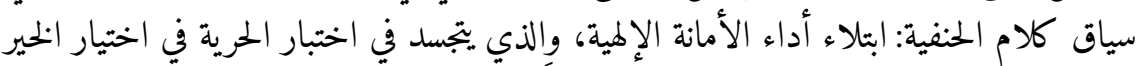

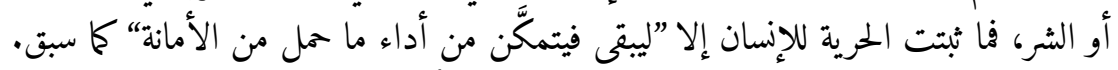

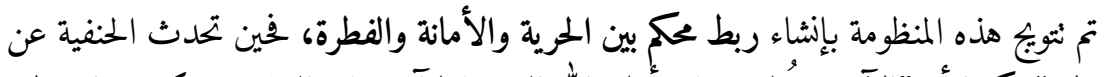

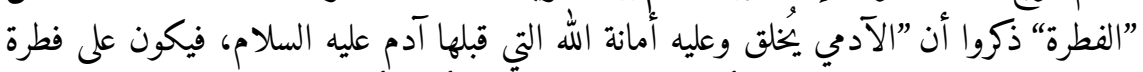

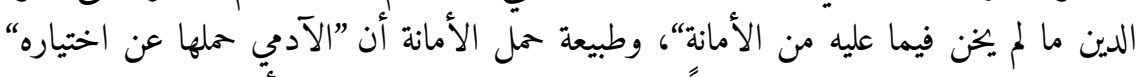

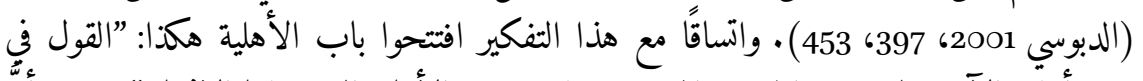

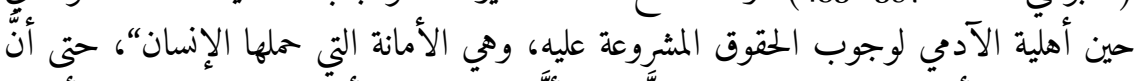

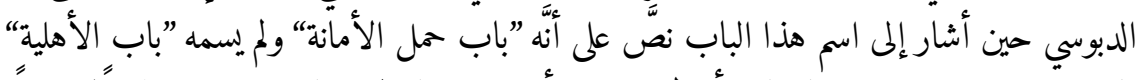

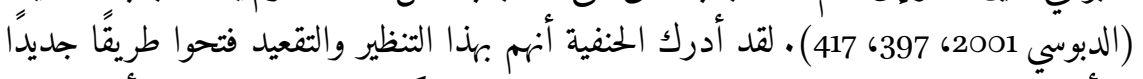

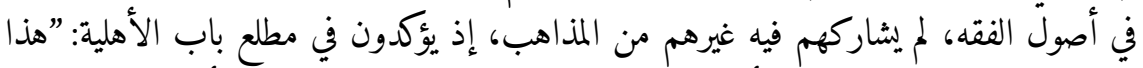

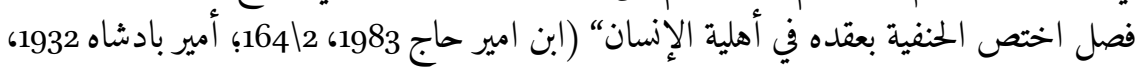
. $(249 \backslash 2$ 
منظومة الحرية وحقوق الإنسان عند الحنفية، كما أوضتها للتو، تقدم وجها جديدًا للحرية في

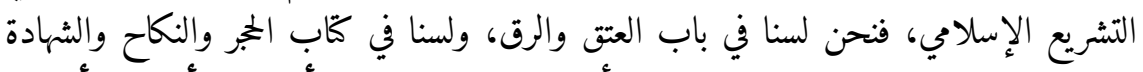

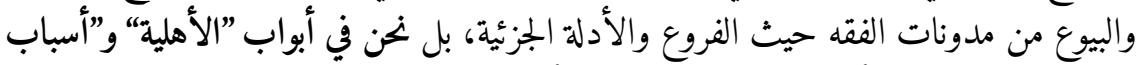

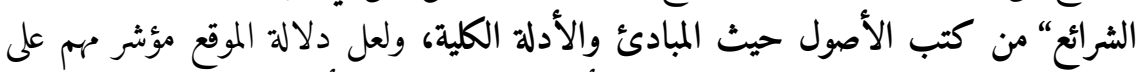

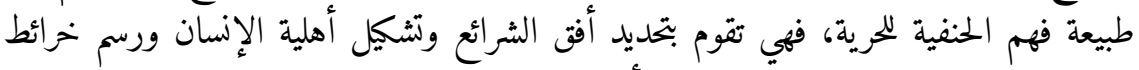

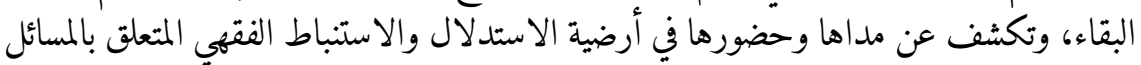

العملية.

شبكة المفاهيم الحافة بالحرية

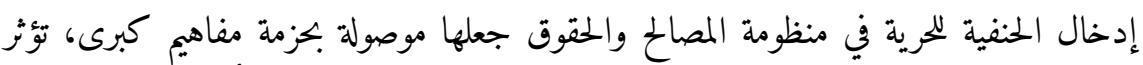

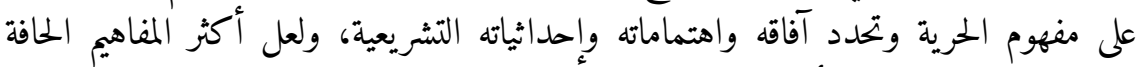

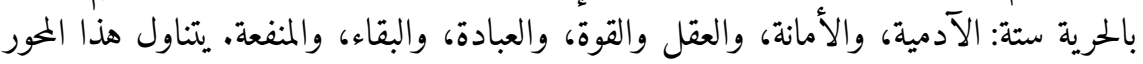

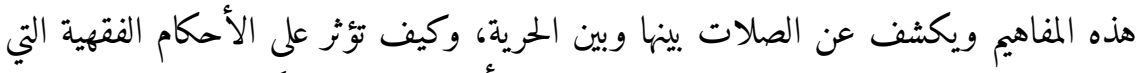

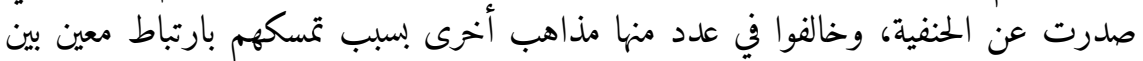

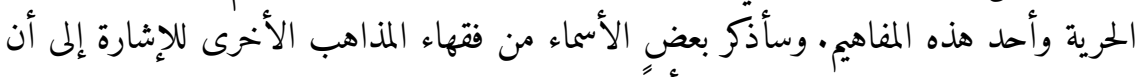

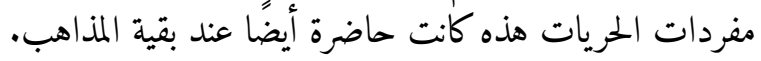

$$
\text { المفهوم الأول: الحرية والبقاء }
$$

ينطلق هذا المفهوم من منظومة الحقوق التي شرحها الحفاء الحنفية، وقد قتَّم الحنفية بقاء العالم قسمين:

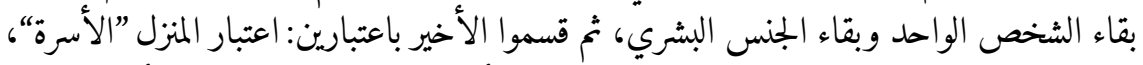

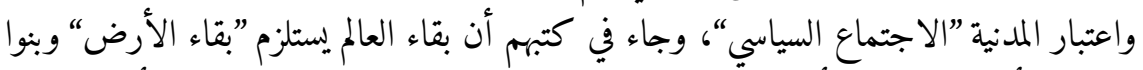

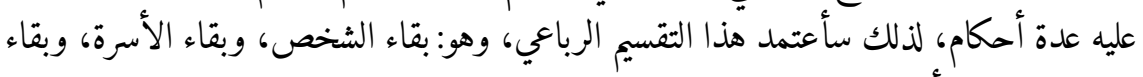

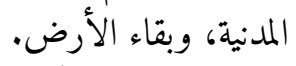
بنى الفقهاء والأصوليون الحنفيون رؤيتهم للبقاء على رؤية اجتماعية سياسية مصاحبة للطرح

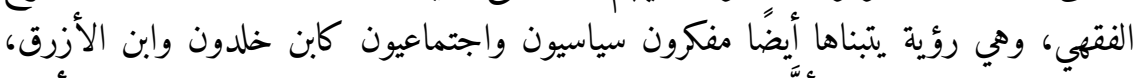

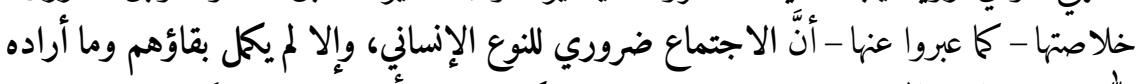

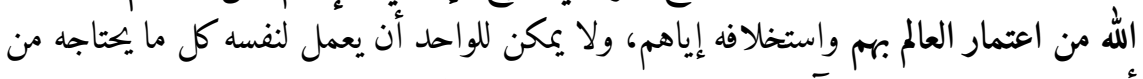

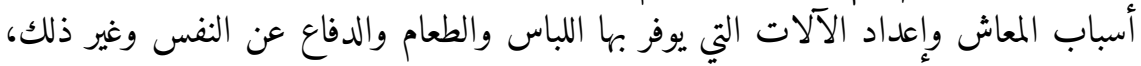

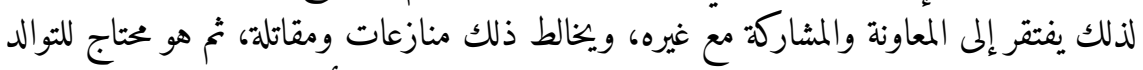

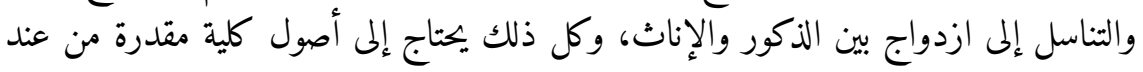

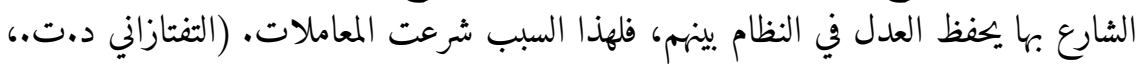




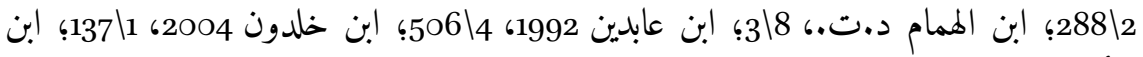

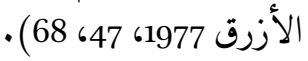

$$
\text { القاعدة الأولى: حفظ البقاء الشخصي }
$$

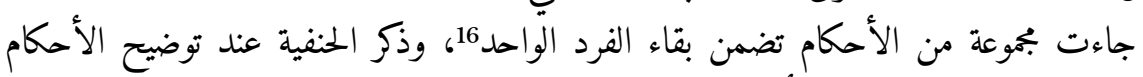
المتعلقة ببقاء الشخص ثلاثة أمور رئيسية:

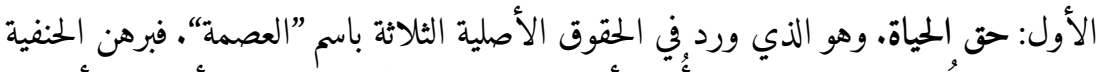

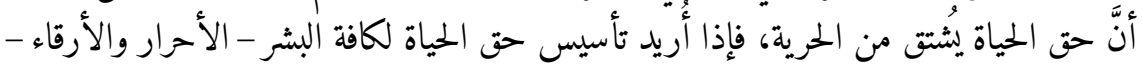

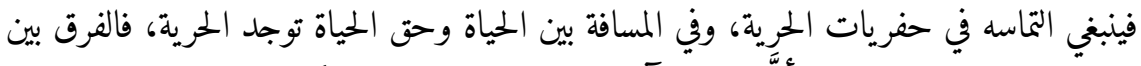

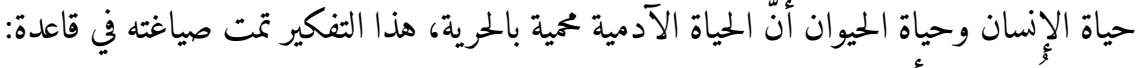

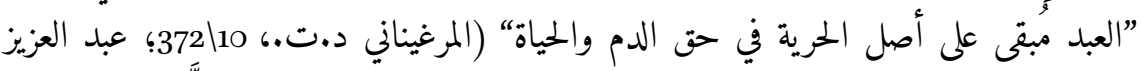

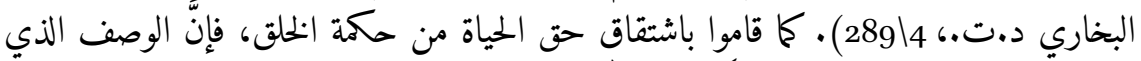

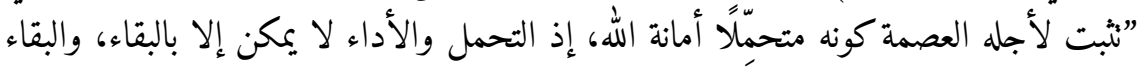

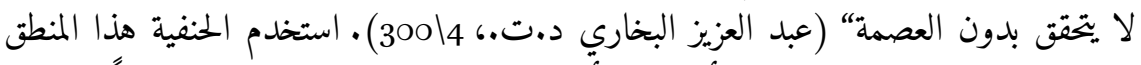

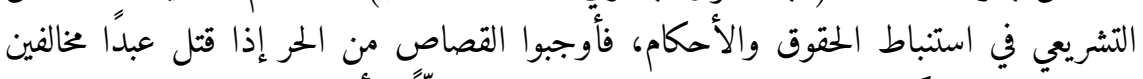

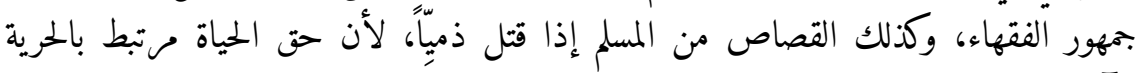

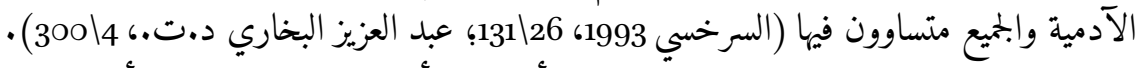

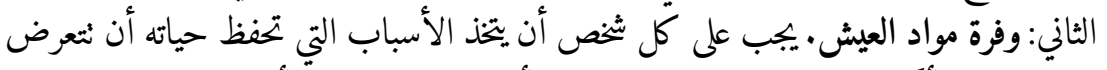

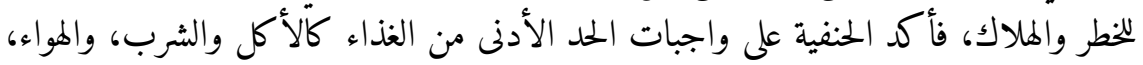

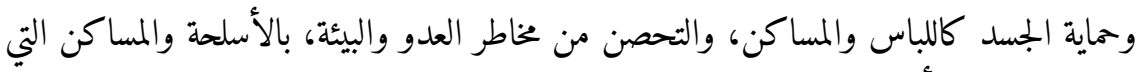

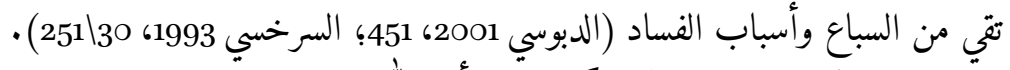

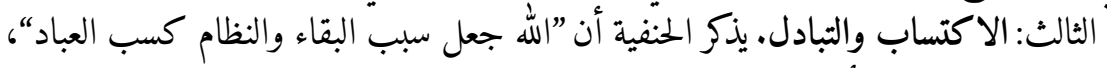

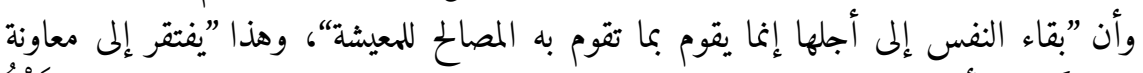

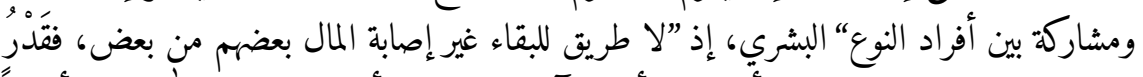

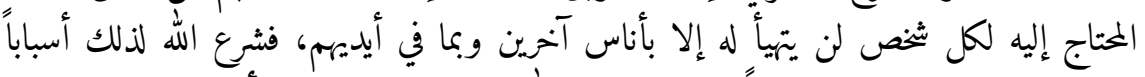

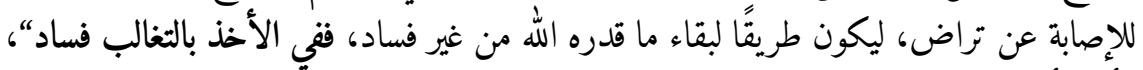

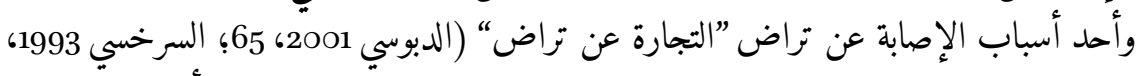

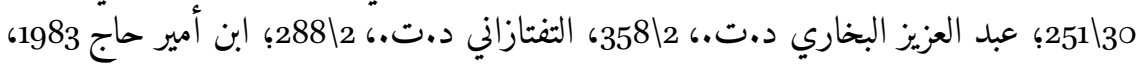


من المسائل الفقهية والأصولية الكبيرة التي انفرد بها الحنفية وخالفوا جمهور الفقهاء مسألة

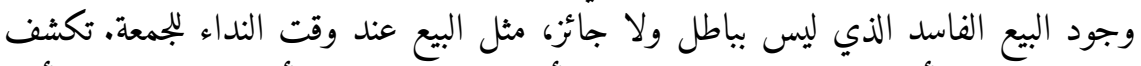

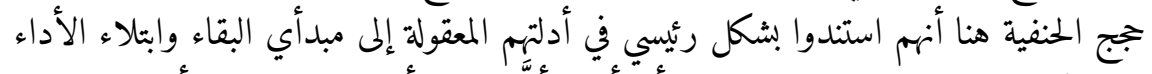

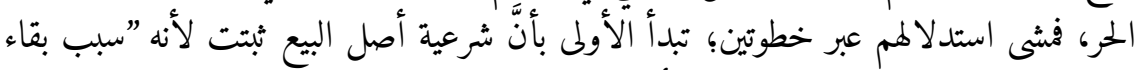

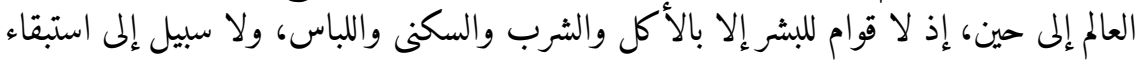

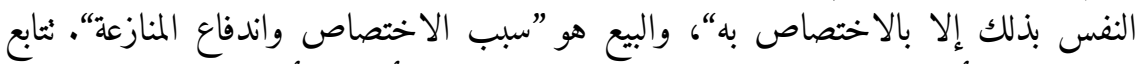

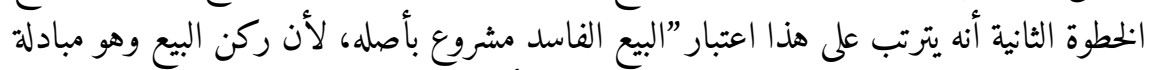

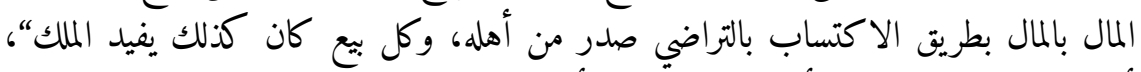

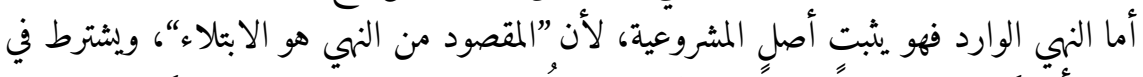

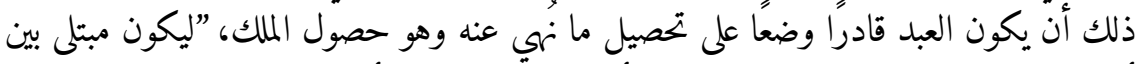

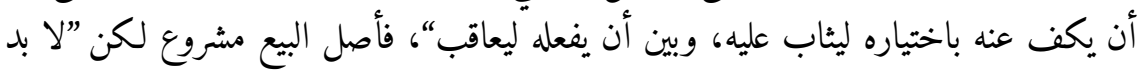

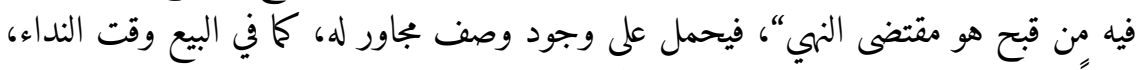

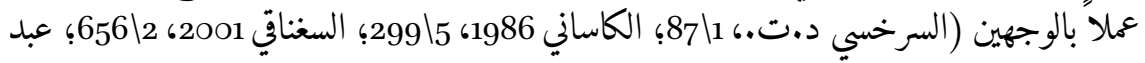

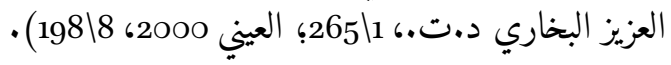

$$
\text { القاعدة الثانية: حفظ البقاء الأسري }
$$

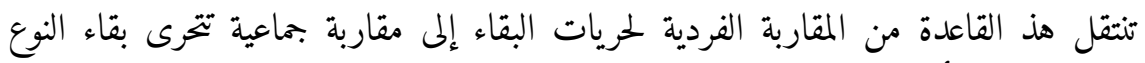

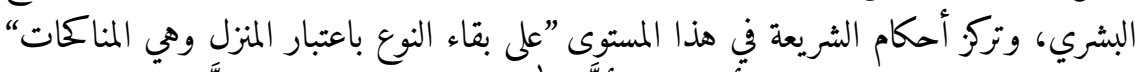

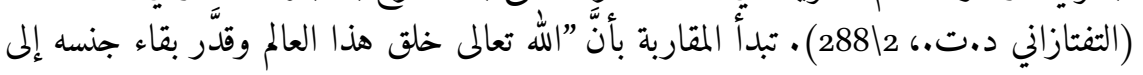

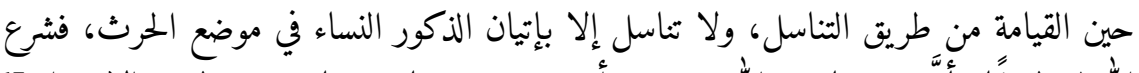

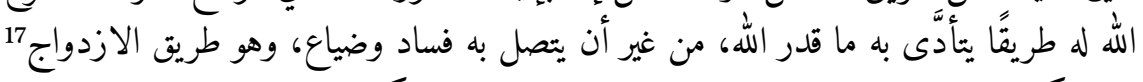

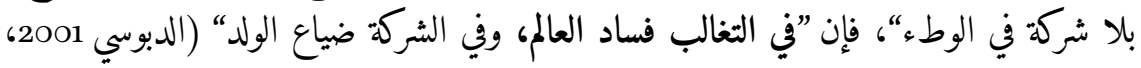

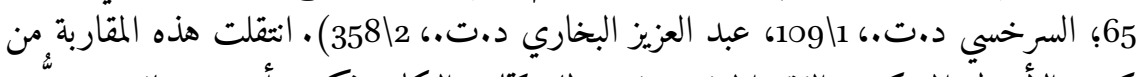

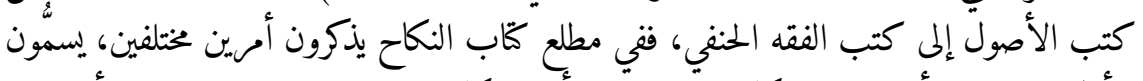

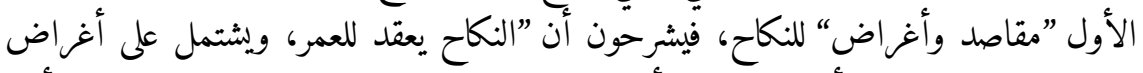

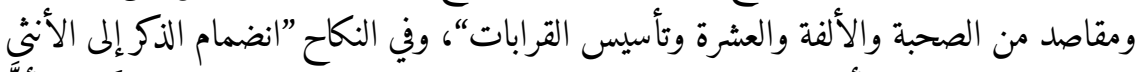

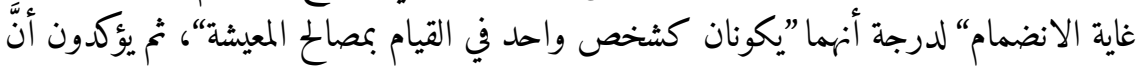

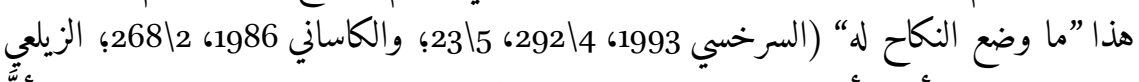

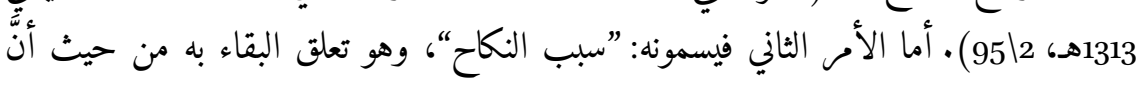

17 


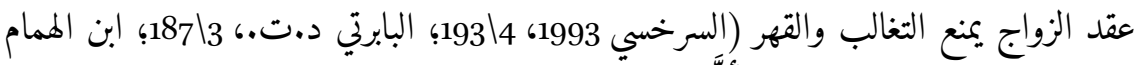

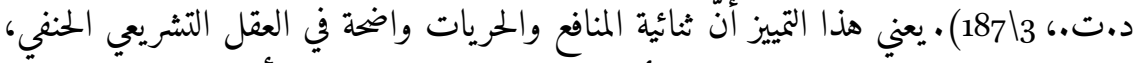

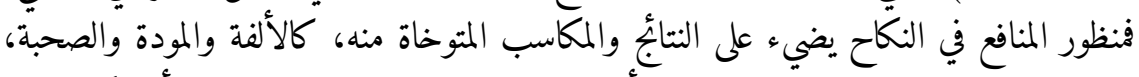

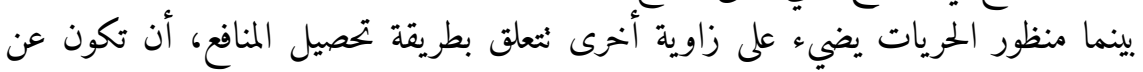

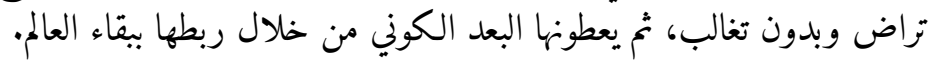

$$
\text { القاعدة الثالثة: حفظ البقاء المدني }
$$

تنتقل هذ القاعدة من المقاربة الجماعية لحريات البقاء إلى مقاربة اجتماعية الماعية سياسية تتحرى بقاء

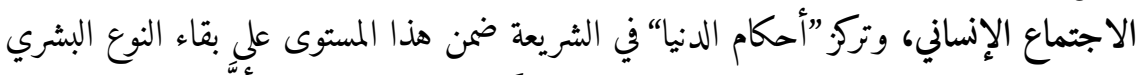

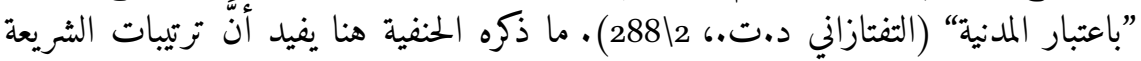

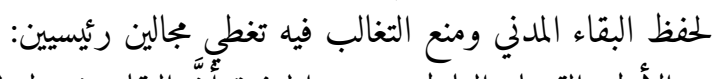

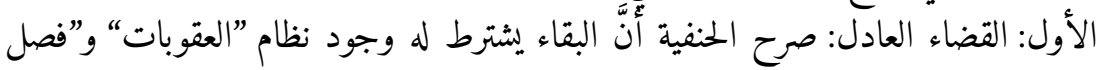

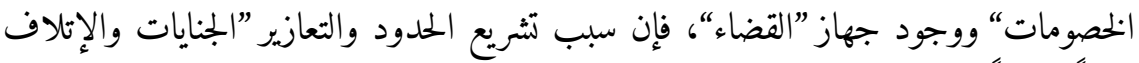

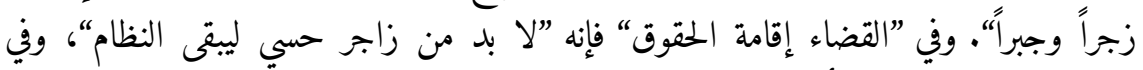

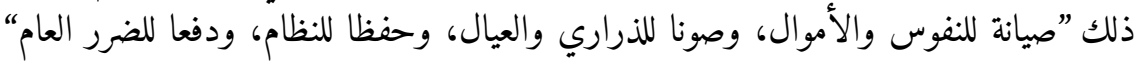

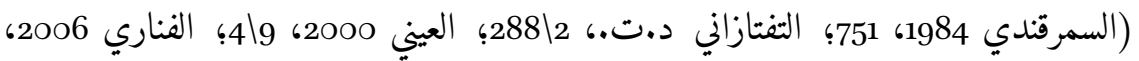

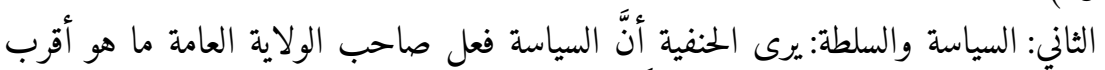

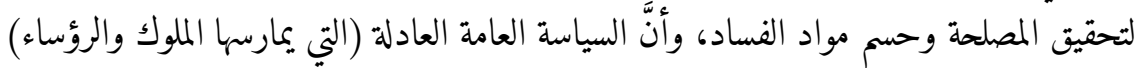

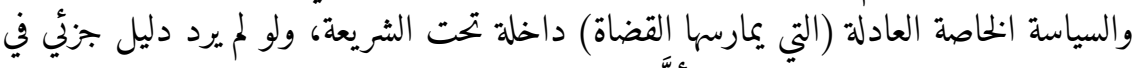

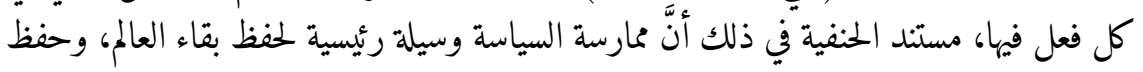
بقاء العالم من صلب الشريعة، فإن ”مدار الشريعة بعد قواعد الإيمان إنمان على حسم مواد الفياد الفساد لبقاء

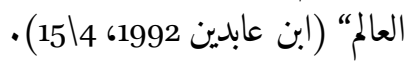

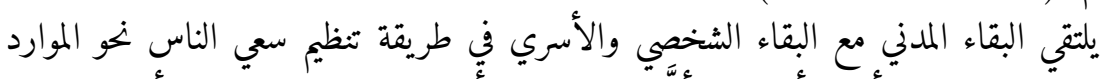

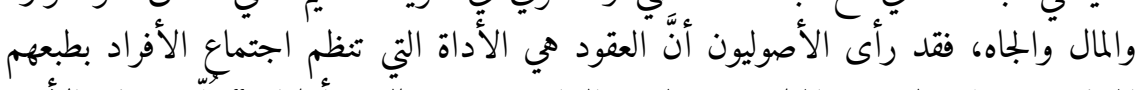

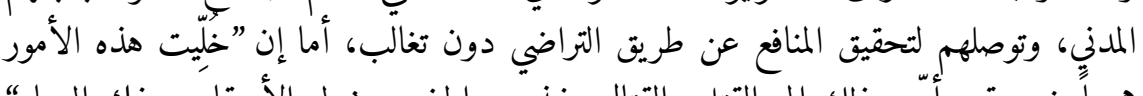

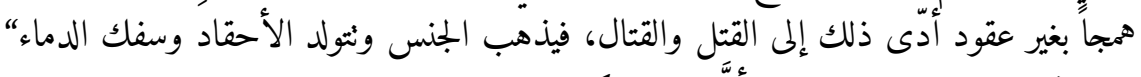

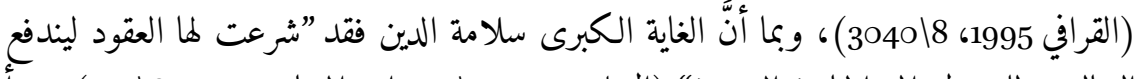

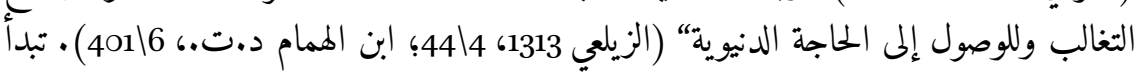

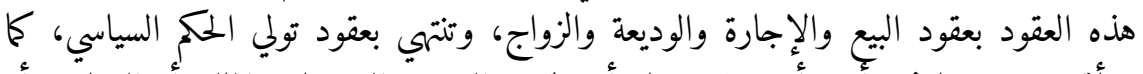

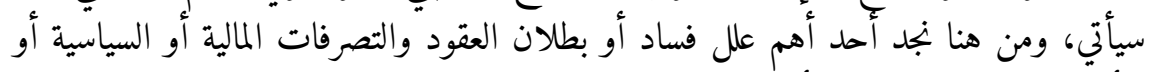

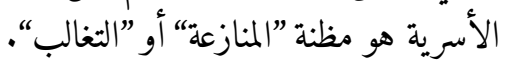




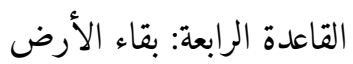

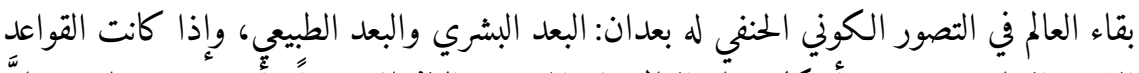

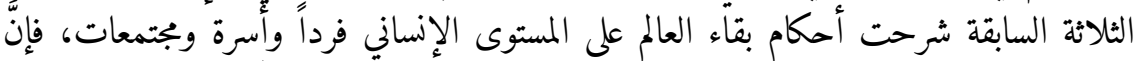

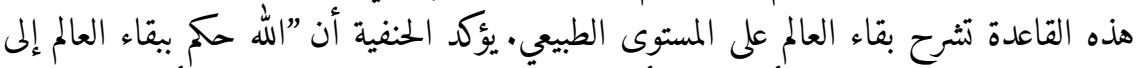

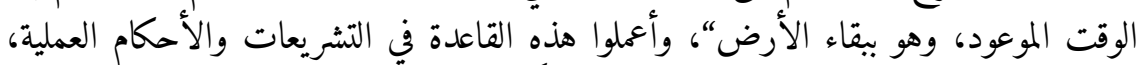

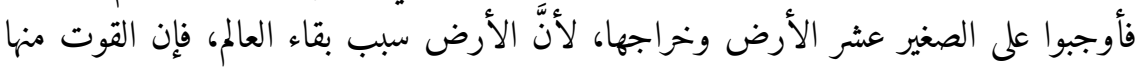

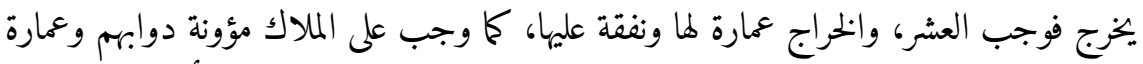

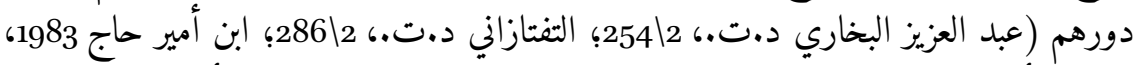

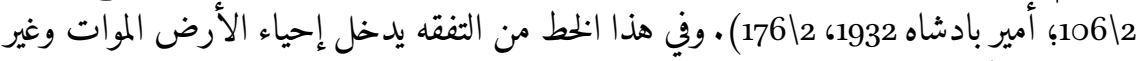
ذلك من الأحكام الفقهية.

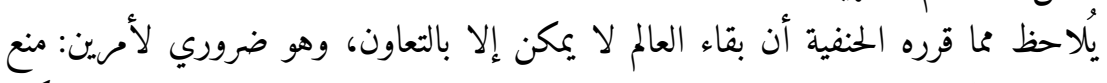

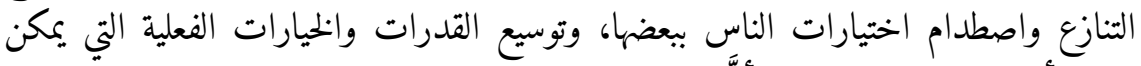

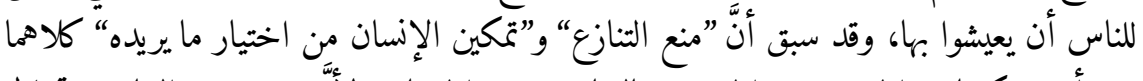

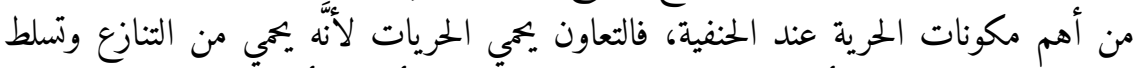

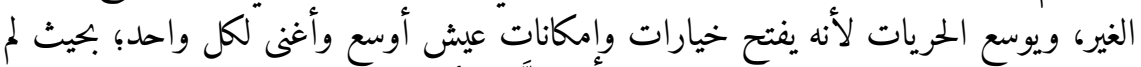

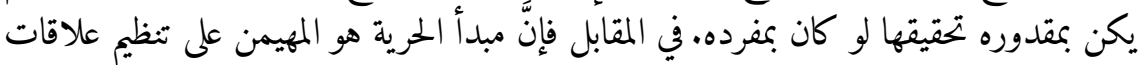
التعاون والتبادل.

\section{3}

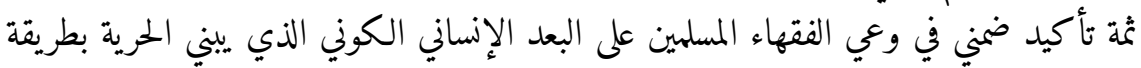

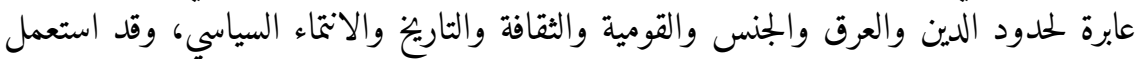

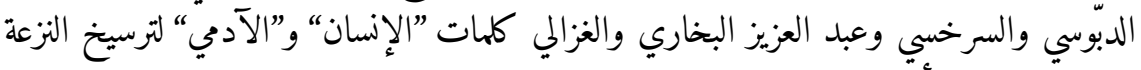

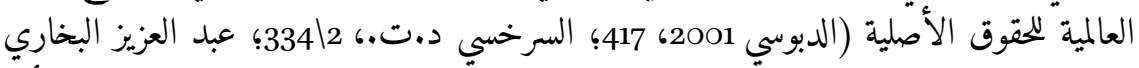

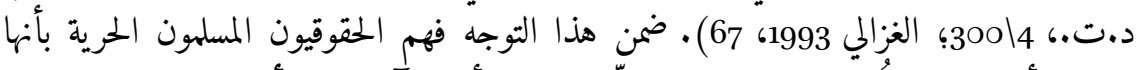

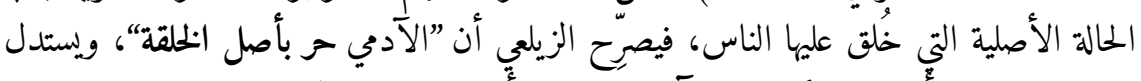

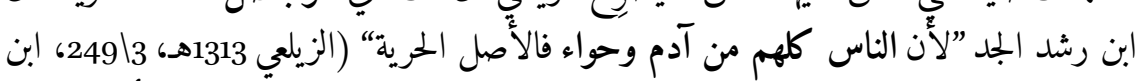

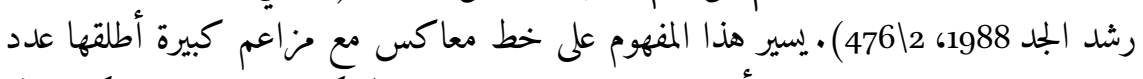

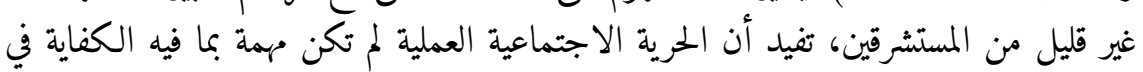

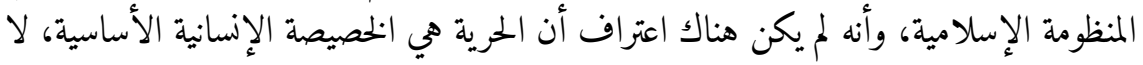

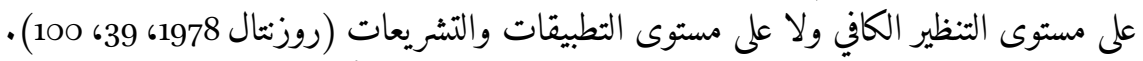

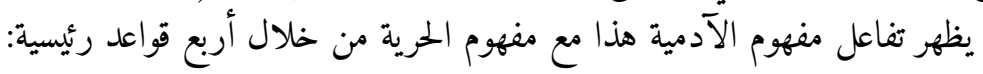


القاعدة الأولى: ما كان من خواص الآدمية فهو على الحرية

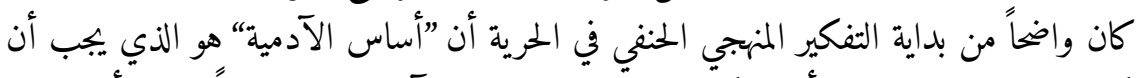

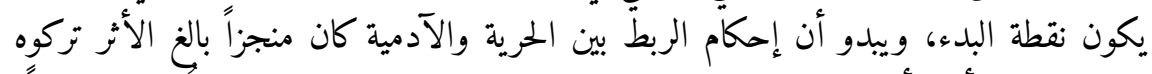

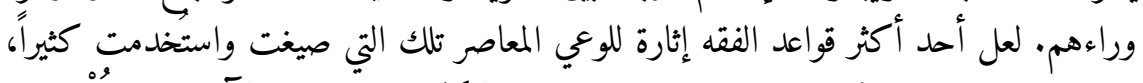

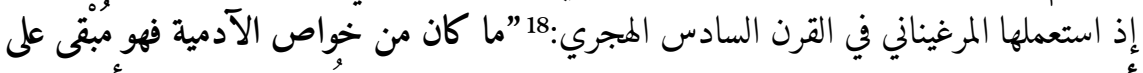

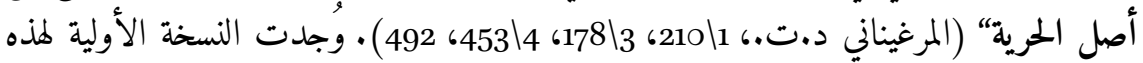

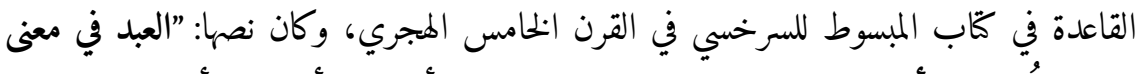

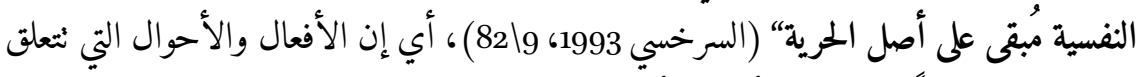

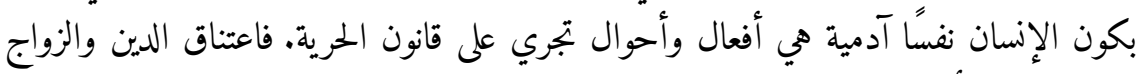

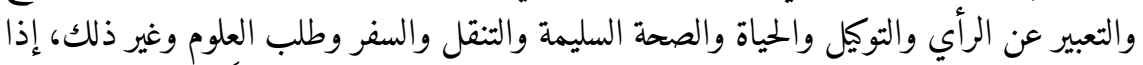

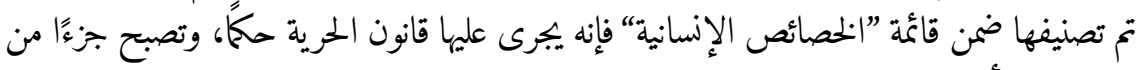

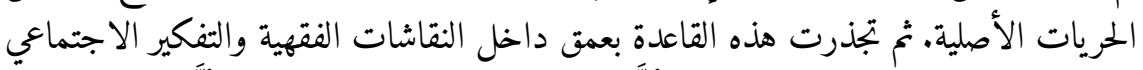

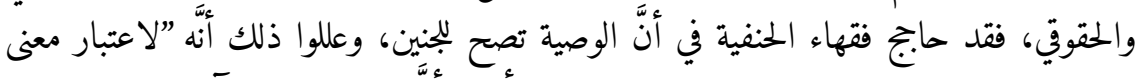

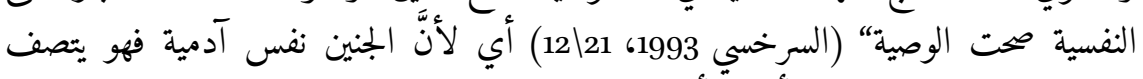

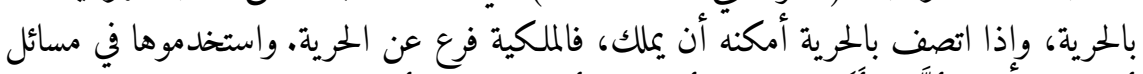

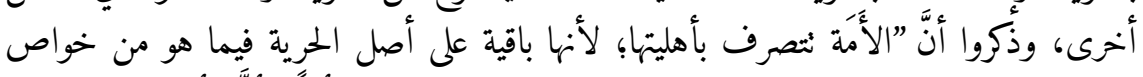

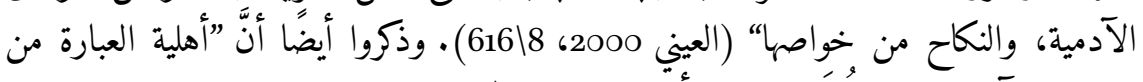

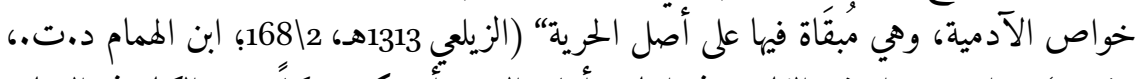

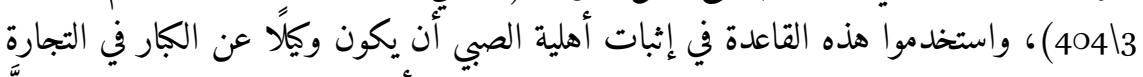

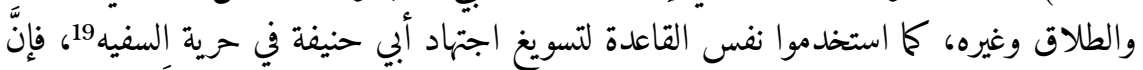

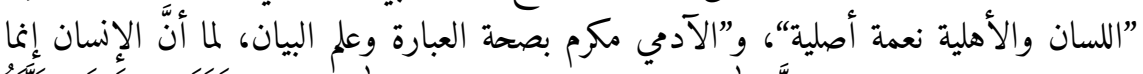

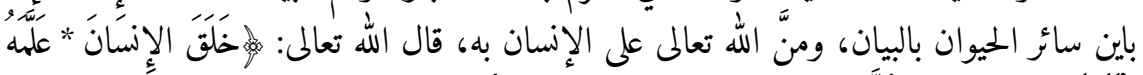

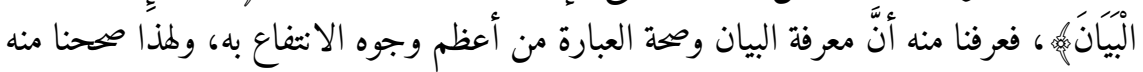

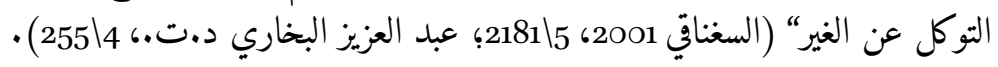

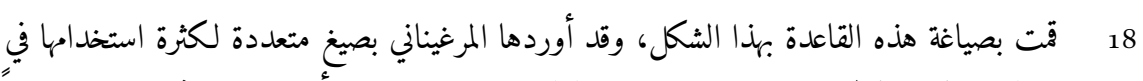

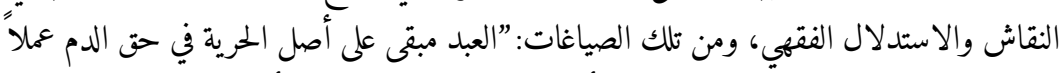

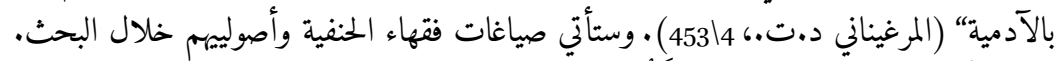

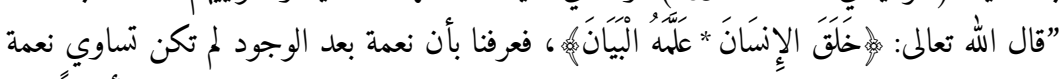
19

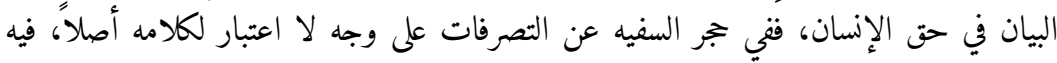
تفويت لأعلى النعم كلها، (السغناقي 2001، 5| 2401) . 


\section{القاعدة الثانية: الحرية الآدمية مدار الحريات الرئيسية}

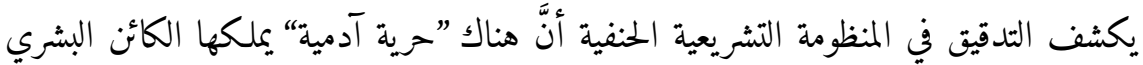

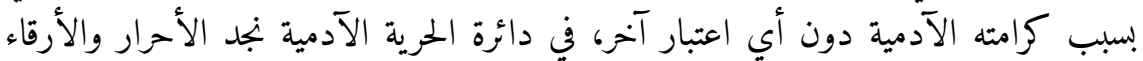

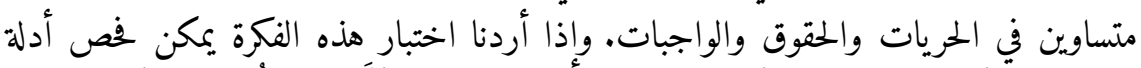

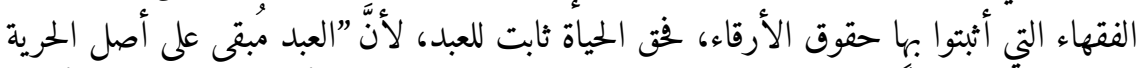

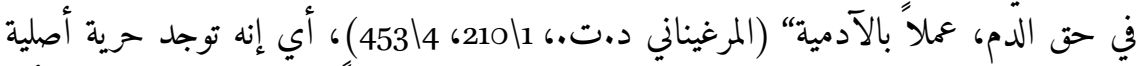

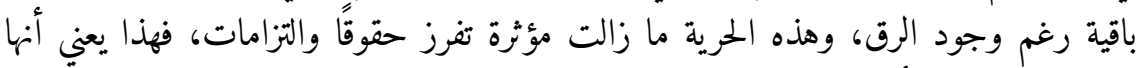

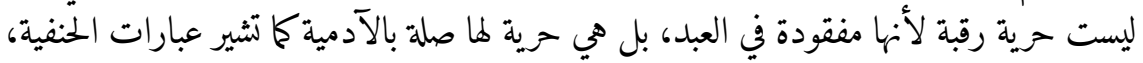

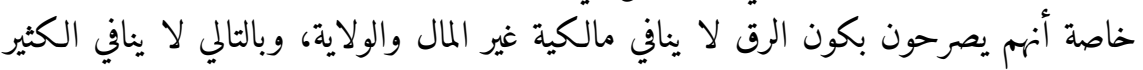

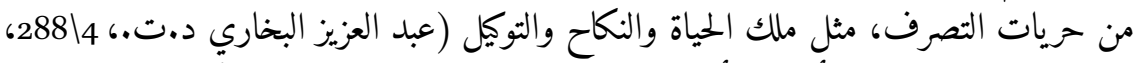

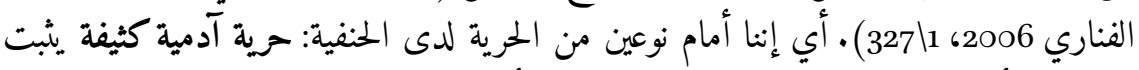

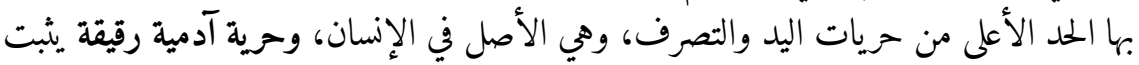

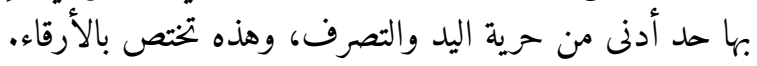

$$
\text { القاعدة الثالثة: الحرية حياة }
$$

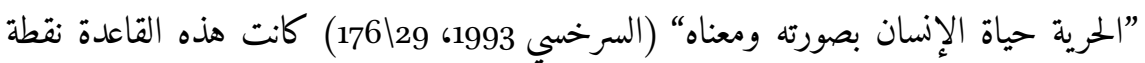

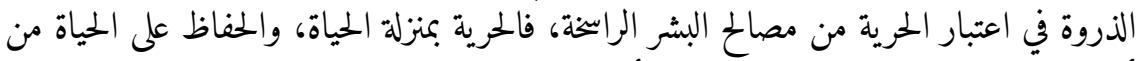

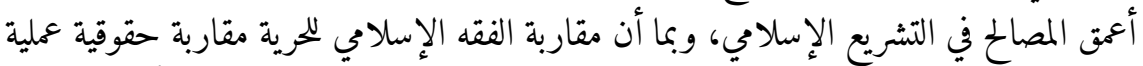

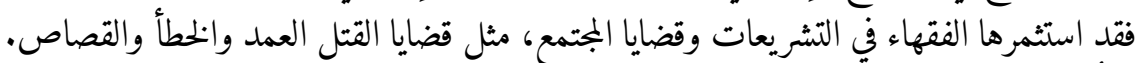

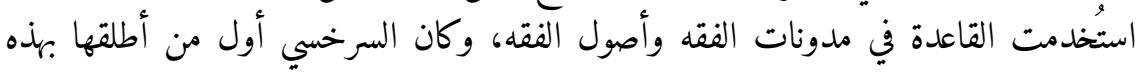

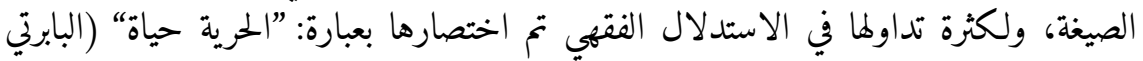
د.ت.ت.

القاعدة الرابعة: الكرامة مصدر الحريات، والحريات أمارة الكرامة 4.2 .3

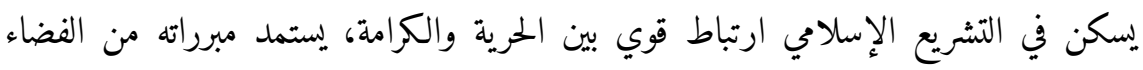

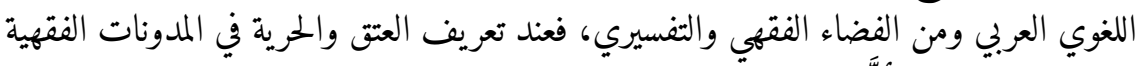

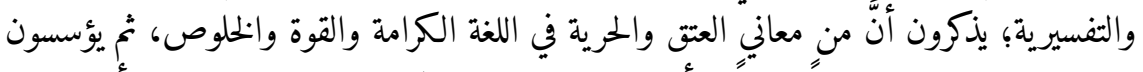

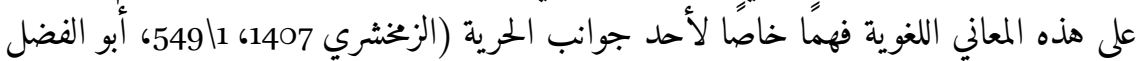

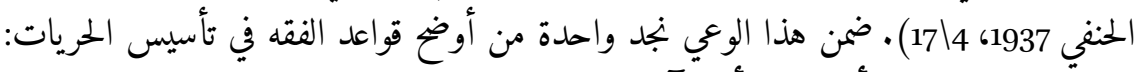

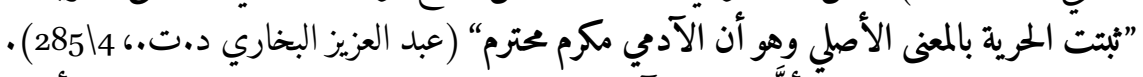

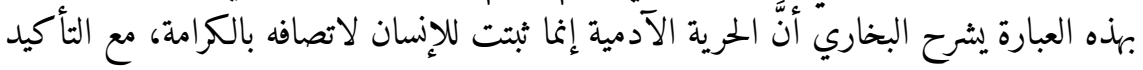




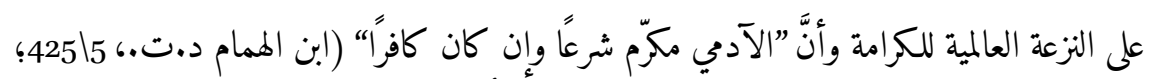

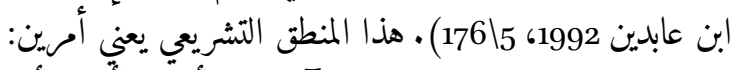

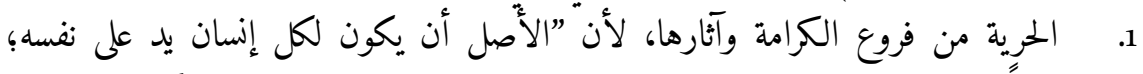

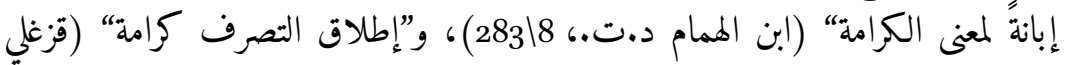

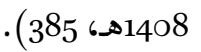

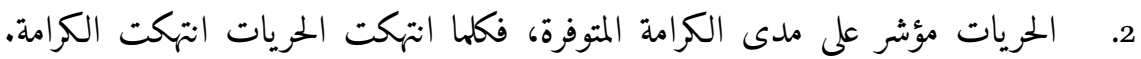

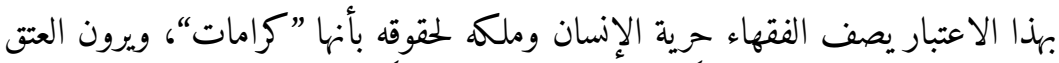

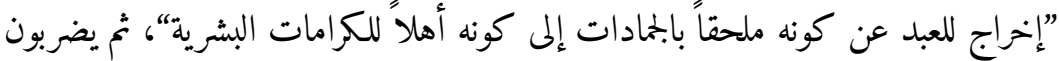

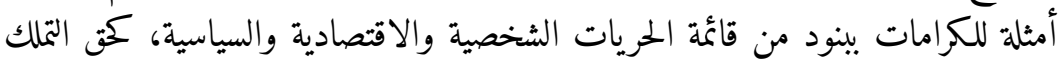

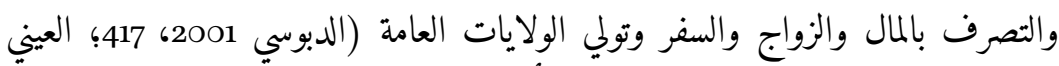

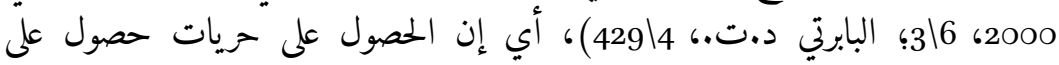

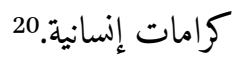

هكذا نتصل الحرية بالكرامة وتثلون بها، والقراءة المعاصرة لهذا الموقف تعني أنَّ ممارسة الحريات

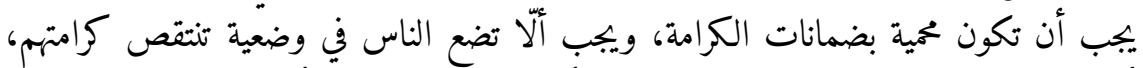

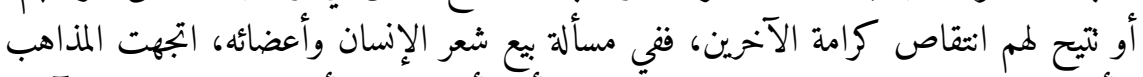

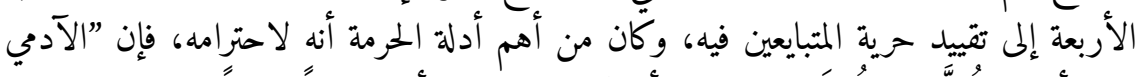

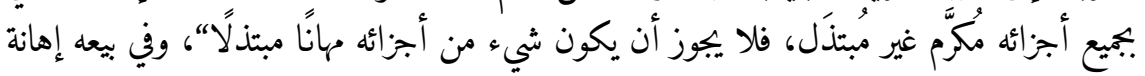

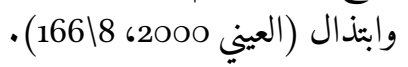

$$
\text { المفهوم الثالث: الحريات أمانات }
$$

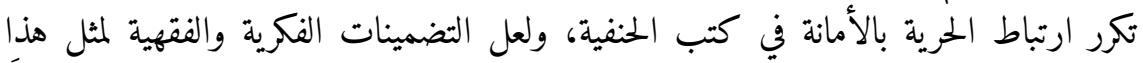

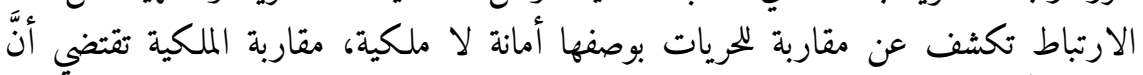

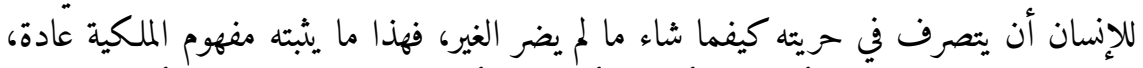

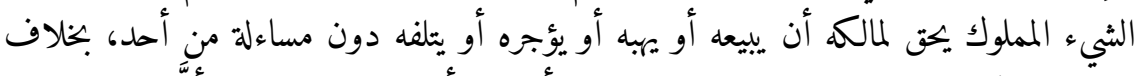

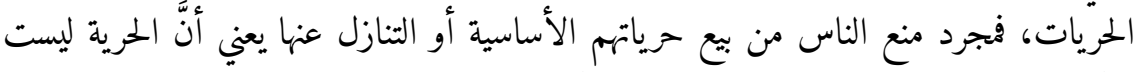

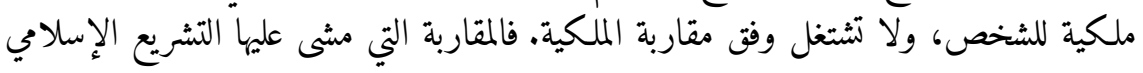

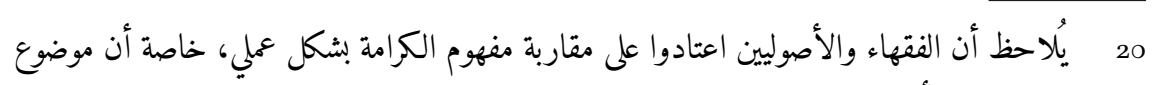

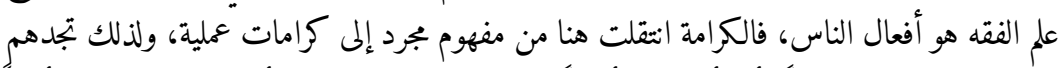

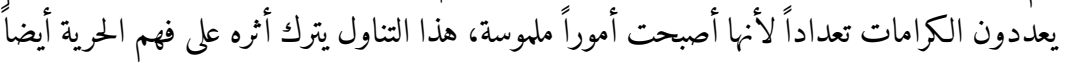

$$
\text { بشكل عملي حيث تتحول إلى حريات عملية. }
$$




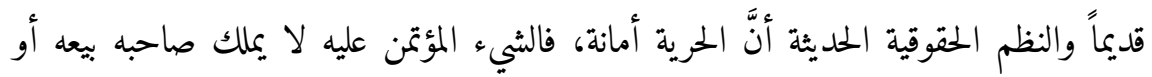

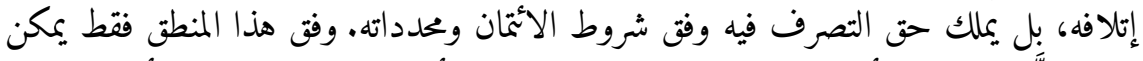

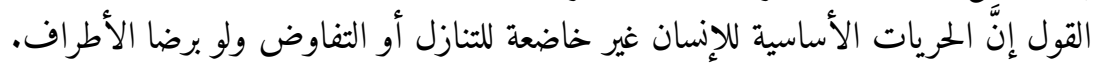

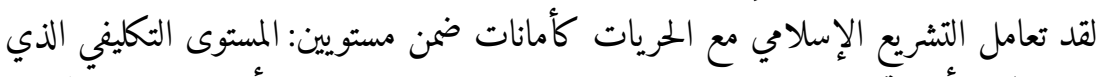

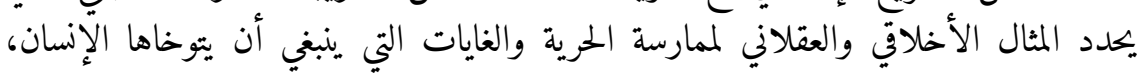

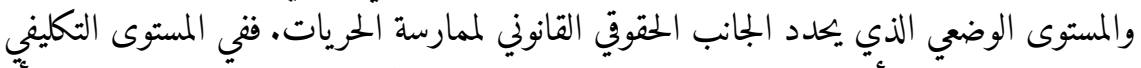

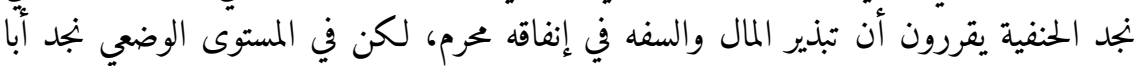

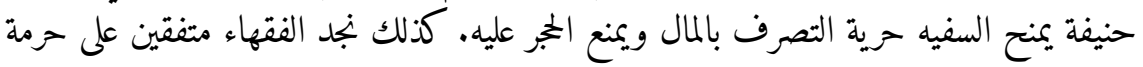

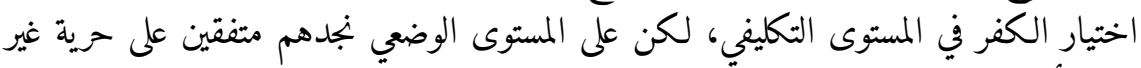

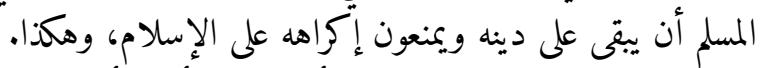

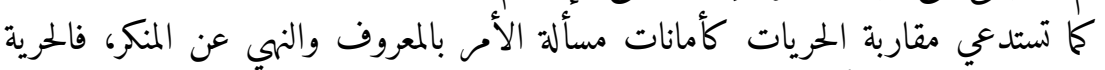

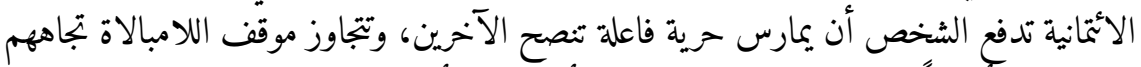

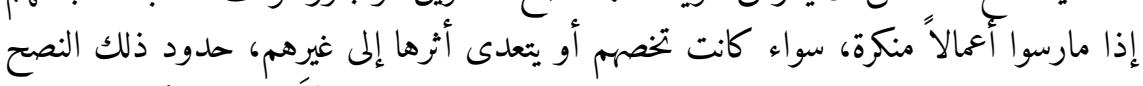

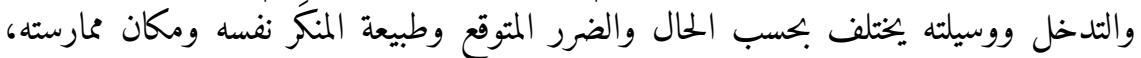

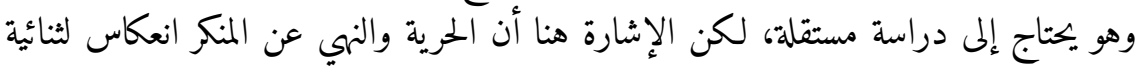

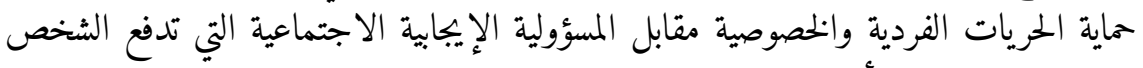

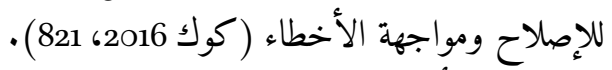

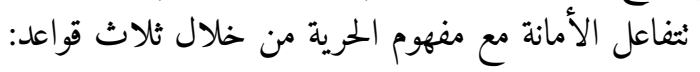

$$
\text { القاعدة الأولى: الحرية من أجل أداء الأمانة }
$$

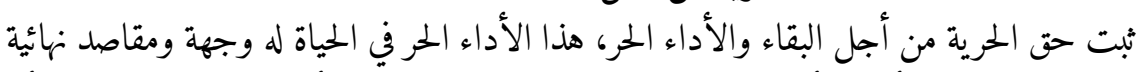

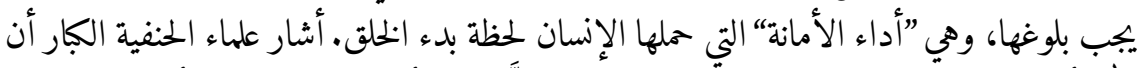

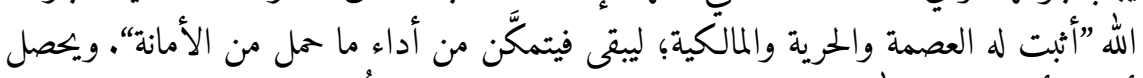

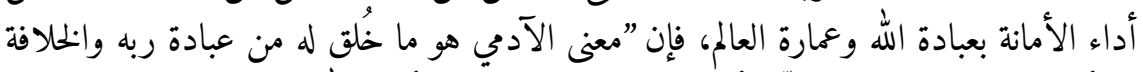

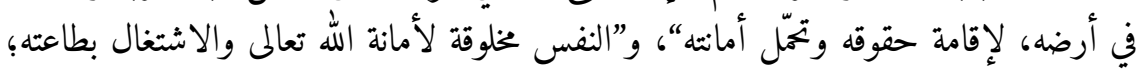

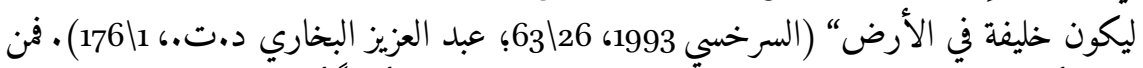

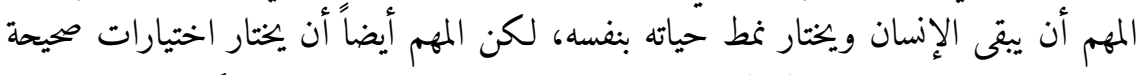

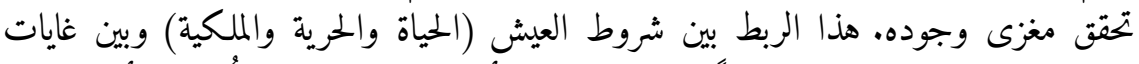

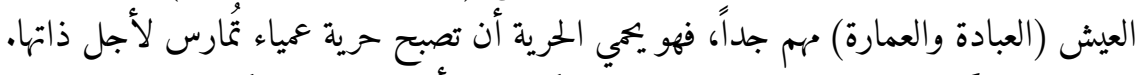

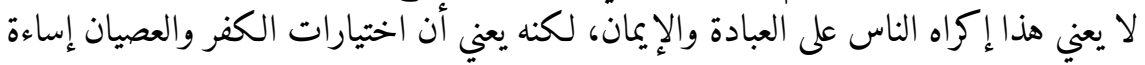
لحرية الاختيار نفسها. 


\section{القاعدة الثانية: عصمة الحرية}

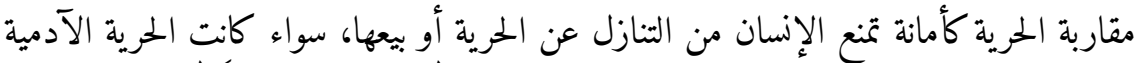

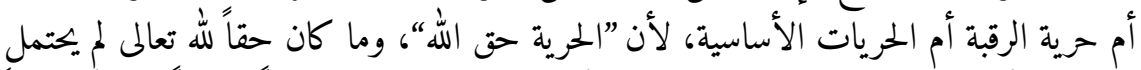

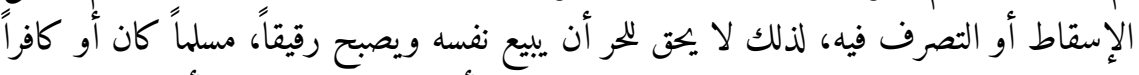

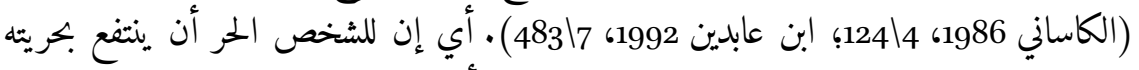

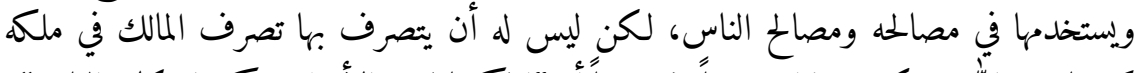

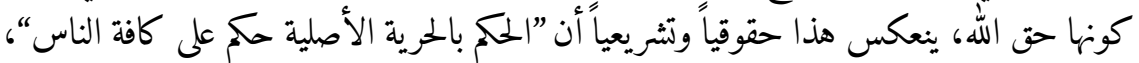

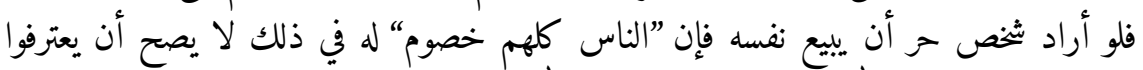

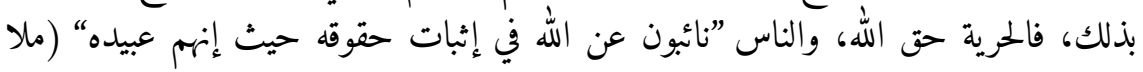

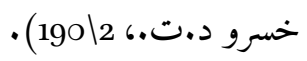

القاعدة الثالثة: الحرية منظومة حقوق ومسؤوليات مقترنة بالعدل $3 \cdot 3 \cdot 3$

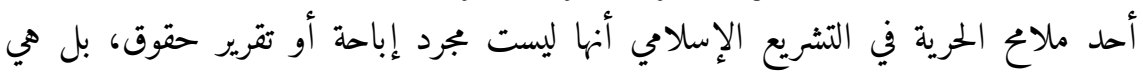

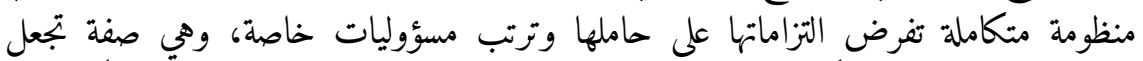

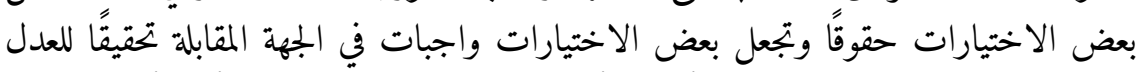

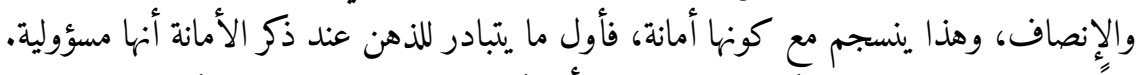

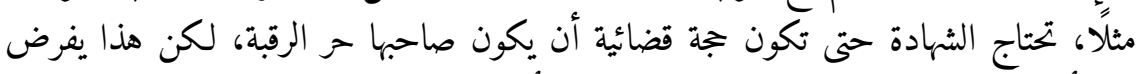

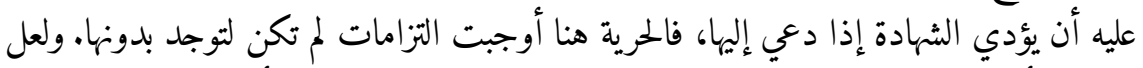

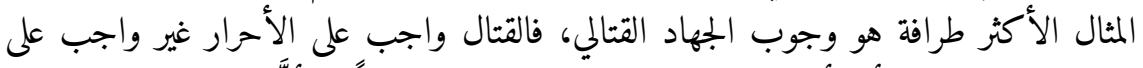

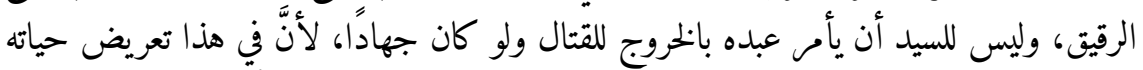

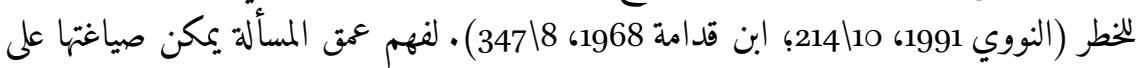

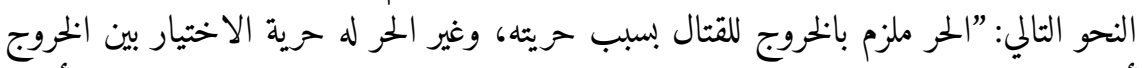

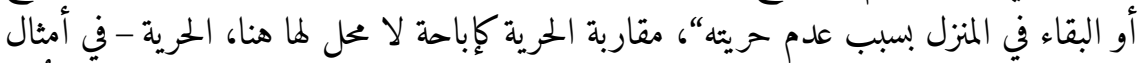

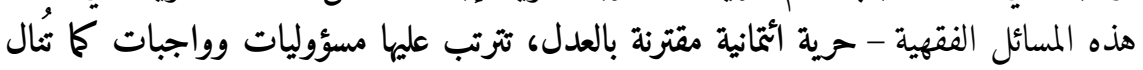
بها حقوق وإباحات.

\section{المفهوم الرابع: الحرية والمنفعة}

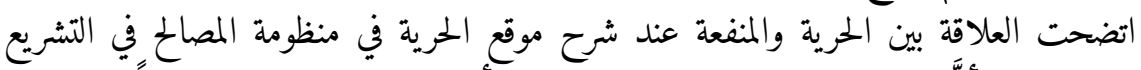

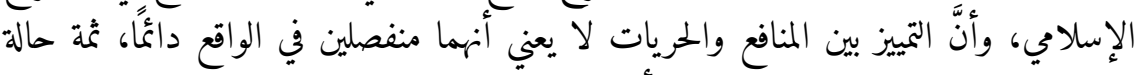

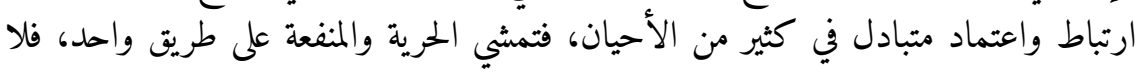

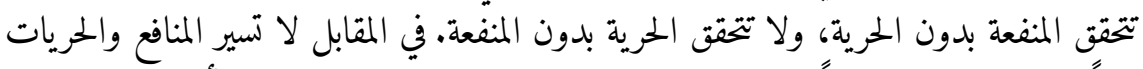

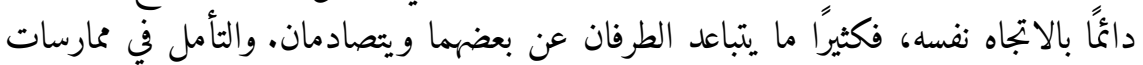




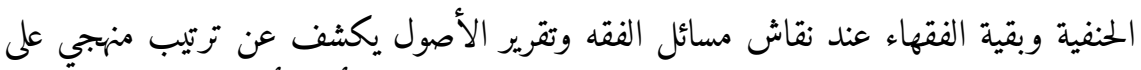

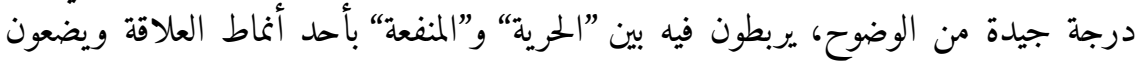

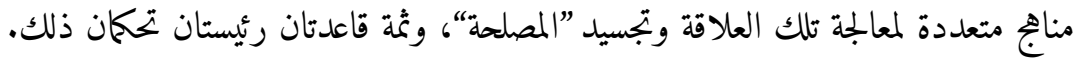

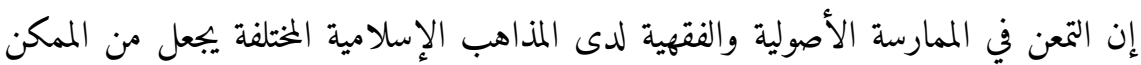

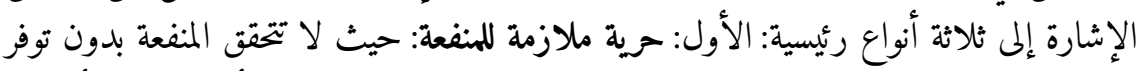

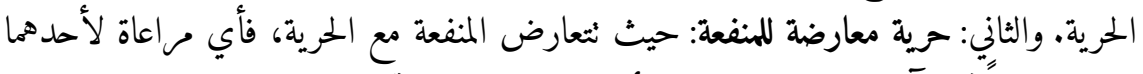

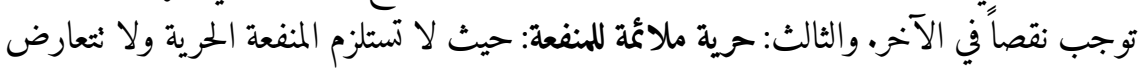
معها، بل تكون ملائمة لها بالمجمل.

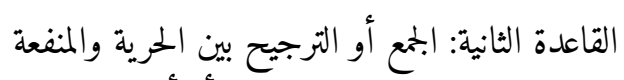

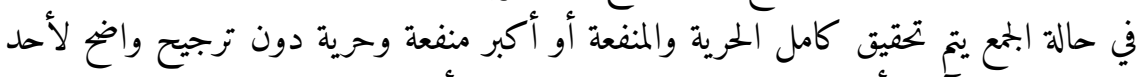

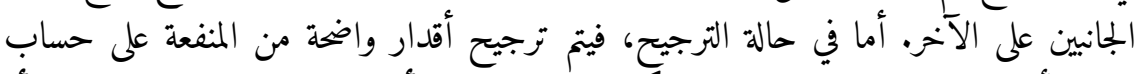

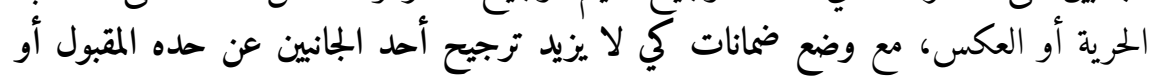

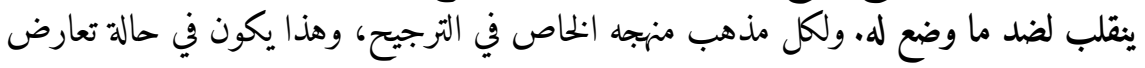
الحرية والمنفعة خاصة.

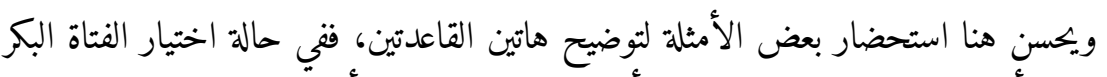

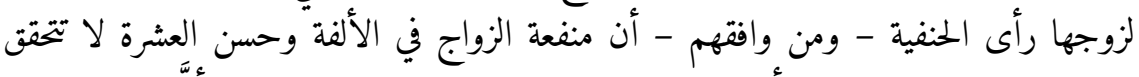

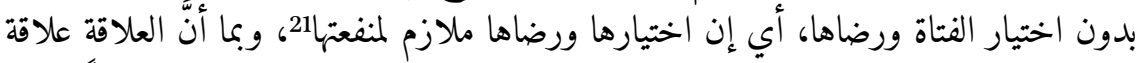

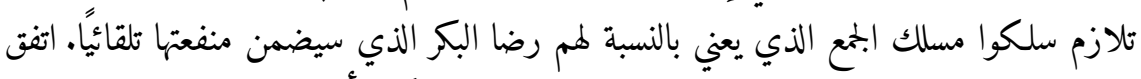

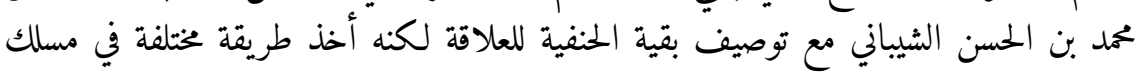

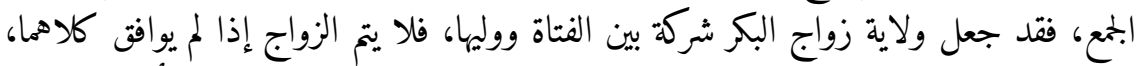

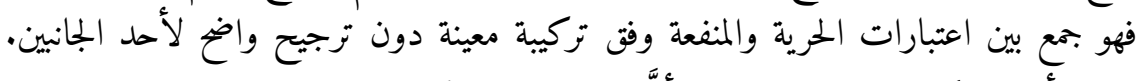

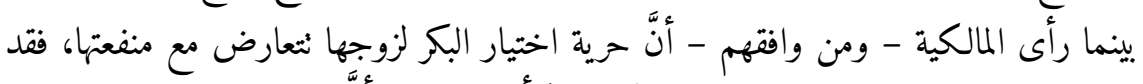

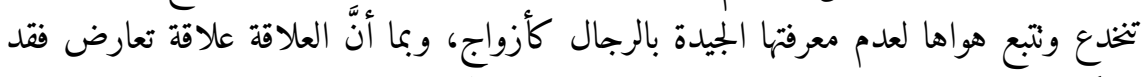

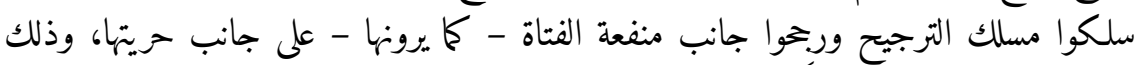

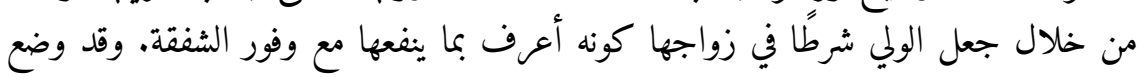

21

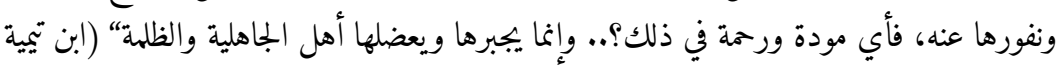




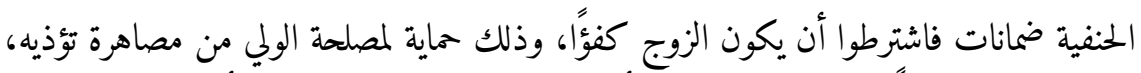

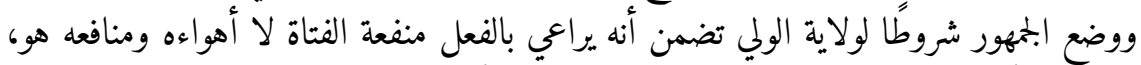

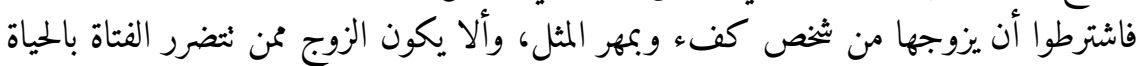

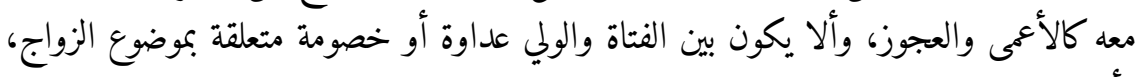

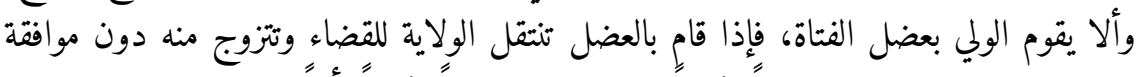

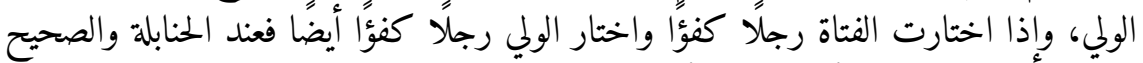

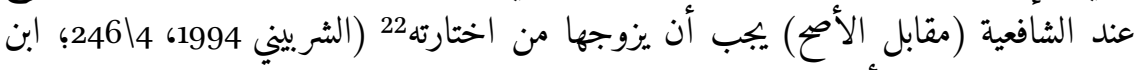

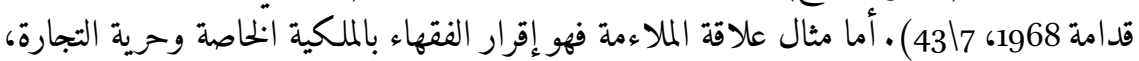

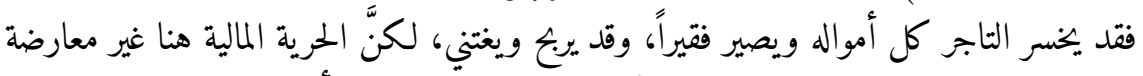

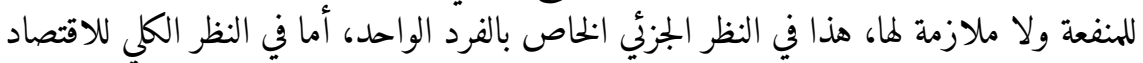

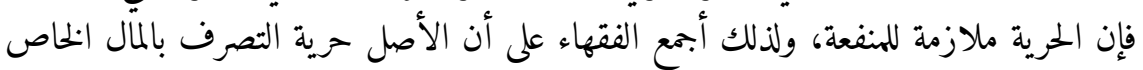
وحرية التسعير. يستثمر الحنفية علاقة الحرية والمنفعة في معالجة مسائل معقدة نتصل باختيارات الأفراد

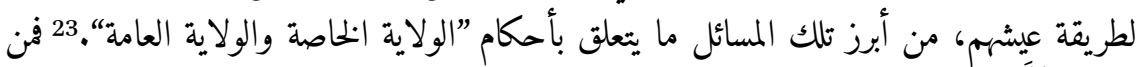

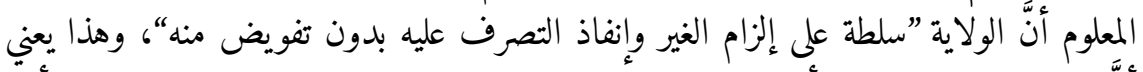

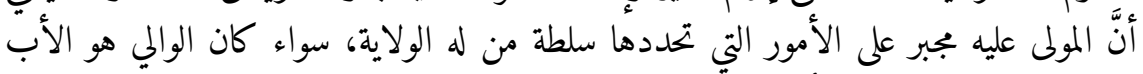

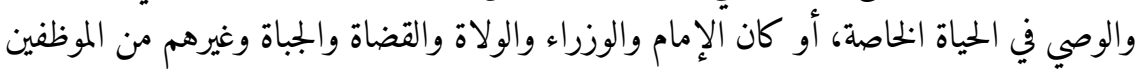

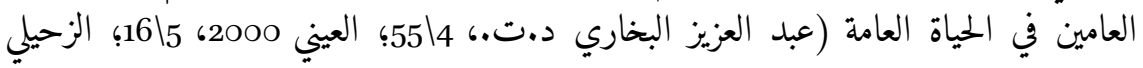
.486\1 62006

توصيف الحنفية لعلاقة الحرية والمنفعة في مسألة الولاية أنها علاقة تعارض بالمجمل، والمسلك المكاك

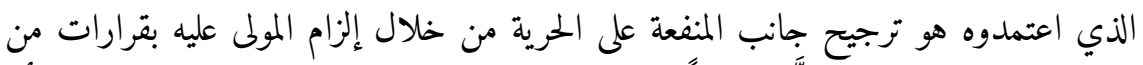

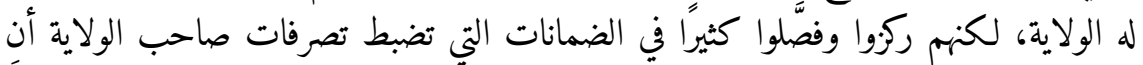

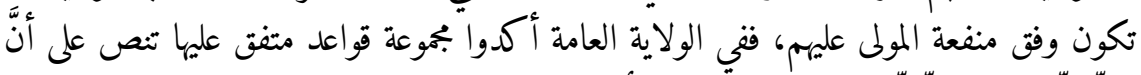

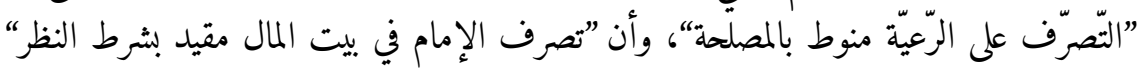

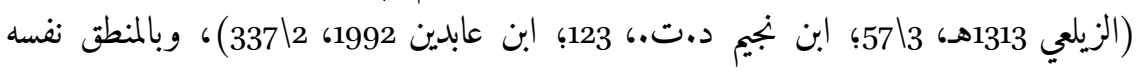

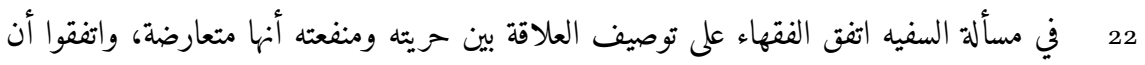

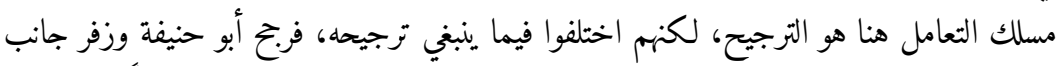

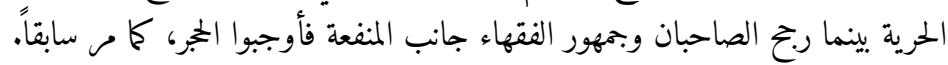

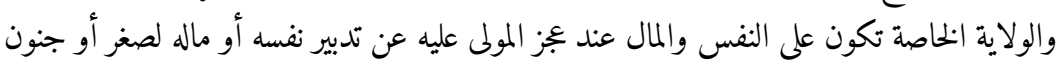
23

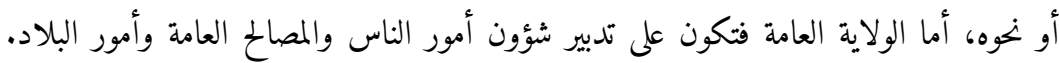

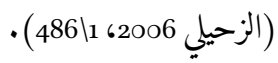




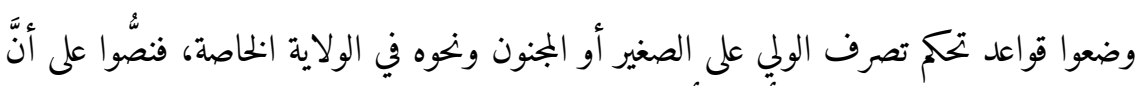

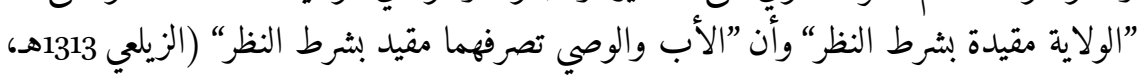

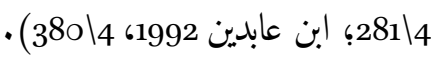

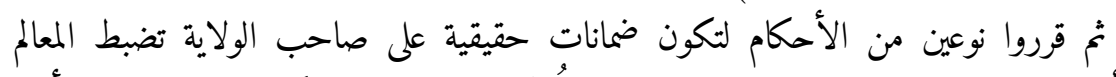

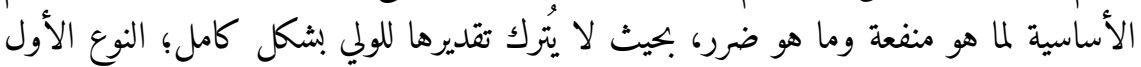

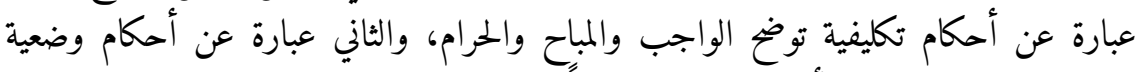

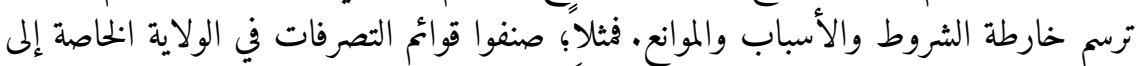

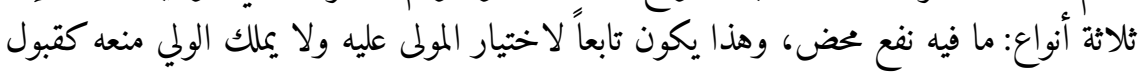

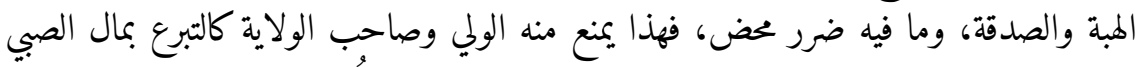

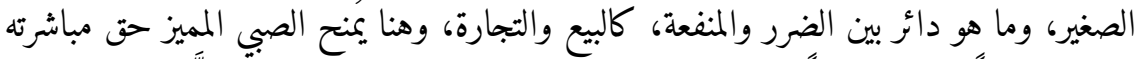

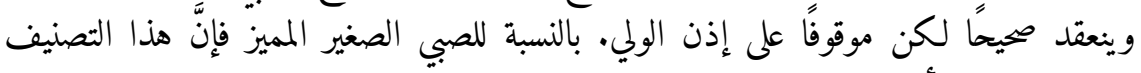

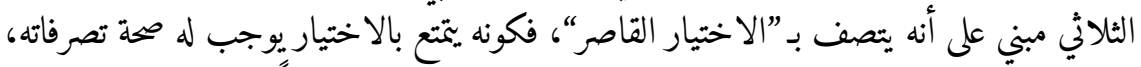

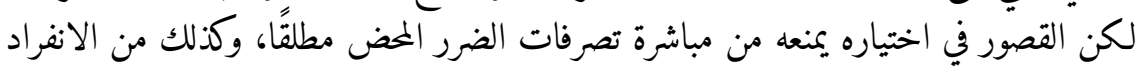

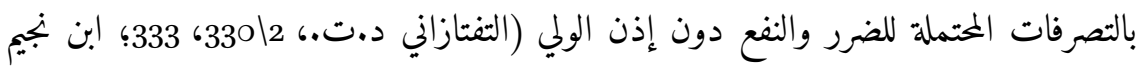
د.ت.

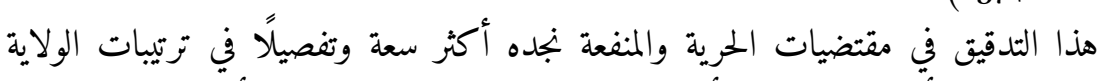

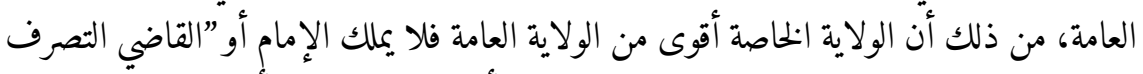

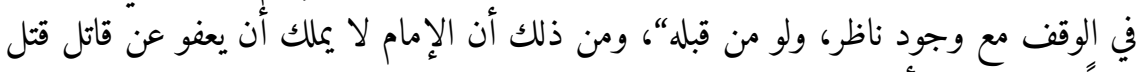

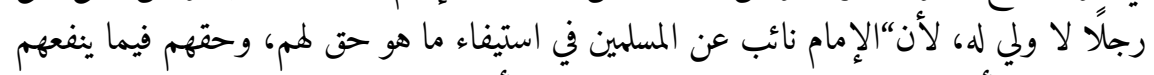

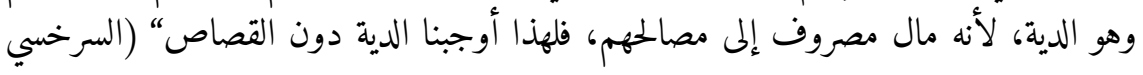

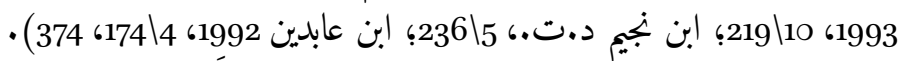

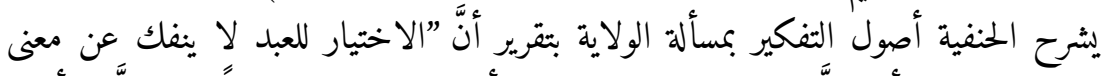

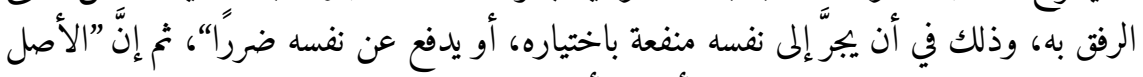

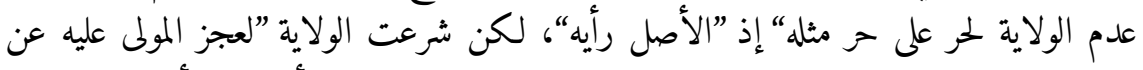

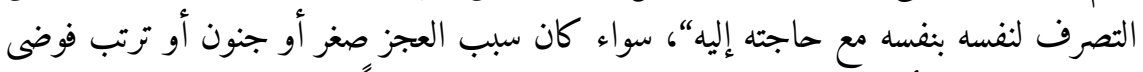

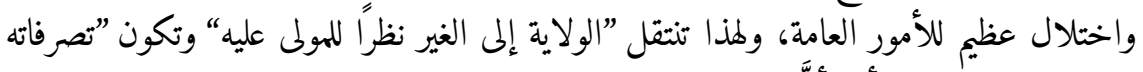

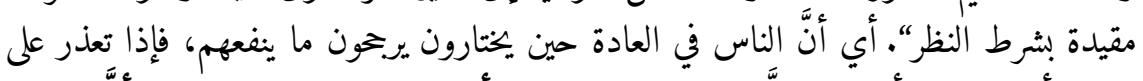

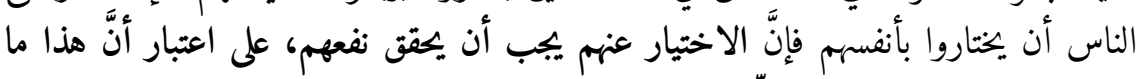

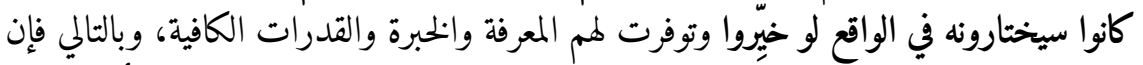

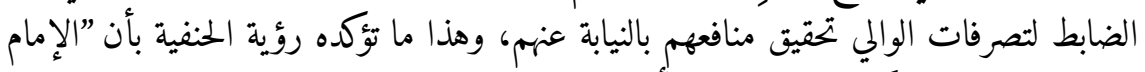

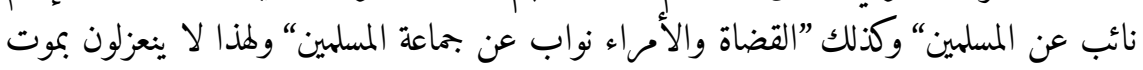




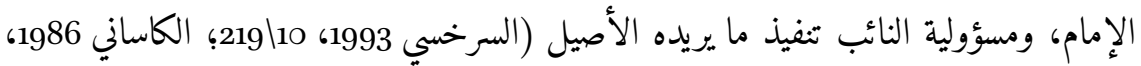

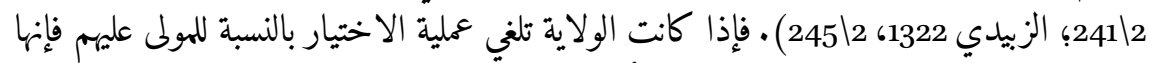
تضمن مغزى ونتيجة الاختيار وهو تحقيق أكبر منفعة.

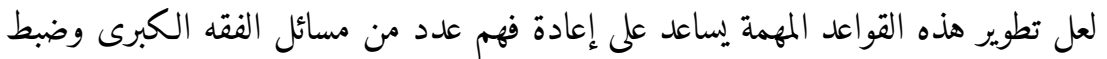

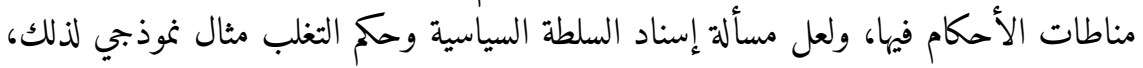

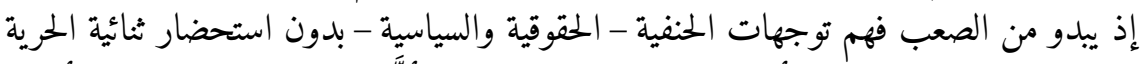

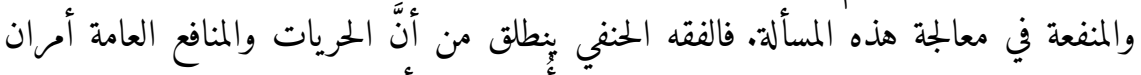

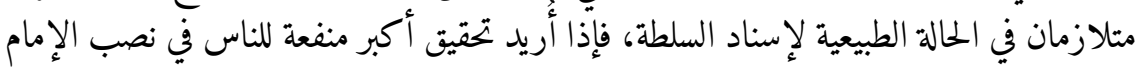

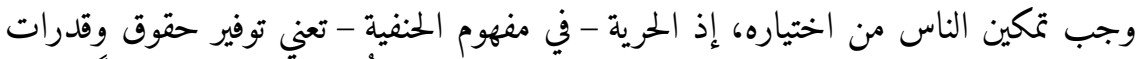

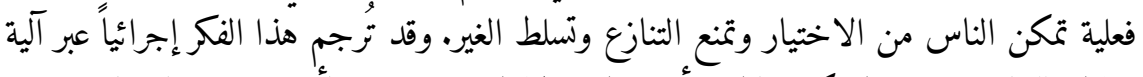

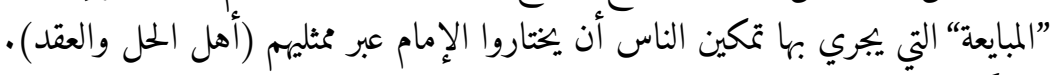

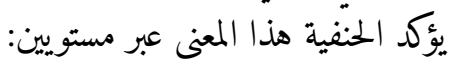

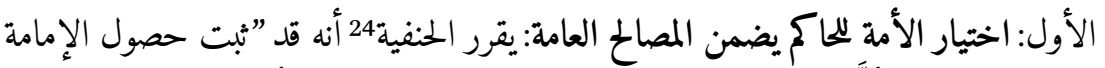

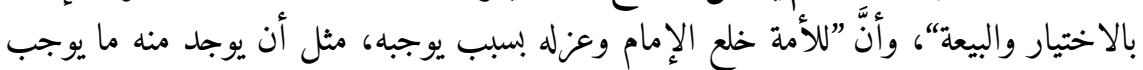

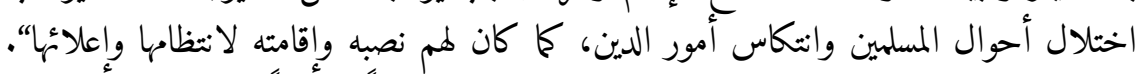

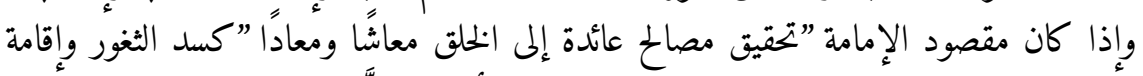

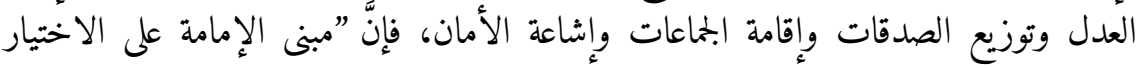

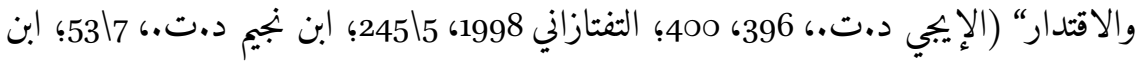

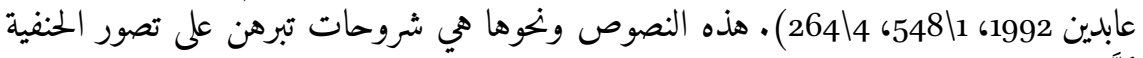
أنَّ الحرية ملازمة للمنفعة هنا.

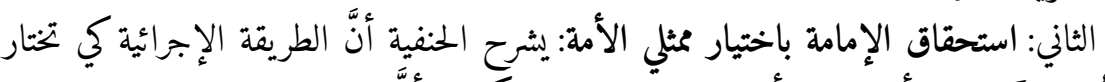

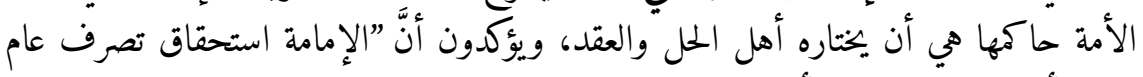

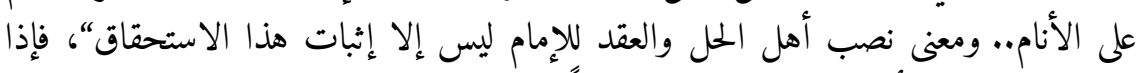

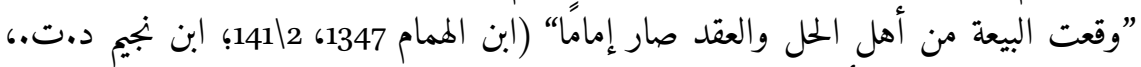

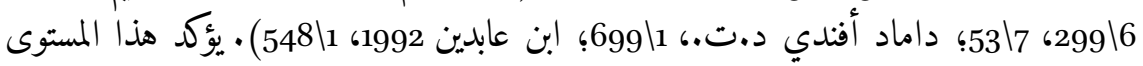

24 يسير الحنفية في كتبه الفتهية على طريقة خاصة في معالجة مسائل الإمامة، فهم يوردون أهم

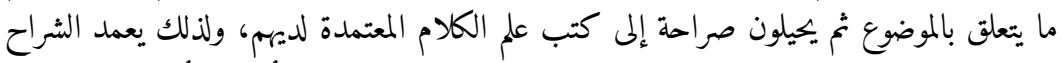

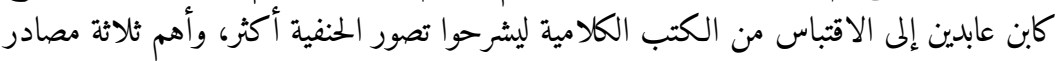

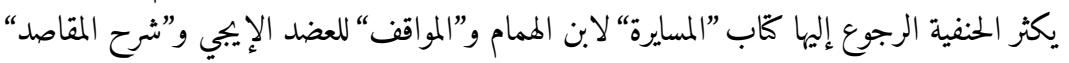


من النصوص على أصالة الاختيار السياسي في موضوع تولي الحكم، فا يُذكر هنا يركز على المنطق الحقوفي الصرف أكثر من منطق المنافع المترتبة.

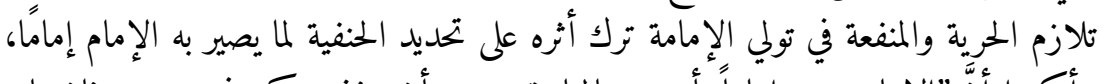

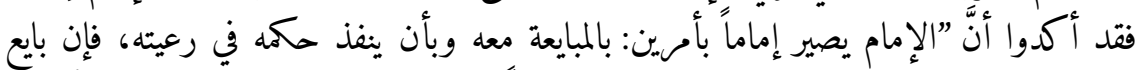

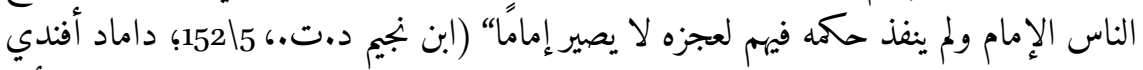

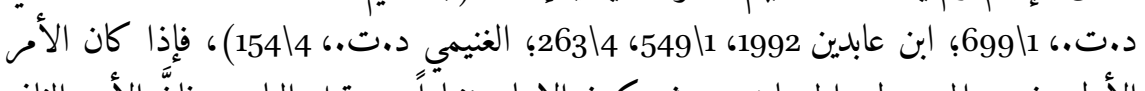

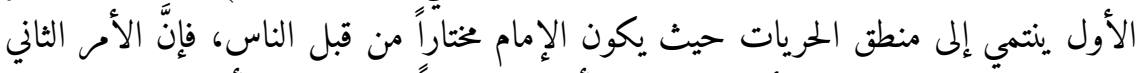

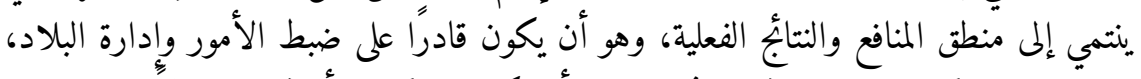

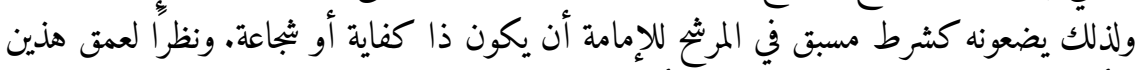

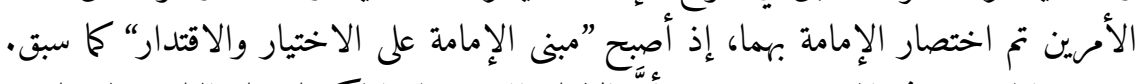

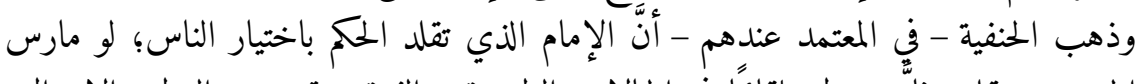

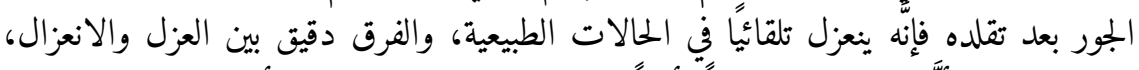

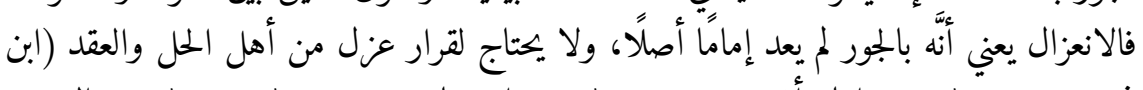
نجيم د.ت. د.ت.

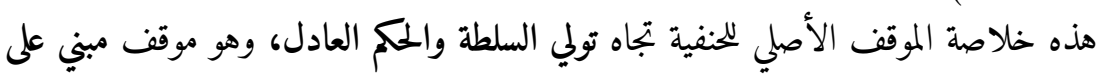

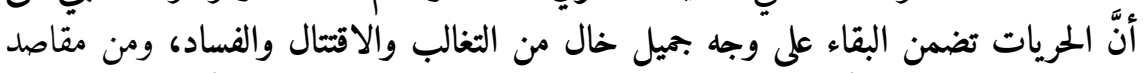

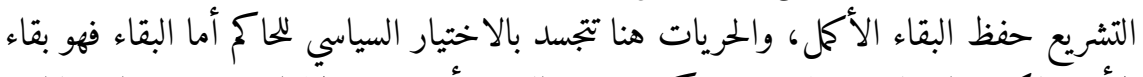

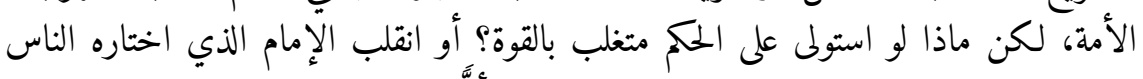

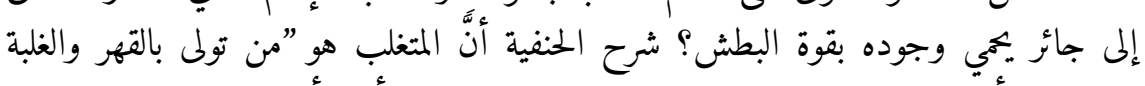

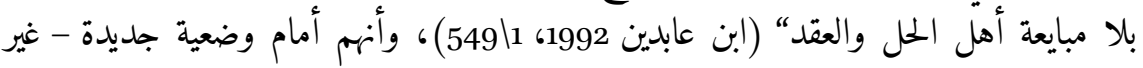

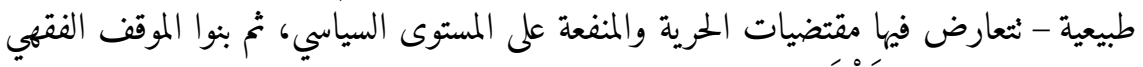

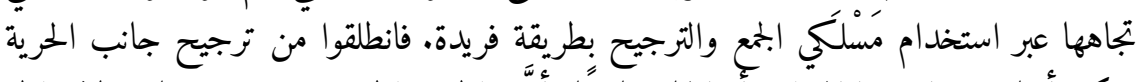

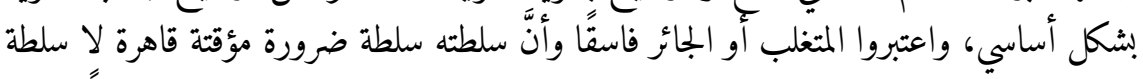

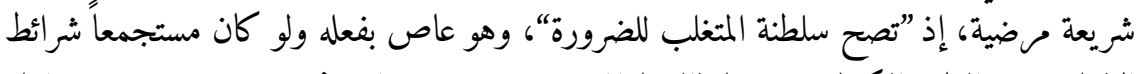

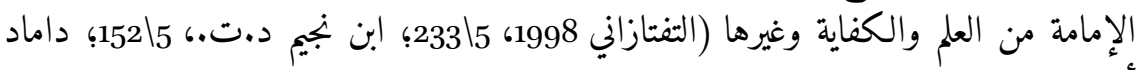

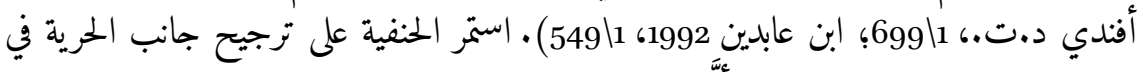

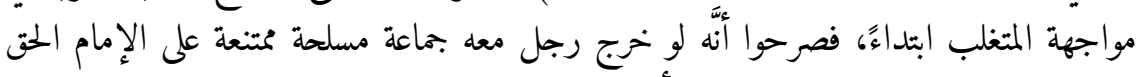

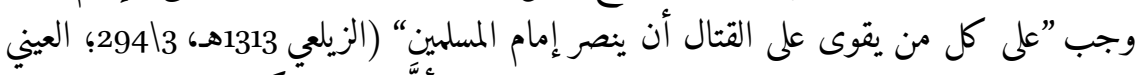

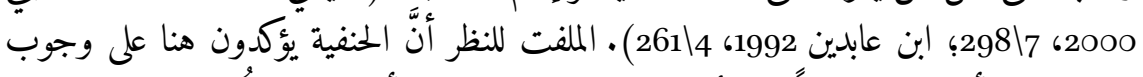

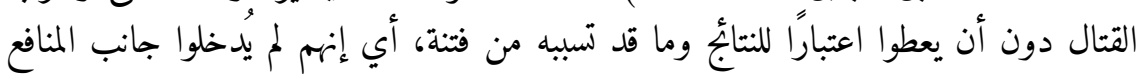


الناتجة بعد. وقريب من هذا الموقف ما قرره الشافعية أن المتغلب إذا استولى على إمام اختاره

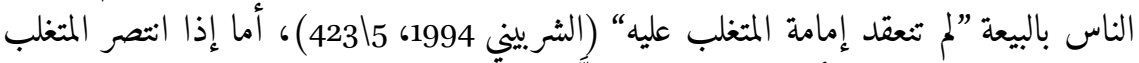

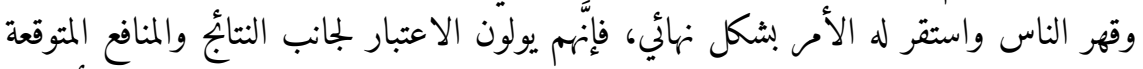

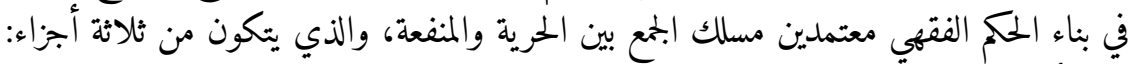

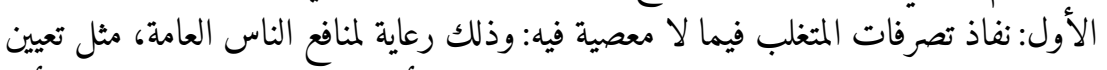

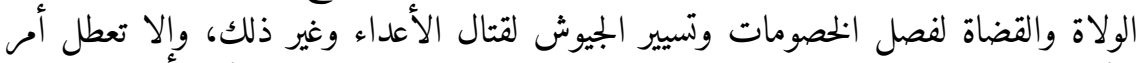

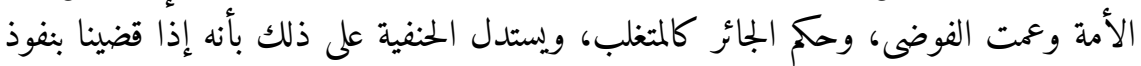

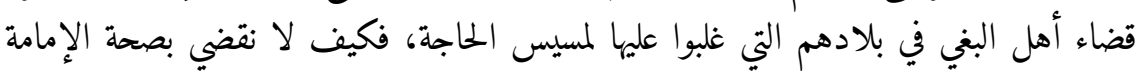

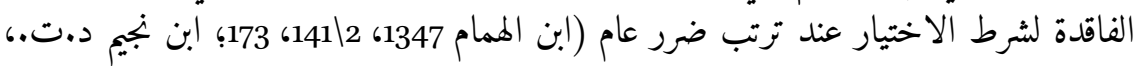

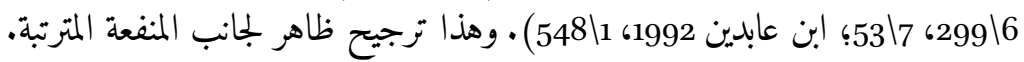

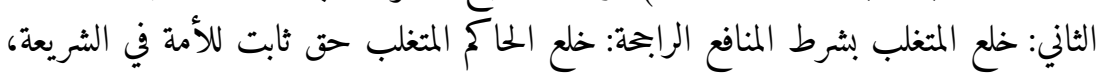

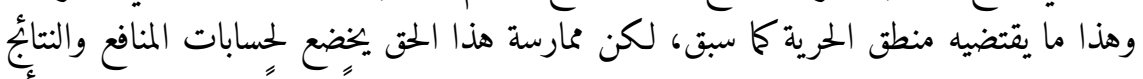

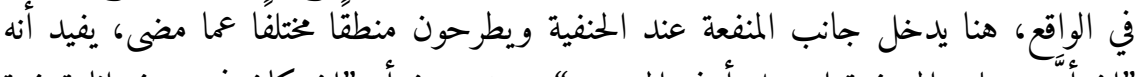

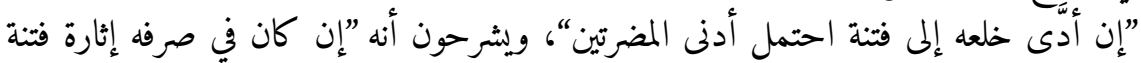

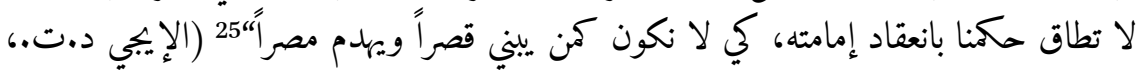

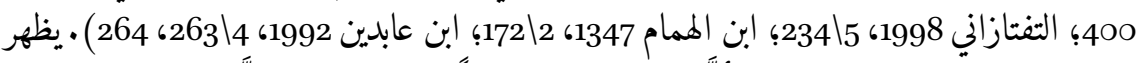

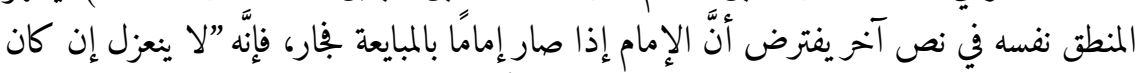

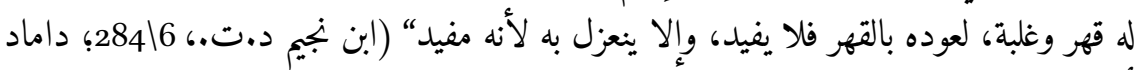

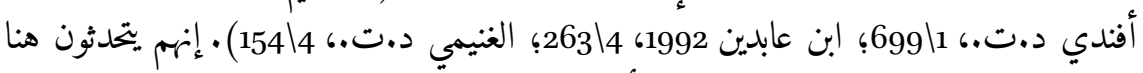

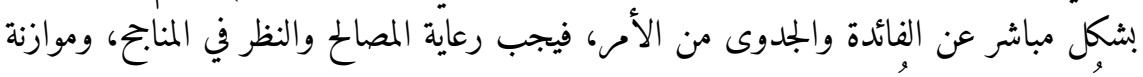

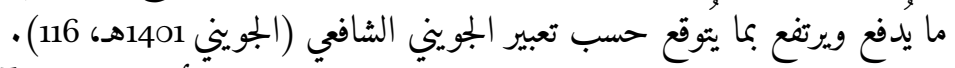

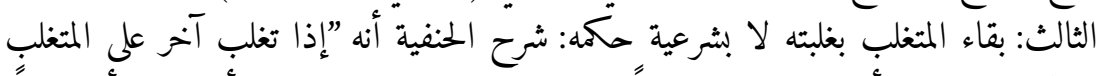

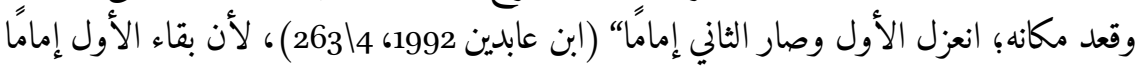
بالتغلب وليس باختيار شرعي، فإذا ذهب تغلبه ذهب سبب وإنب وجوده، ومثل هذا قال الشافعية

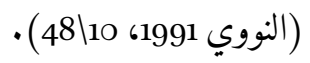

من هذا المنطلق يغدو مفهومًا التحليل الفقهي السياسي الذي قدمه ابن حجر، فقد ذكر أنَّ النّا

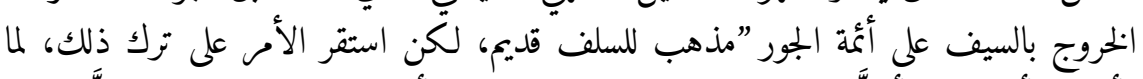

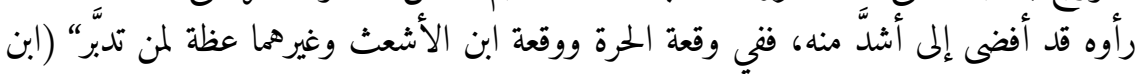

25 في هذا الموقف الصعب الذي لا ينغ فيه خلع المتغلب يركز الحنفية بشكل أساسي على انتشار العدل

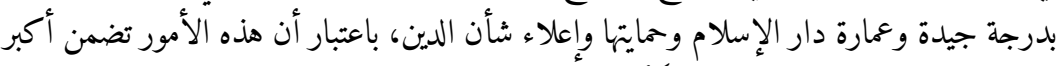

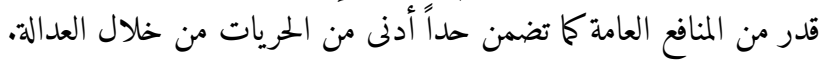


جرج 1326هـ، 288/2) • فهو يشرح أنَّ موقف العلماء بالمجمل تغير من ترجيح جانب الحريات

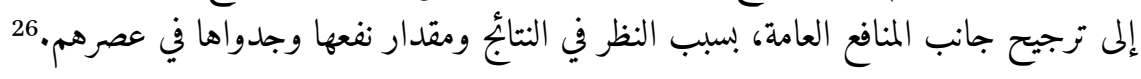

$$
\text { المفهوم الخامس: الحريات والعبادة الدينية }
$$

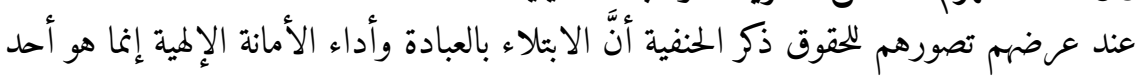

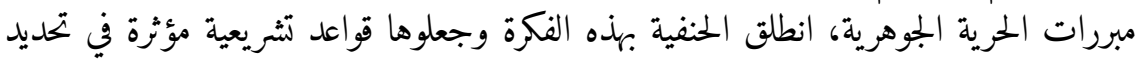

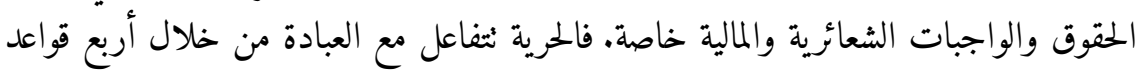

رئيسية:

$$
\text { القاعدة الأولى: اختيار الدين والإيمان }
$$

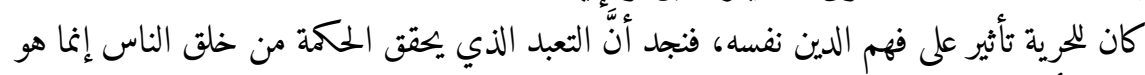

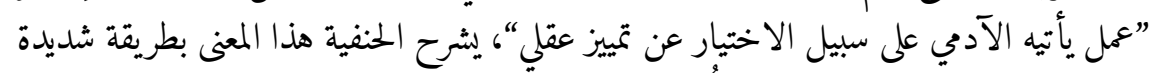

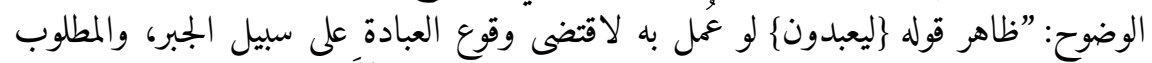

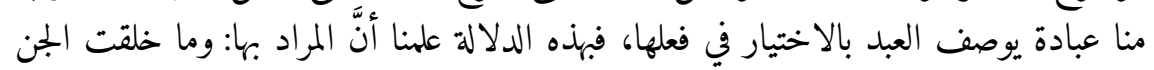

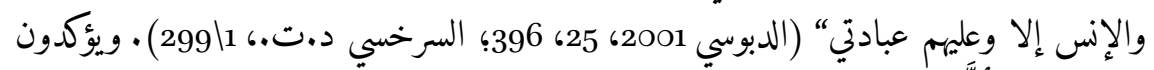

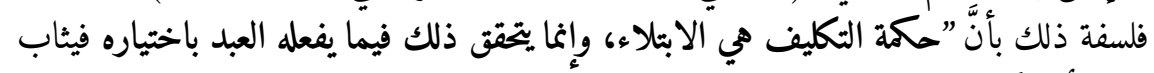

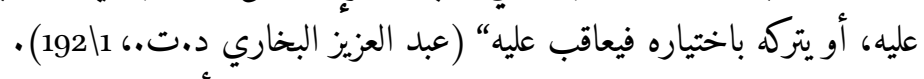

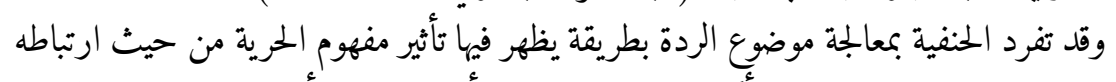

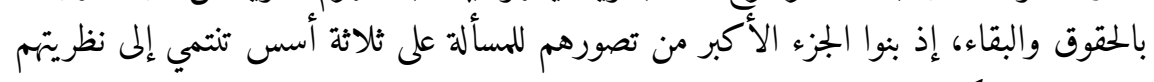

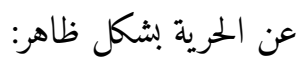

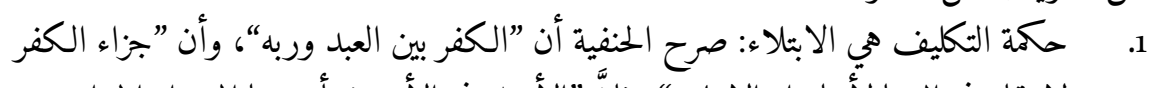

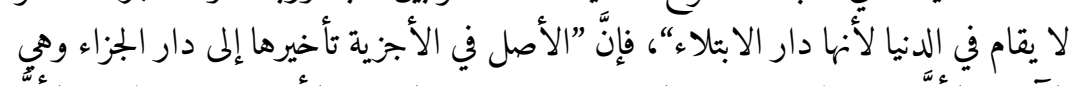

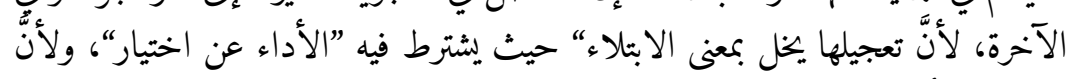

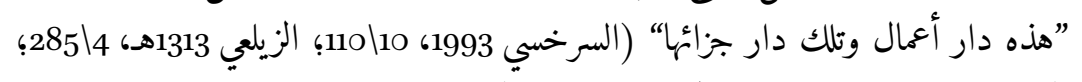

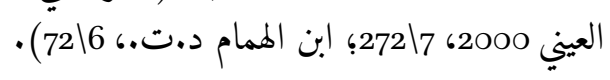

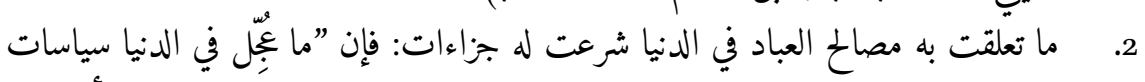

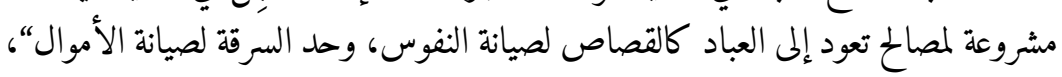

26 26 لعل ابن ججر يشير إلى أبي حنيفة ضمن ما يشير إليه، فقد كان يرى قتال أئمة الجور ضمن معايير

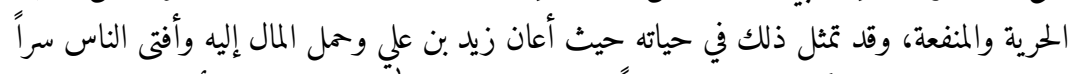

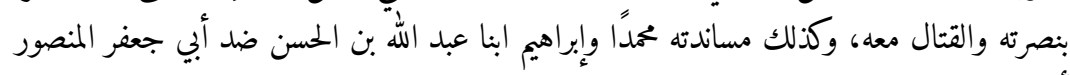

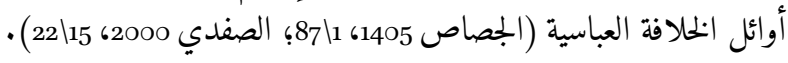


وكل جزاء شرع في هذه الدار ما هو إلا لمصالح تعود إلينا في هذه الدارة (السرخسي

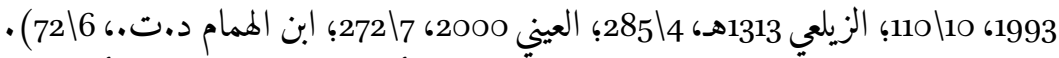

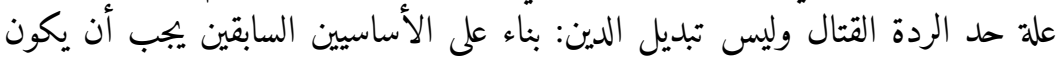

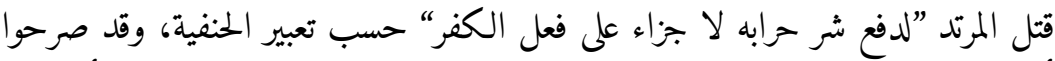

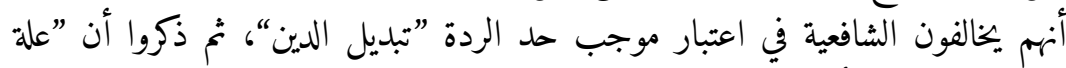

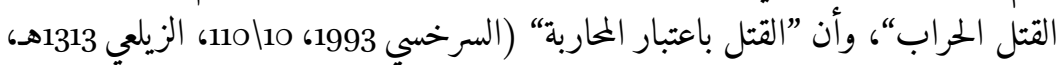
.

ينبغي أن يفضي ذلك المنطق بالحنفية إلى أن الردة لا توجب القتل، وقدأ وقد حصل هذا فهلاً

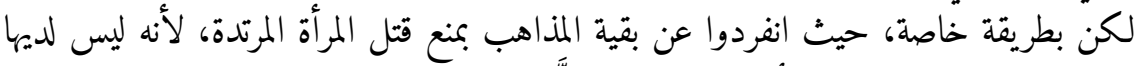

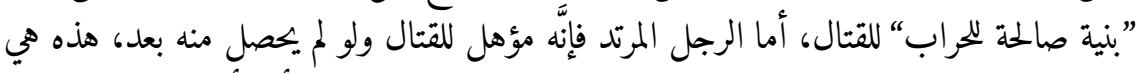

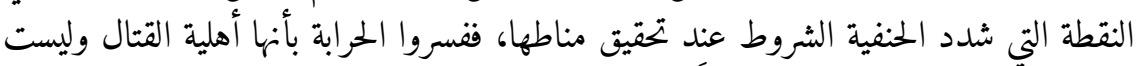

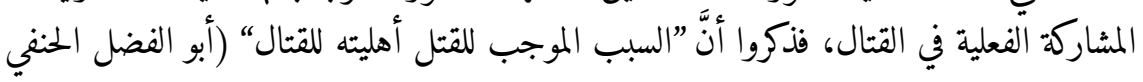
27.(149\461937

$$
\text { القاعدة الثانية: ما ظهر فيه معنى التعبد اتسع فيه الاختيار }
$$

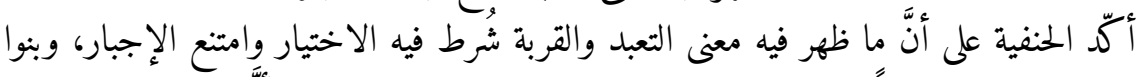

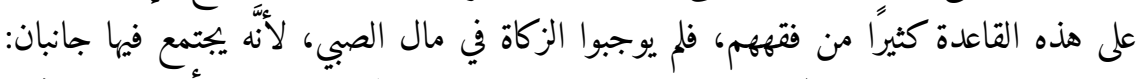

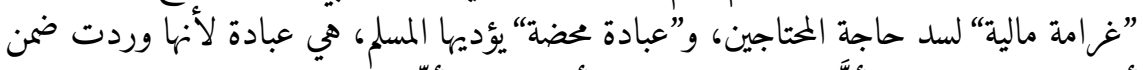

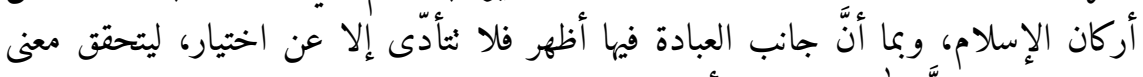

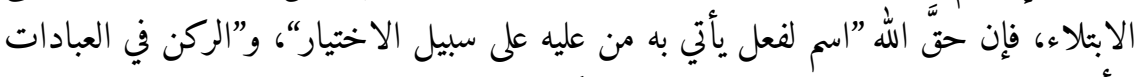

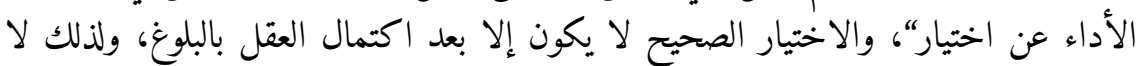

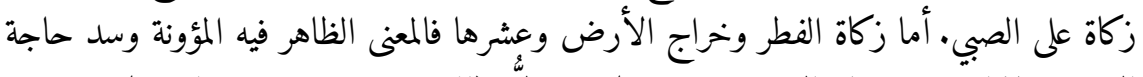

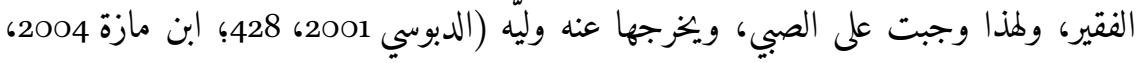
301>2

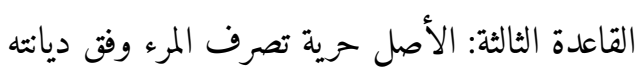

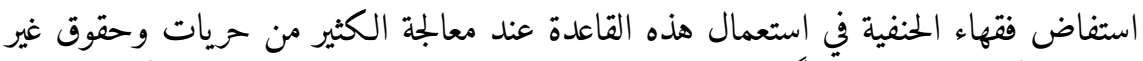

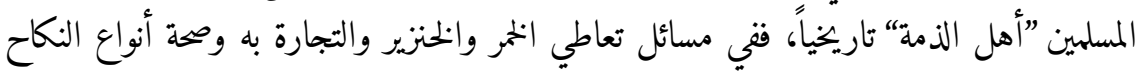

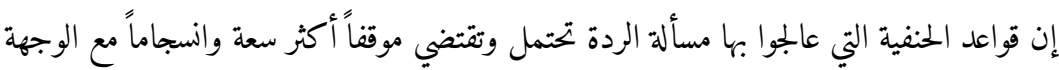
27

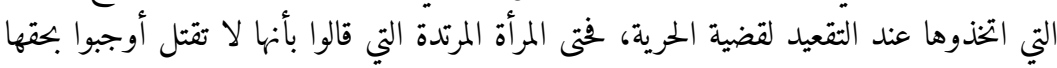

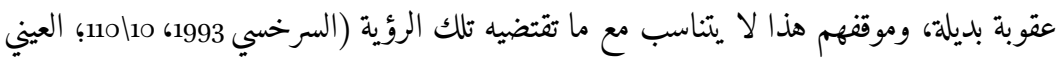
. $(272 \backslash 7$ 62000 


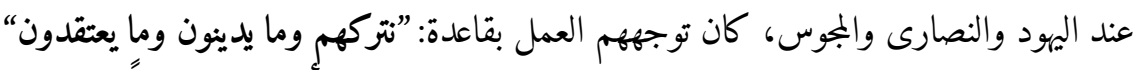

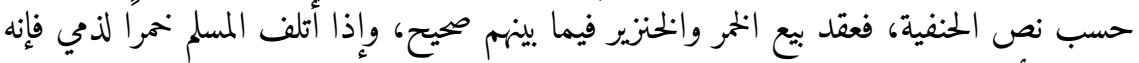

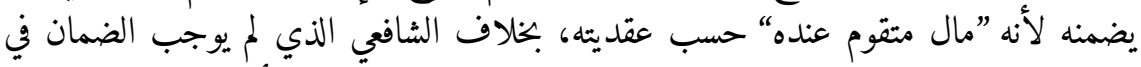

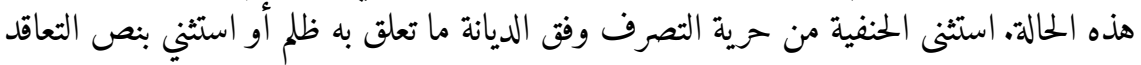

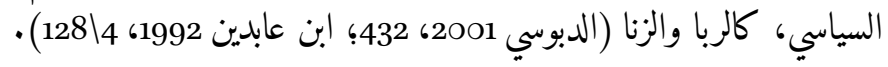

$$
\text { القاعدة الرابعة: الحرية والإسلام لا يتعارضان }
$$

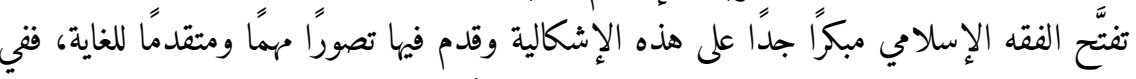

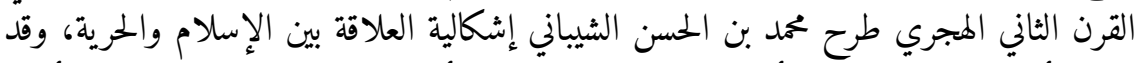

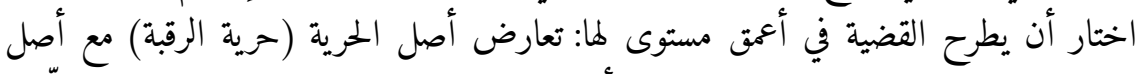

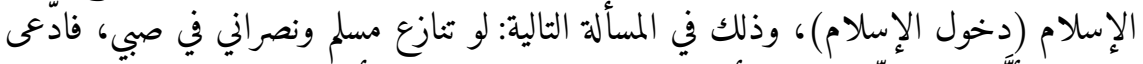

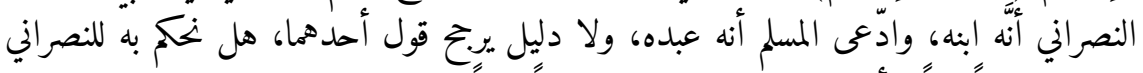

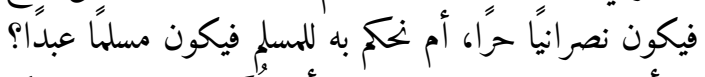

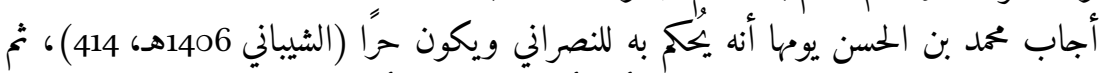

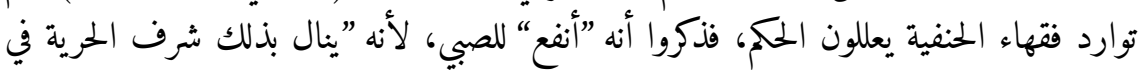

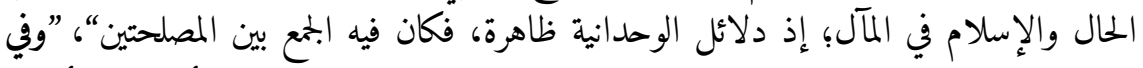

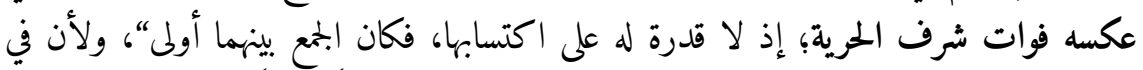

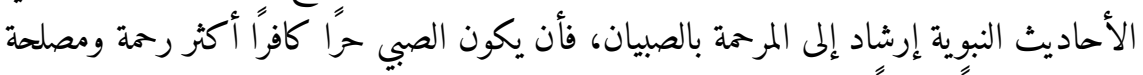

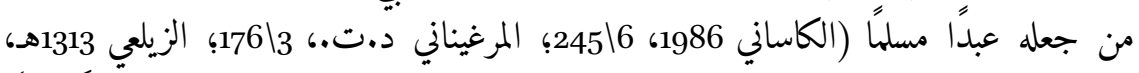

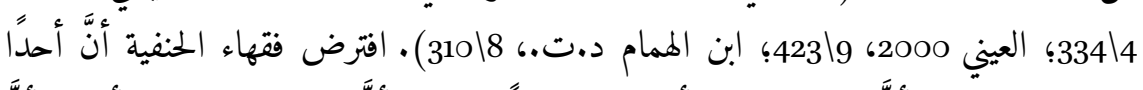

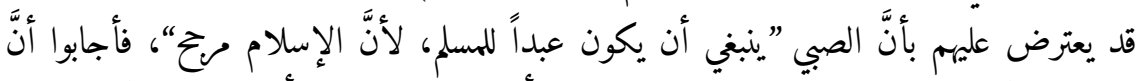

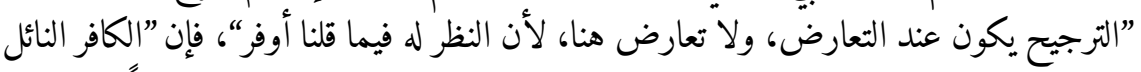

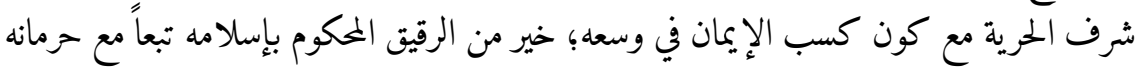

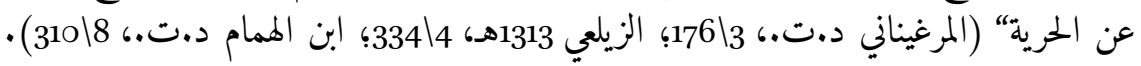

$$
\text { المفهوم السادس: الحرية والعقل والقدرة }
$$

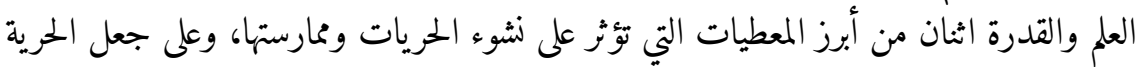

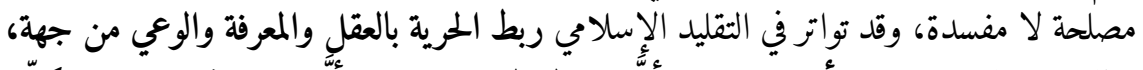

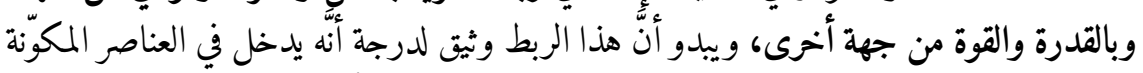

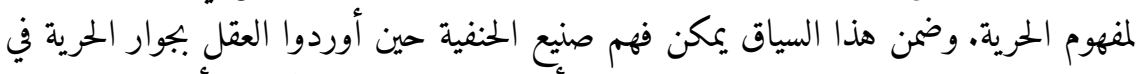

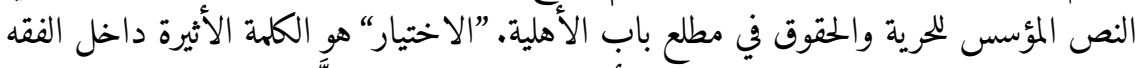

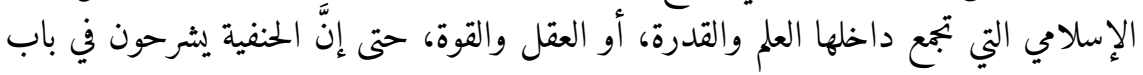




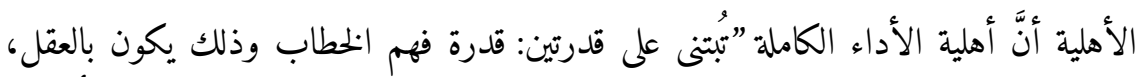

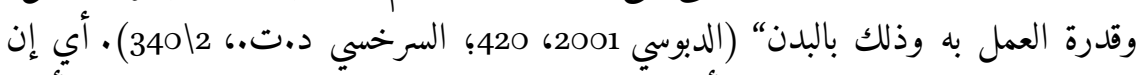

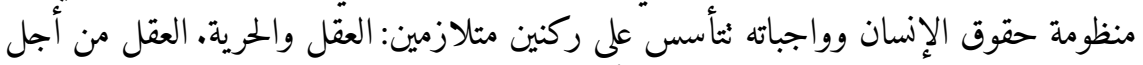

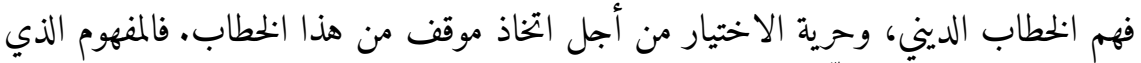

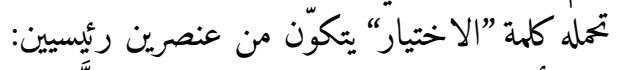

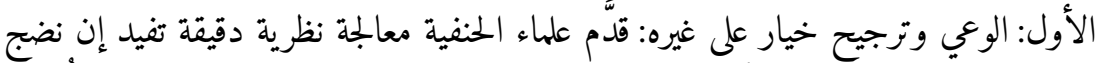

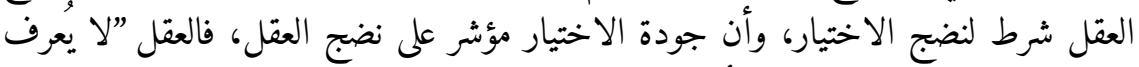

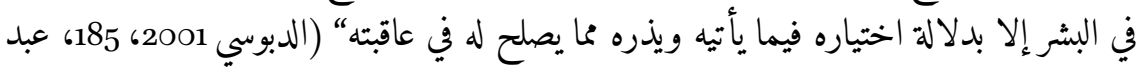

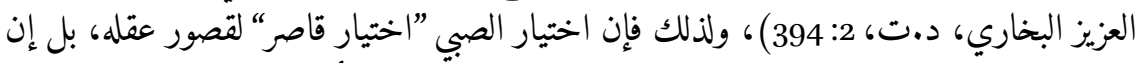

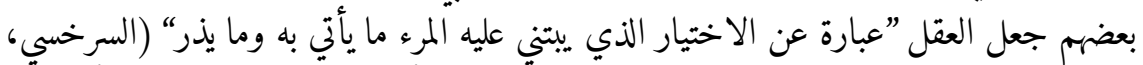

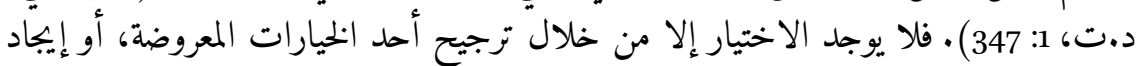

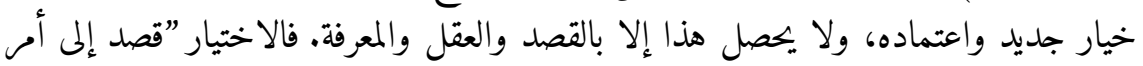

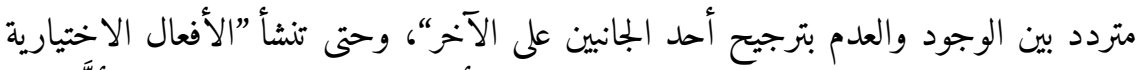

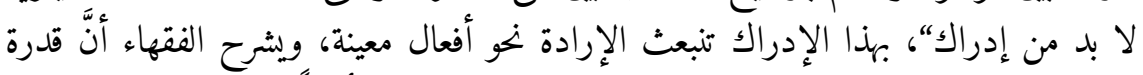

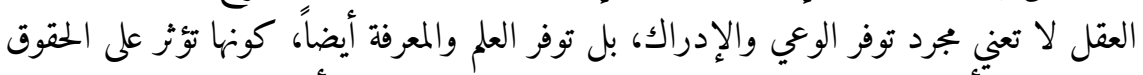

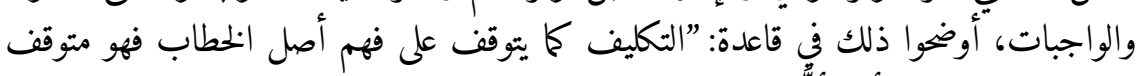

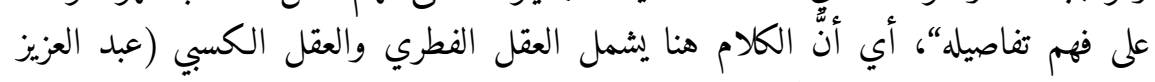

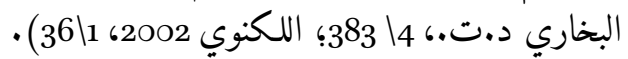

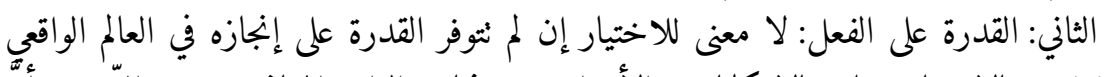

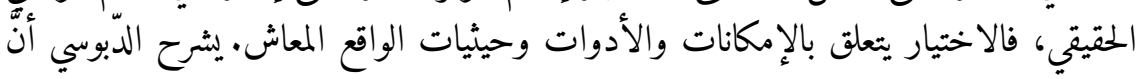

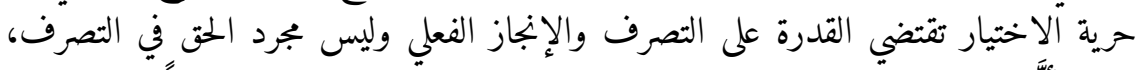

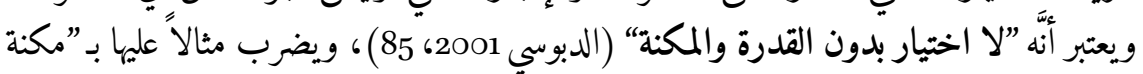

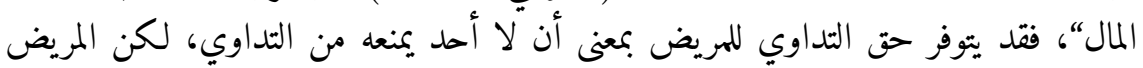

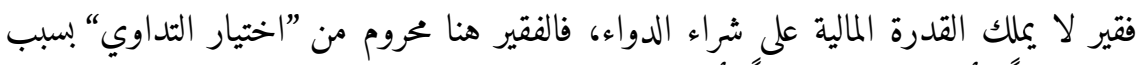

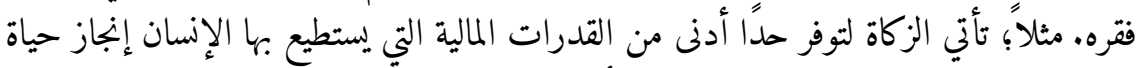

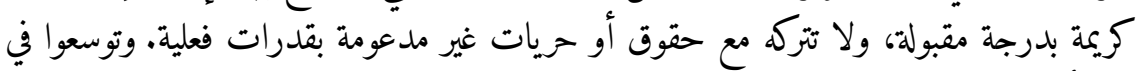

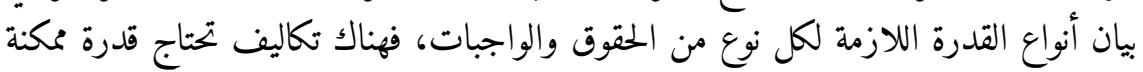

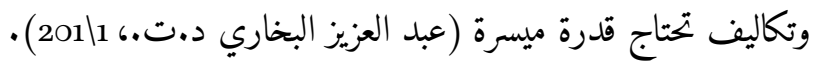

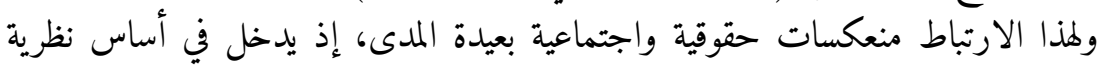

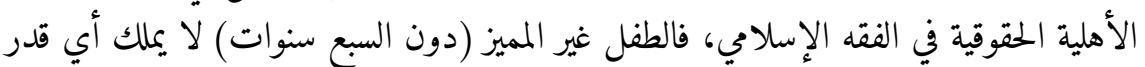

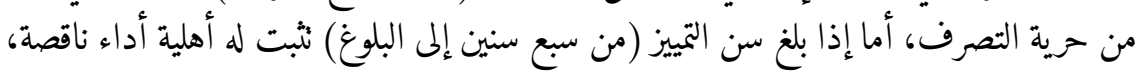




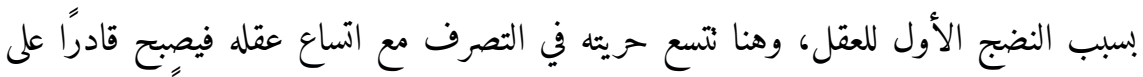

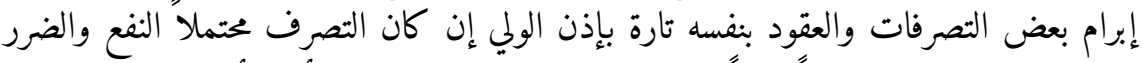

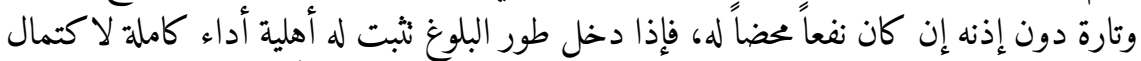

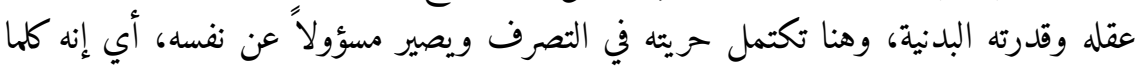
اتسعت العقلانية اتسعت الحرية وكلما اتسعت القدرة اتسعت الحتبة الحرية.

\section{الخاتمة}

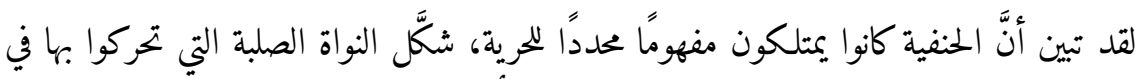

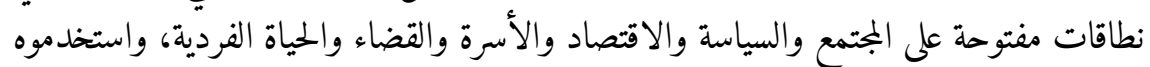

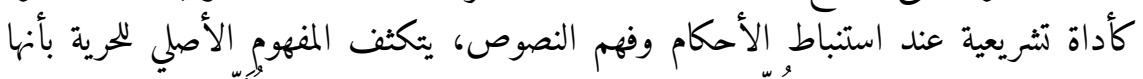

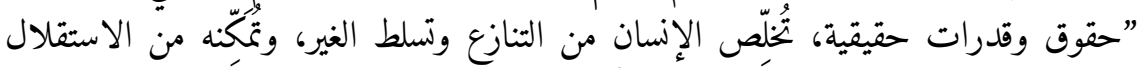

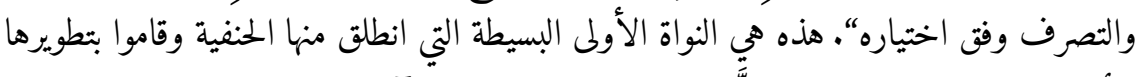

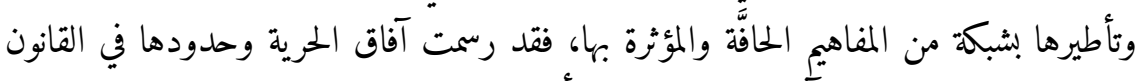

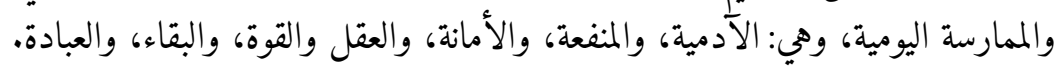

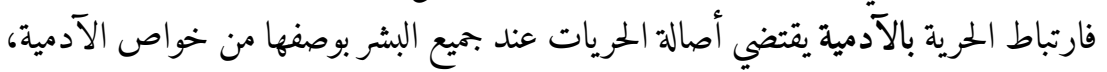

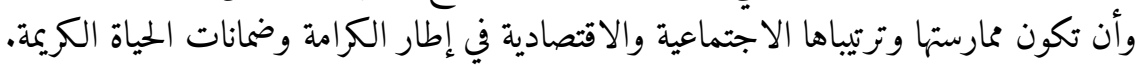

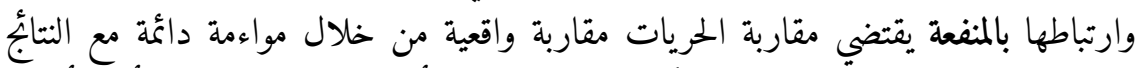

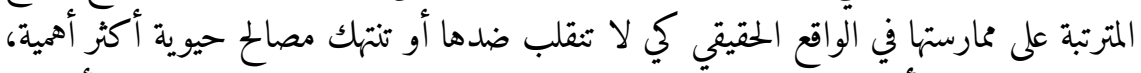

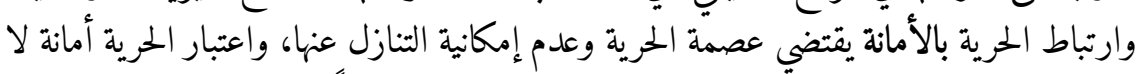

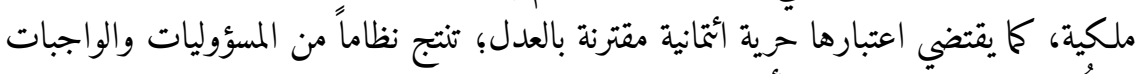

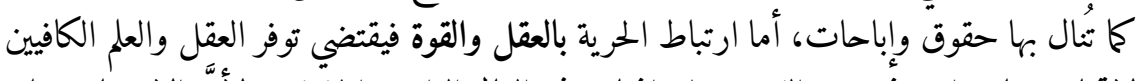

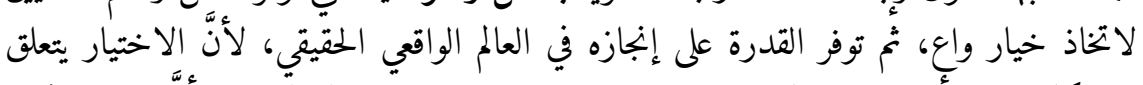

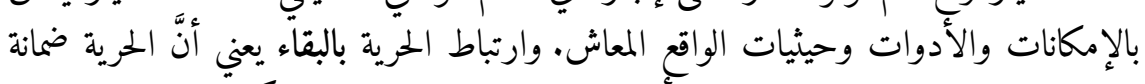

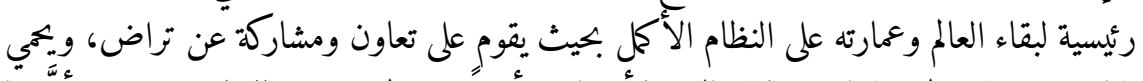

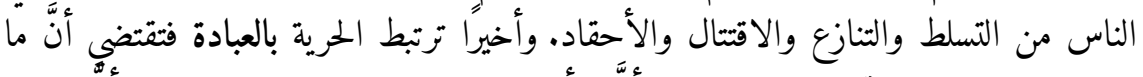

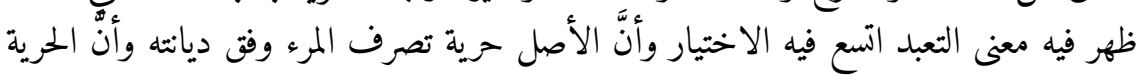
والإسلام لا يتعارضان.

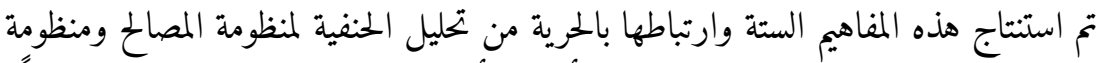

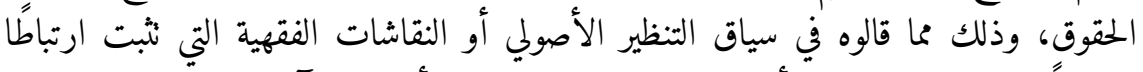

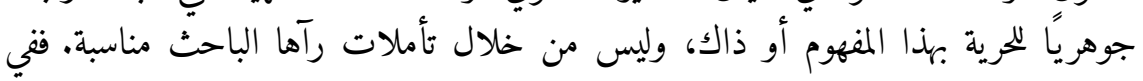




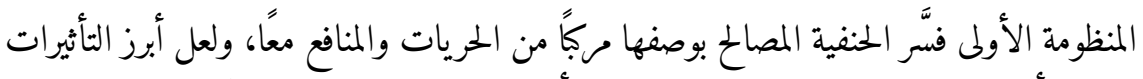

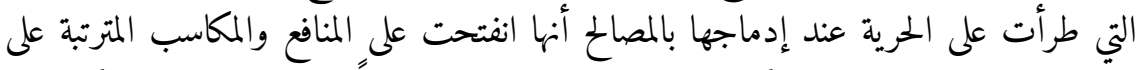

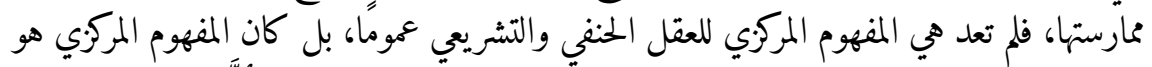

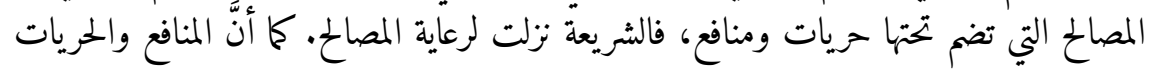

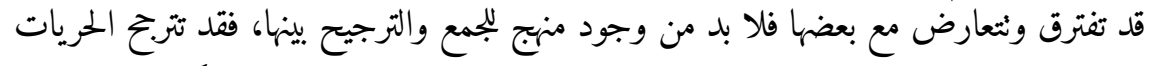

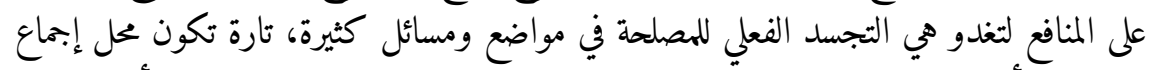

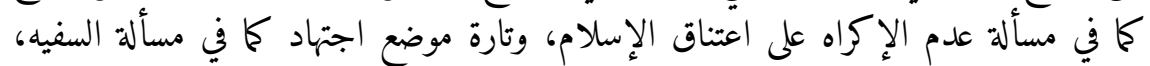

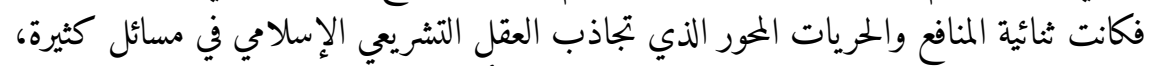

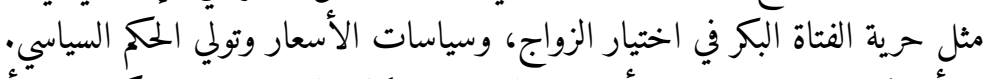

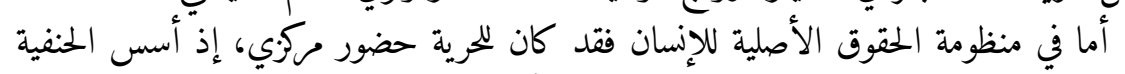

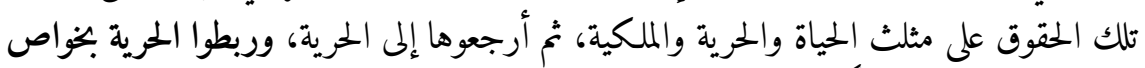

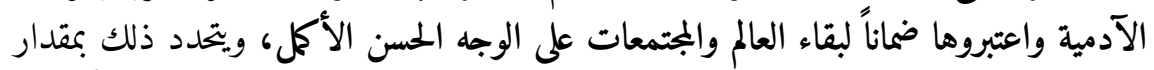

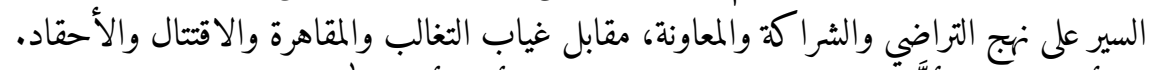

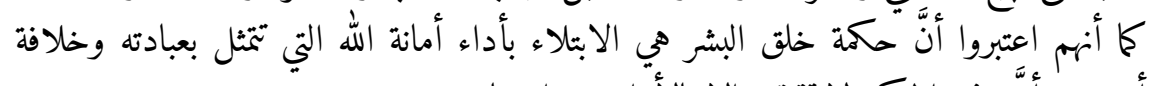

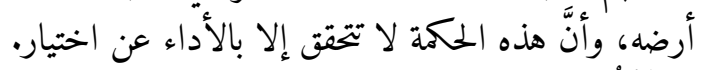

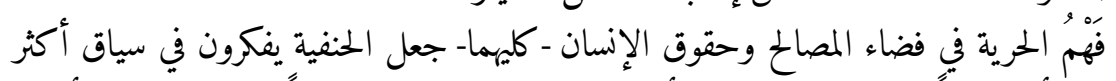

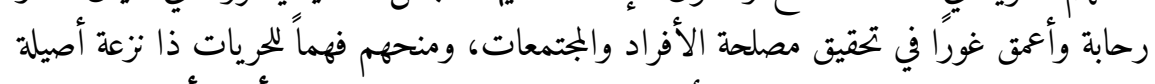

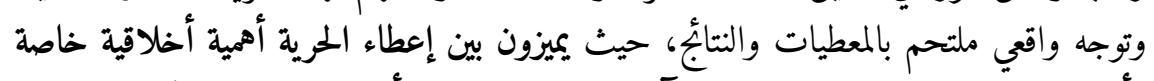

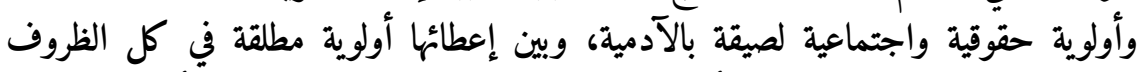

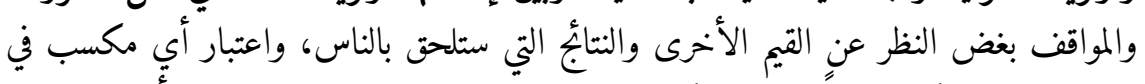

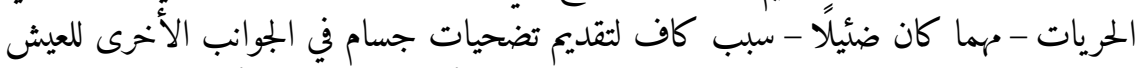

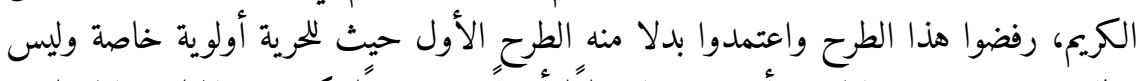

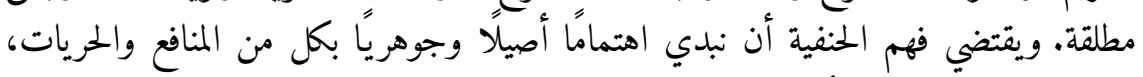

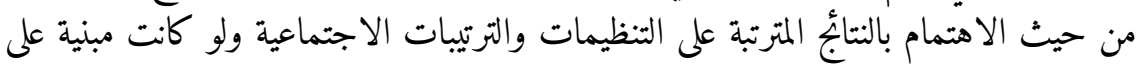

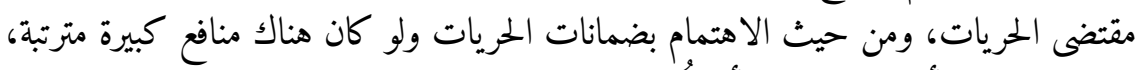

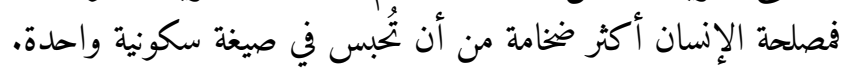

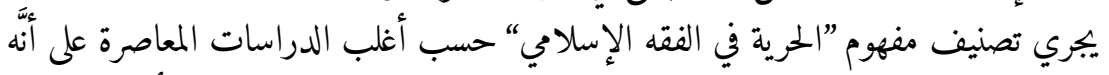

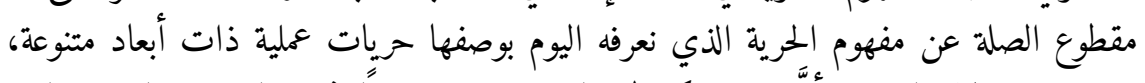

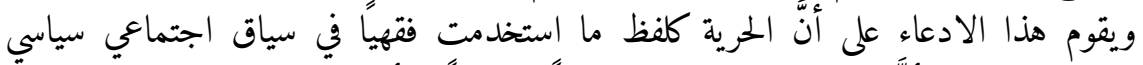

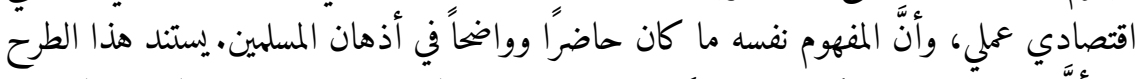

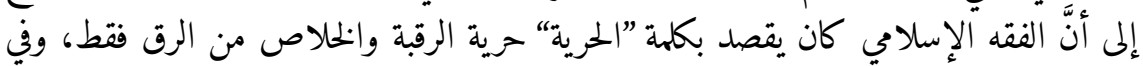




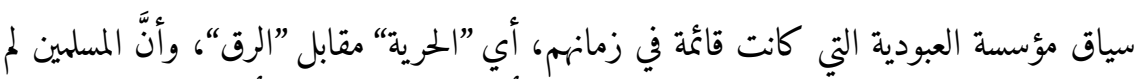

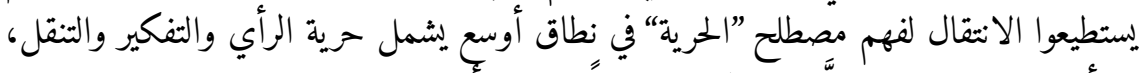

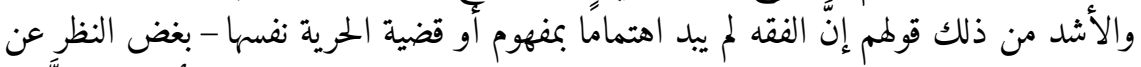

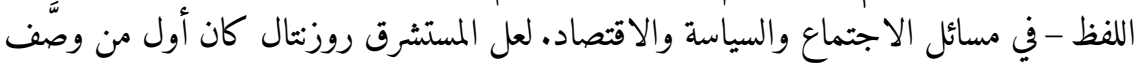

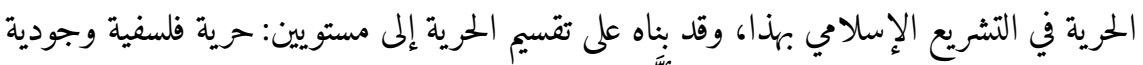

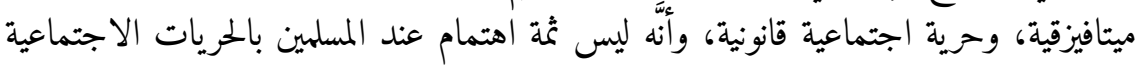

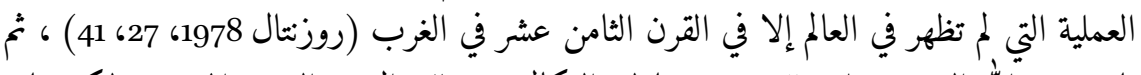

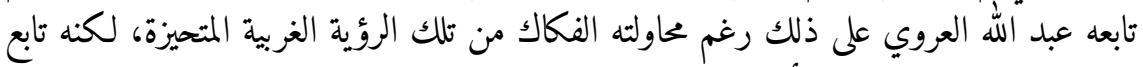

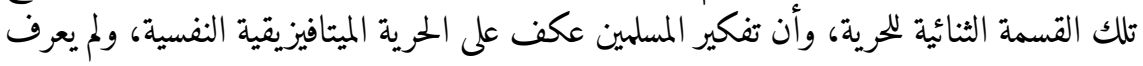

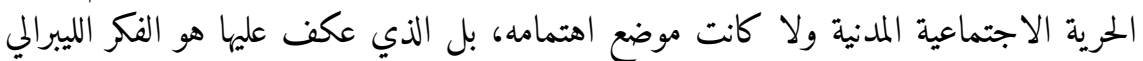

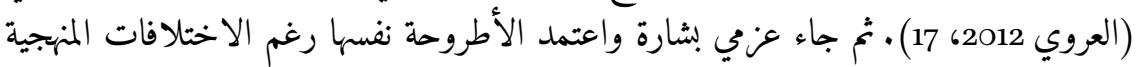

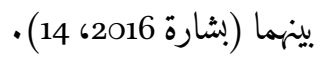
المقاربة التي يقترحها هذا البحث إنما هي خطاطة أولية للتفكير بالحريات في التراث التهاث التشريعي

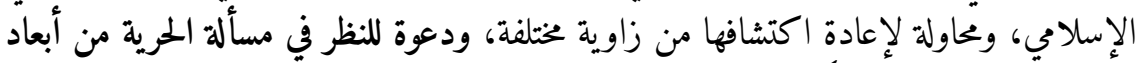

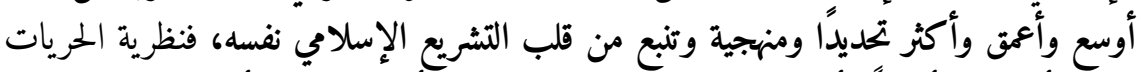

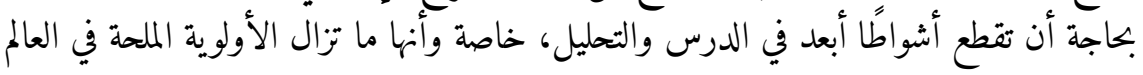

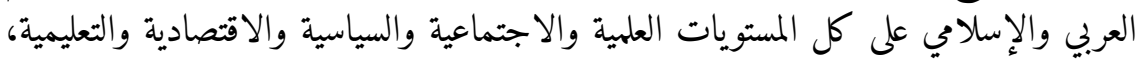

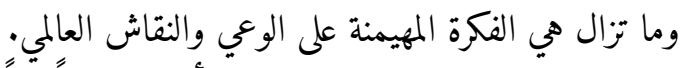

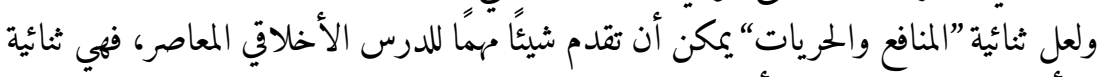

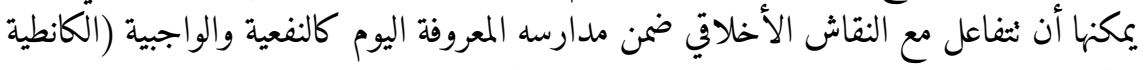

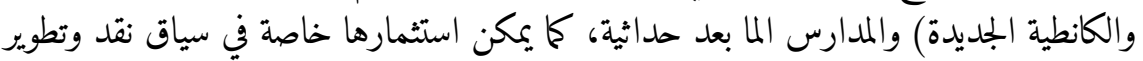

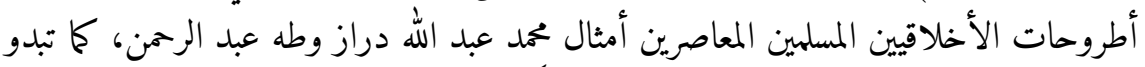

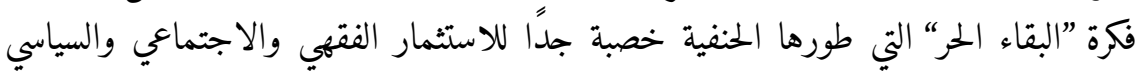
الراهن.

ومن جانب آخر فإنَ فكرة ”خواص الآدمية“ تصلح أن تؤسس لمشتركٍ إنساني عالمي يساهمٍ

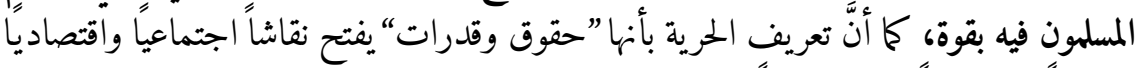

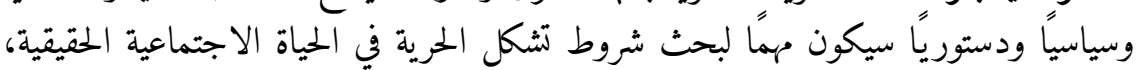

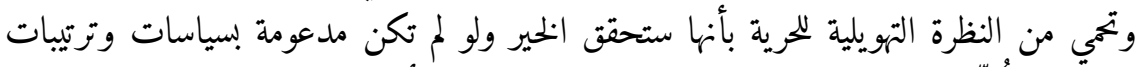

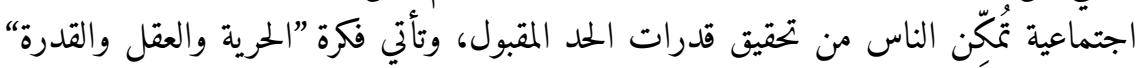
لتبرز أهمية العَلم والتعليم في بناء أرضية صلبة للمرية. 
التوصية الرئيسية لهذا البحث أن تخصص دراسات معمقة تكشف منظور الحريات في

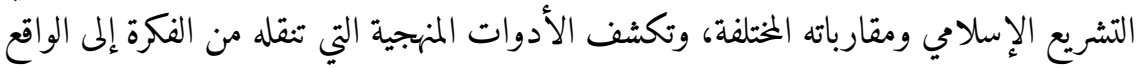

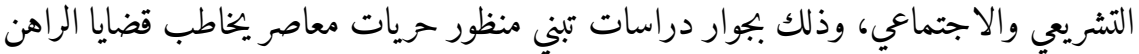

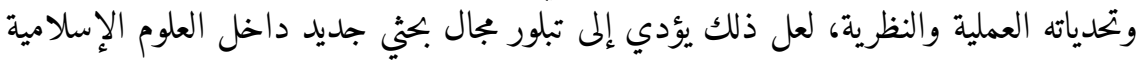

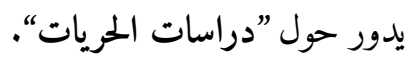

\section{المصادر والمراجع}

ابن أمير حاج، شمس الدين (ابن الموقت الحنفي) • 1983. التقرير والتحبير. بيروت: دار الكتب العلمية.

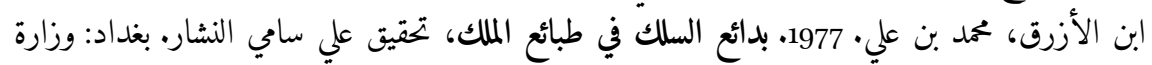
ابن تيمية، أحمد بن عبد الحليم، 1995. بمجوع الفتوى، تحقيق عبد الرحمن بن محمد بن قاسم. المدينة المنورة:

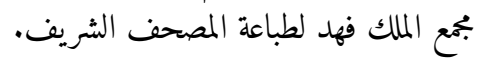

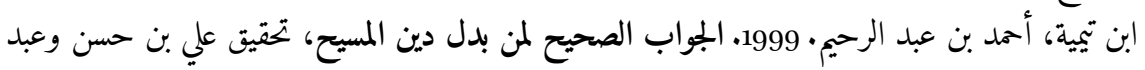

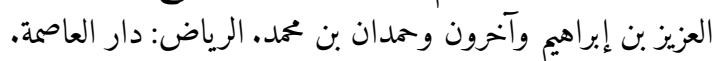

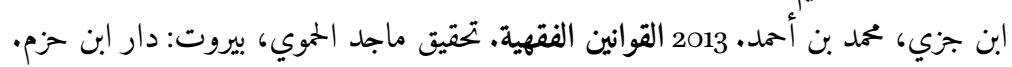

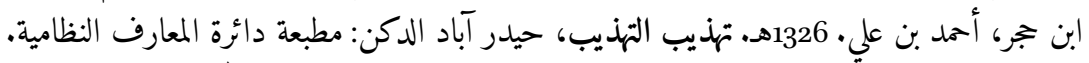

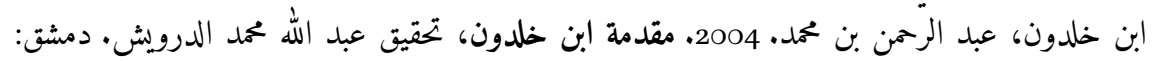
دار يعرب. ابن رشد، أبو الوليد محمد بن أحمد، 1988. المقدمات الممهدات، تحقيق محمد جي. بيروت: دار الغرب الإسلامي.

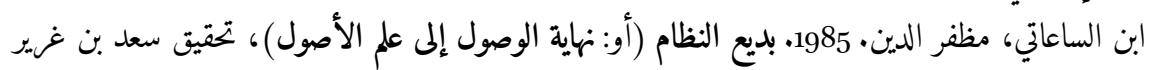

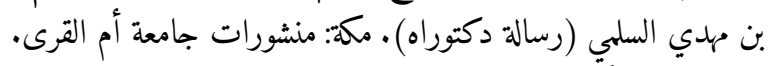

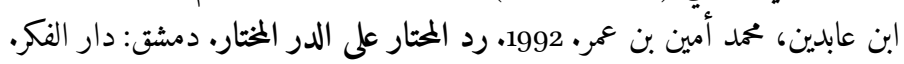

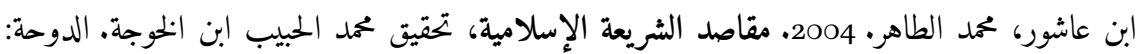
وزارة الأوقاف والشؤون الإسلامية. ابن العربي، محمد بن عبد الله. 2003. أحكام القرآن، مراجعة وتعليق محمد عبد القادر عطا. بيروت: دار الإداف الكتب العلمية. ابن قدامة، موفق الدين. 1968. المغني. القاهرة: مكتبة القاهرة.

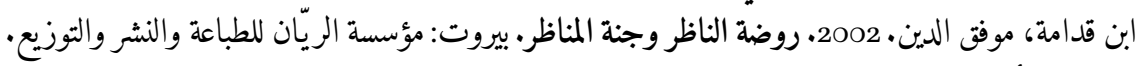

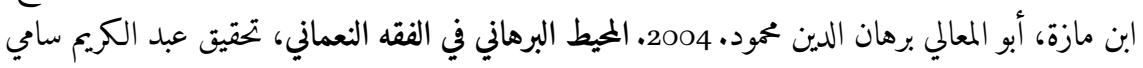
الجندي. بيروت: دار الكتب العلمية. 
ابن نجيم، زين الدين المصري. د.ت. البحر الرائق شرح كنز الدقائق. القاهرة: دار الكتاب الإسلامي.

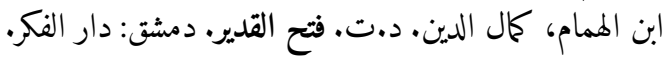
ابن الممام، الكمال بن أبي شريف. المبح. 1347هـ. المسامرة في شرح المسايرة، مع حاشية قاسم بن قطلوبغا. القاهرة: مطبعة السعادة.

أبو زهرة، محمد، 1947. أبو حنيفة حياته وعصره آراؤه الفقهية، القاهرة: دار الفكر العربي.

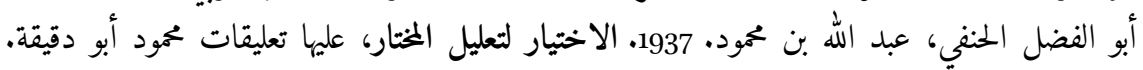
القاهرة: مطبعة الحلبي.

الأزميري، محمد، 1285هـ، حاشية الأزميري على مرآة الأصول. اسطنبول: مطبعة محمد البوسنوي.

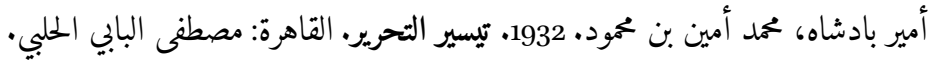

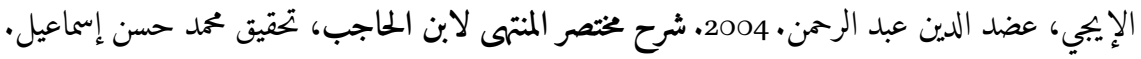

$$
\text { بيروت: دار الكتب العلمية. }
$$

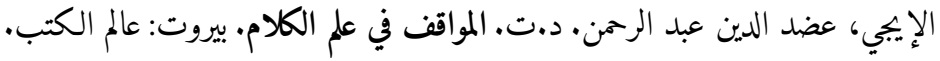

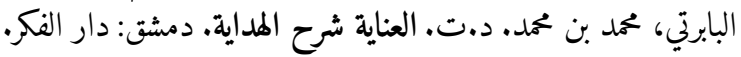

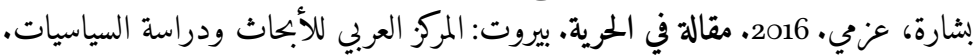

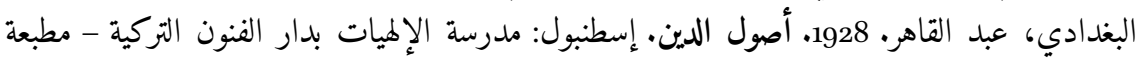
الدولة. البغوي، الحسين بن مسعود. 1997. معالم التزيل في تفسير القرآن، تحقيق محمد عبد الله النمر وعثمان جمعة

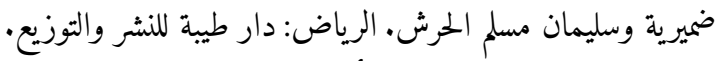
البهوتي، شمس الدين. 1993. دقائق أولي النهى لشرح المنتهى المعروف بشرئ بشرح منتهى الإرادات. بيروت:

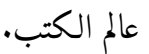
الترمذي، أبو عبد الله الحكيم، 1965. الصلاة ومقاصدها، تحقيق حسني نصر زيدان. القاهرة: مطابع دار الكناب العربي.

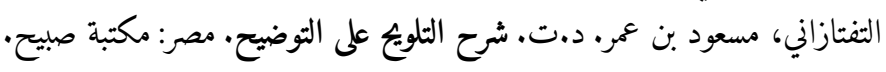

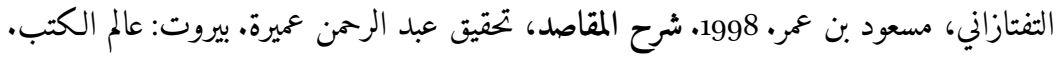

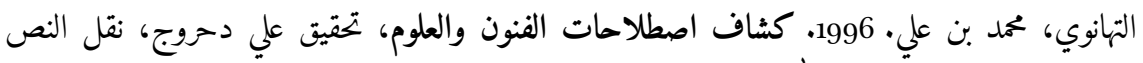

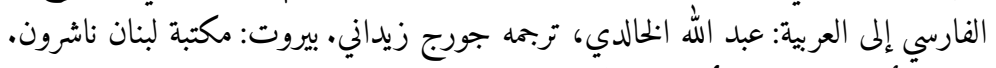

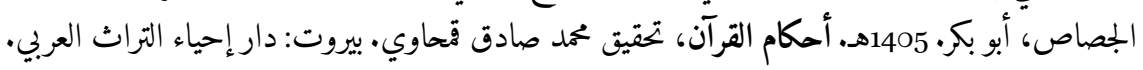

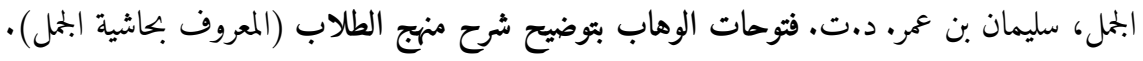
دمشق: دار الفكر.

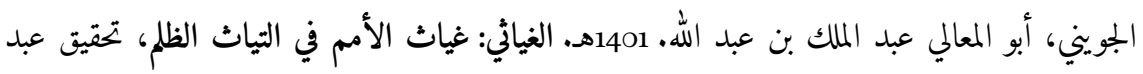

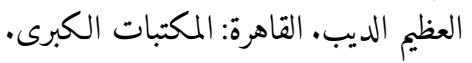
الحطاب، شمس الدين. 1992. مواهب الجليل في شرح مختصر خليل. دمشق: دار الفكر. 
داماد أفندي، عبد الرممن بن محمد. د.ت. بمع الأنهر في شرح ملتقى الأبحر. بيروت: دار إحياء التراث العربي.

الدبوسي، عبد الله بن عمر. 2001. تقويم الأدلة في أصول الفقه، تحقيق خليل محيي الدين الميس. بيروت: دار الكتب العلمية.

الدسوقي، محمد بن أحمد. د.ت. حاشية الدسوقي على الشرح الكبير. دمشق: دار الفكر.

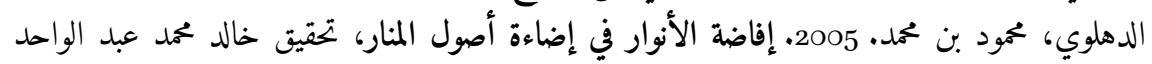
حنفي. الرياض: مكتبة الرشد.

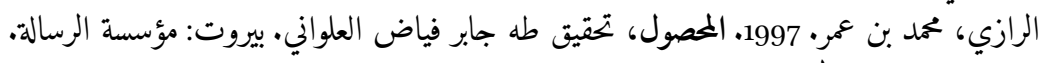

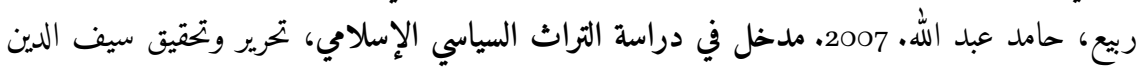

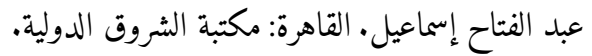

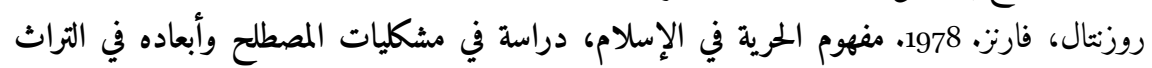

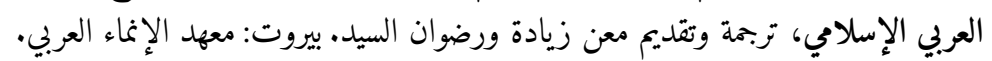

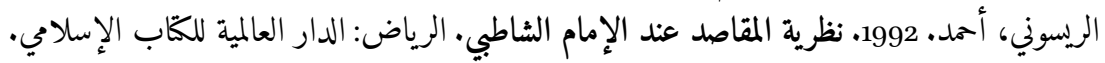

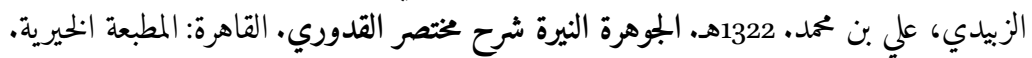

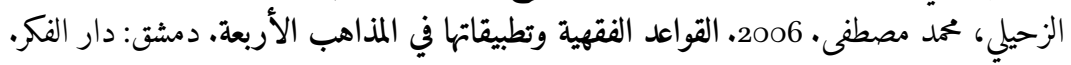

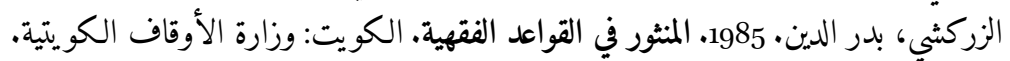

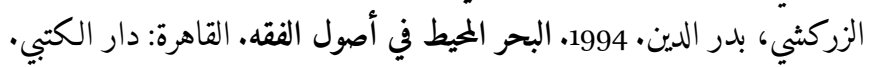

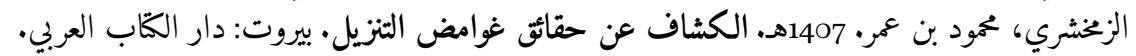

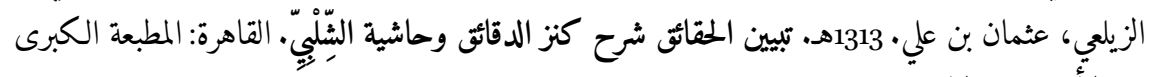
الأميرية - بولاق. السرخسي، شمس الأمعة محمد بن أحمد. د.ت. أصول السرخسي، بيروت: دار المعرفة.

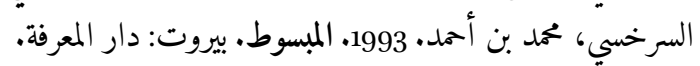

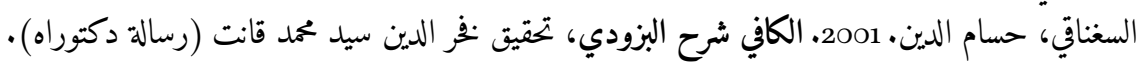
الرياض: مكتبة الرشد للنشر والتوزيع. السمرقندي، علاء الدين، 1984. ميزان الأصول في نتائج العقول، تحقيق محمد زكي عبد البر. الدوحة: مطابع الدولة الحديثة.

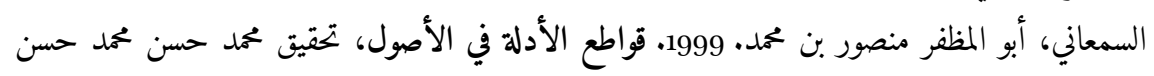

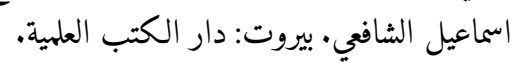
الشاطبي، إبراهيم بن موسى. 1997. الموافقات، تحقيق أبو عبيدة مشهور بن حسن الكية آل سلمان. الجيزة: دار ابن عفان. الشربيني، شمس الدين. 1994. مغني المحتاج إلى معرفة معاني ألفاظ المنهاج· بيروت: دار الكتب العلمية. 


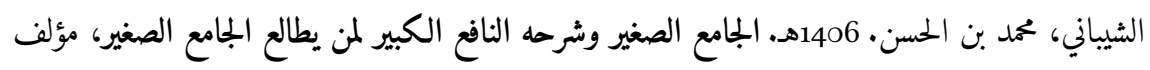

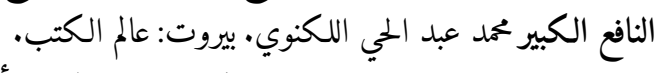

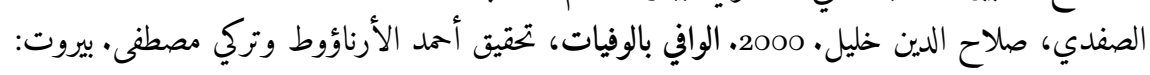
دار إحياء التراث.

الطوفي، سليمان بن عبد القوي. 1987. شرح مختصر الروضة، تحقيق عبد الله بن عبد المحسن التركي. مؤسسة الرسالة.

الطوفي، سليمان بن عبد القوي. 2005. درء القول القبيح بالتحسين والتقبيح، تحقيق أيمن محمود شحادة. بيروت: الدار العربية للموسوعات.

عبد العزيز البخاري، علاء الدين. د.ت. كشف الأسرات العرار شرح أصول البزدوي. قم: دار الختاب الإسلامي.

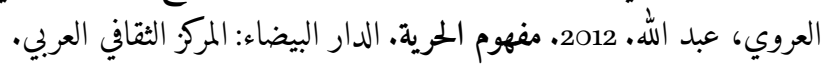

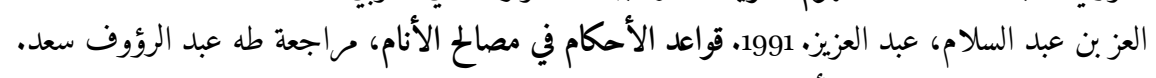
القاهرة: مكتبة الكليات الأزهرية.

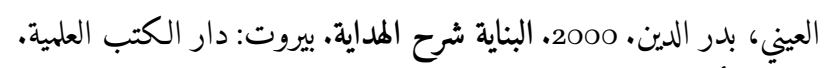

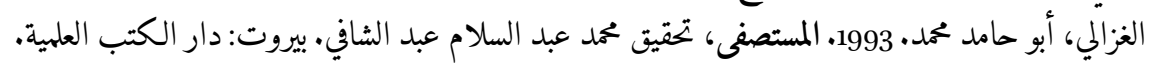

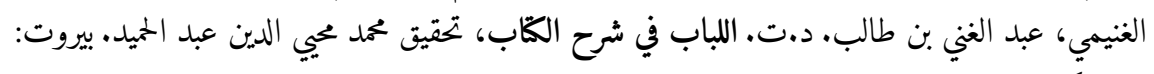
المكتبة العلمية.

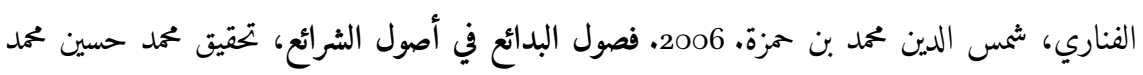
حسن إسماعيل. بيروت: دار الكتب العمبية.

القرافي، أحمد بن إدريس. 1973. شرح تنقيح الفصول، تحقيق طه عبد الرؤوف سعد. بيروت: شركة الطباعة الفنية المتحدة. القرافي، شهاب الدين. 1994. الذخيرة، تحقيق محمد ججي وسعيد أعراب ومحمد بو خبزة. بيروت: دار الغرب المباع الإسلامي.

القرافي، شهاب الدين• 1995. نفائس الأصول في شرح المحصول، تحقيق عادل أحمد عبد الموجود وعلي محمد معوض. مكة: مكتبة نزار مصطفى الباز. القرطبي، محمد بن أحمد. 1964. الجامع لأحكام القرآن، تحقيق أحمد البردوني وإبراهيم أطفيش. القاهرة:

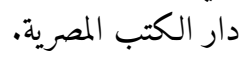
قزغلي، شمس الدين. 1408هـ. إيثار الإنصاف في آثار الخلاف، تحقيق ناصر العلي الناصر الخليفي. القاهرة: دار السلام.

قليوبي، أحمد سلامة وأمد البرلسي عميرة. 1995. حاشيتا قليوبي وعميرة. دمشق: دار الفكر.

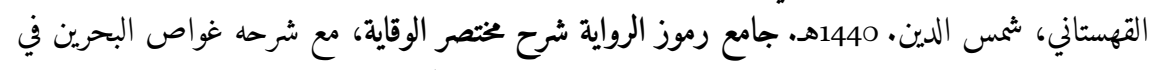

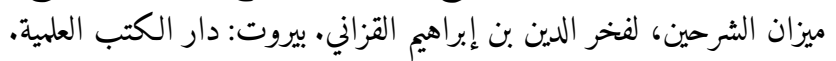

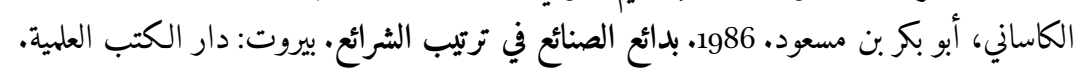




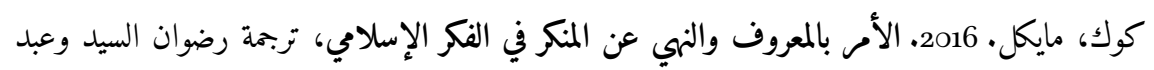

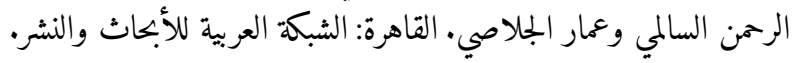

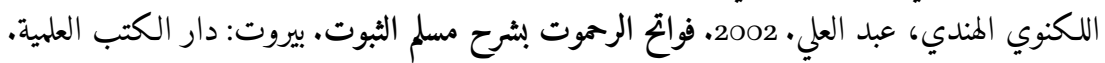

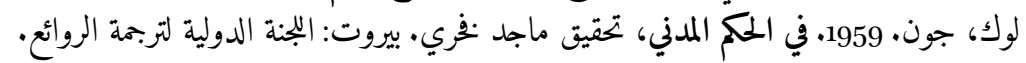

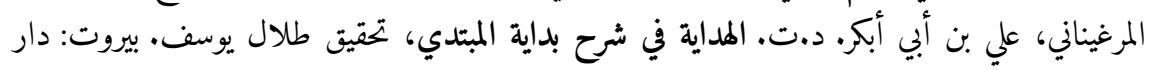
إحياء التراث العربي.

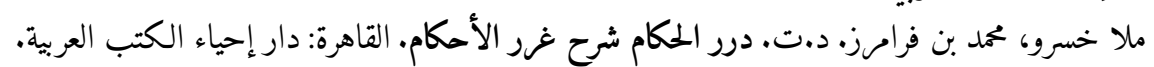

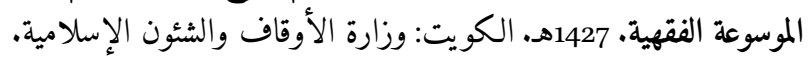

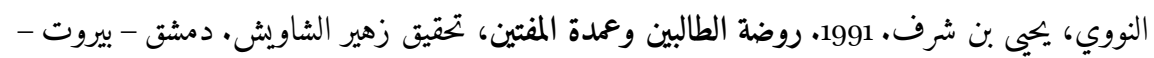

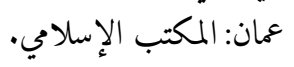

